\title{
4. Die Schwerpunkte der Arbeitskräftelenkung
}

\section{Anforderungen der sowjetischen Besatzungsmacht}

Der Arbeitsmarkt in der SBZ war in den ersten Nachkriegsjahren sehr stark gekennzeichnet durch Ad-hoc-Maßnahmen, so daß längerfristige Planungen überhaupt nicht möglich waren. Das hing unter anderem mit der Besatzungspolitik der SMAD zusammen. So belasteten die sowjetischen Reparationsansprüche die ostdeutsche Wirtschaft erheblich. Neben Sachleistungen ${ }^{1}$, die von Betrieben in der SBZ erbracht wurden, mußten zahlreiche Fachleute als sogenannte Spezialisten in der UdSSR beim dortigen Wirtschaftsaufbau mitarbeiten². Darüber hinaus blieben viele Unternehmen in der SBZ noch längere Zeit in der sowjetischen Verfügungsgewalt. Erst zwischen 1949 und 1954 gab die Sowjetunion diese Betriebe, die sie als Sowjetische Aktiengesellschaft (SAG) geführt hatte, an die DDR wieder zurück ${ }^{3}$. Einzige Ausnahme blieb bis zur staatlichen Vereinigung Deutschlands 1990 der Uranbergbau im Erzgebirge, die Sowjetisch-deutsche Aktiengesellschaft (SDAG) Wismut ${ }^{4}$.

Der Einfluß der sowjetischen Besatzungsmacht war auch auf dem Arbeitsmarkt bzw. den Teilarbeitsmärkten zu spüren: Die SMAD, die SMA in den Ländern und Provinzen, sogar einzelne sowjetische Dienststellen auf lokaler Ebene richteten nahezu pausenlos Anforderungen an die Arbeitsämter zur Zusammenstellung von Arbeitskräftekontingenten für Demontagetätigkeiten oder für einzelne SAG-Betriebe. Diese Reparationsform ${ }^{5}$ verlief im einzelnen oftmals unkoordiniert, obwohl die Besatzungsmacht bemüht war, entsprechende Richtlinien herauszugeben und auch durchzusetzen, um dadurch die Tätigkeit der deutschen Arbeitsverwaltung zu erleichtern. Damit war sie jedoch bis 1947 weitgehend erfolglos. Zu unterscheiden ist in dem Zusammenhang zwischen kurzfristigen und langfristigen Anforderungen von seiten der sowjetischen Dienststellen. Langfristige Aufträge waren in der Regel auf mehrere Wochen angelegt und konnten von den Arbeitsämtern häufig erfüllt werden. Sehr viel problematischer waren dagegen kurzfristige Forderungen, denen innerhalb von ein bis zwei Wochen nachgekommen werden mußte. Mit dieser Aufgabe war die Arbeitsverwaltung in der Regel überfordert. So erteilte etwa die SMA Sachsen dem Landesarbeitsamt in Dresden am 6. November 1946 den Auftrag, binnen zwei Wochen 4200 Arbeitskräfte für 48 Betriebe aus dem Maschinen- bzw. Schwermaschinenbau bereitzustellen ${ }^{6}$. Daraufhin wandte sich der Vizepräsident der sächsischen Landesverwaltung, Fritz Selbmann, am 16. November direkt an Walter Ulbricht und beklagte, daß die SMA die sächsische Landesverwaltung „zu einem einfachen Befehlsempfänger“

1 Vgl. allgemein zur Thematik: Fisch, Reparationen. Zur SBZ/DDR: Karlsch, Allein bezahlt?; Karlsch/Ciesla, Vom „Karthago-Frieden“.

2 Vgl. Ciesla, Der Spezialistentransfer; ders., „Intellektuelle Reparationen“.

3 Vgl. zur historischen Entwicklung dieser Betriebsform: Karlsch, Allein bezahlt?, S. 110-135;

Karlsch/Bähr, Die Sowjetischen Aktiengesellschaften.

4 Vgl. Karlsch, „Ein Staat im Staate“; Karlsch/Schröter (Hrsg.), „Strahlende Vergangenheit“.

5 Zu den Konzeptionen der vier Besatzungsmächte: Mai, Der Alliierte Kontrollrat, S. 370-384.

6 SAPMO, NY 4182/1189, Bl. 21 f. Unter dieser Signatur zitiert Mai cin völlig anderes Dokument. Vgl. Mai, Der Alliierte Kontrollrat, S. 381, Anm. 316. 
degradiere7. Ulbricht wurde gebeten, eine Verbesserung ,in der Praxis der SMA Abteilung Arbeitskraft - [...] zu erwirken." Die unterschiedliche Arbeitsmarktlage in den Ländern und Provinzen sowie die unterschiedlich hohen Anforderungen durch die sowjetische Militäradministration auf Landesebene müssen bei einer Gesamtbeurteilung berücksichtigt werden. Außerdem hatten die einzelnen Befehlsauflagen für die sowjetische Besatzungsmacht nicht dieselbe Priorität: Vordringlich zu erfüllen waren die Anforderungen für die Wismut AG in Sachsen und Thüringen.

Mit dem Befehl Nr. 153 vom 29. November 1945 hatte der Oberste Chef der SMAD die Wirtschaftsbereiche genannt, die bevorzugt mit Arbeitskräften zu versorgen waren. Dazu zählten allgemein Unternehmen, die für Reparationsaufgaben produzierten, ferner die Brennstoffindustrie, die Elektrizitätswerke, Betriebe, die landwirtschaftliches Inventar herstellten, das Eisenbahntransportwesen sowie Instandsetzungsarbeiten von Brücken, Straßen und Wohnungen ${ }^{8}$. Diese Prioritätenliste wiederholte der damalige ZVAS-Präsident Gustav Gundelach in seinen Richtlinien zum SMAD-Befehl Nr. 1539. Darüber hinaus wurden erstmals die Berufe genannt, bei denen nach Einschätzung der Berliner Zentralverwaltung ein großer Bedarf bestand. Dieser Mangel betraf in erster Linie Facharbeiter der metallverarbeitenden Industrie, des Bauhandwerks, der Bekleidungs- sowie der holzverarbeitenden Industrie. Die Arbeitsämter erhielten die Anweisung, „den Mangelberufen bevorzugt Lehrlinge zuzuführen“ sowie Facharbeiter „durch laufende Umschulungen zu gewinnen" 10 . Zur Umschulung sollten vor allem arbeitsfähige Arbeitslose herangezogen werden. Insgesamt kann hervorgehoben werden, daß sowohl die Berufsausbildung als auch die Berufsumschulung frühzeitig Bestandteil der staatlichen Arbeitskräftelenkung war; dies erfolgte in enger Abstimmung zwischen sowjetischer Besatzungsmacht und ZVAS. Gleichzeitig schälten sich aber auch rasch die Grenzen dieses arbeitsmarktpolitischen Ansatzes heraus, da bereits die Richtlinien eine nicht unerhebliche Einschränkung der beruflichen Mobilität vorsahen. So konnten etwa Arbeitslose die ihnen zugewiesene Arbeit verweigern, wenn gesundheitliche Gründe, die vom Amtsarzt bestätigt werden mußten, dagegen sprachen. Als weiterer Grund galten mangelnde Versorgung mit Wohnraum und Verpflegung ${ }^{11}$. Diese Bestimmungen sollten das Verfahren der Arbeitseinweisung korrekt regeln, schränkten aber auf der anderen Seite die Eingriffsmöglichkeiten der Arbeitsämter nicht unerheblich ein.

Die Praxis der Arbeitseinsatzpolitik sah allerdings in den ersten Nachkriegsjahren etwas anders aus und wurde durch stellenweise rüdes Vorgehen einzelner sowjetischer Kommandanten geprägt, wodurch sich das Stimmungsbild in der Bevölkerung erheblich negativ prägen sollte. So monierte der SED-Landesvorstand Thüringen (Abteilung Arbeit und Sozialfürsorge) in einem Bericht an das Zentralsekretariat der SED vom 15. Januar 1947 die „rigorose Betreibung [sic] von Arbeitskräften und zum Teil unwürdige Behandlung deutscher Arbeiter" durch die

SAPMO, NY 4182/953, Bl. 54.

Arbeit und Sozialfürsorge 1 (1946), S. 4.

Ebenda, S. 4-8.

10 Ebenda, S. 5.

11 Ebenda, S. 6. 
sowjetischen Dienststellen ${ }^{12}$. Bei der gewaltsamen Rekrutierung der Arbeitskräfte werde auf Befehl sowjetischer Offiziere auch die Polizei mit eingeschaltet. Die SED-Landesleitung wies in dem Zusammenhang darauf hin, daß „durch die Übergriffe, die Nichtbeachtung von Gesetz und Recht, die Ablehnung alter marxistischer Forderungen [...] in weiten Kreisen der Thüringer Arbeiterschaft die Abneigung gegen die russische Besatzungsmacht" um sich greife ${ }^{13}$. Darüber hinaus erwies sich die sowjetische Besatzungsmacht oftmals als unberechenbar, was die Dauer der Arbeitsverpflichtungen anging. In Pölitz (Mecklenburg-Vorpommern) waren im Juni 1946 rund 3000 Arbeiter für Demontagetätigkeiten verpflichtet worden ${ }^{14}$. Nach Beendigung der Arbeiten Anfang August sollten die Eingewiesenen wieder in ihre Heimatorte zurückkehren dürfen. Diese Absprache wurde von sowjetischen Offizieren, welche die Demontagearbeiten leiteten, einseitig gebrochen. Nach Angaben der DVAS, die sich deshalb umgehend an die Abteilung Arbeitskraft in Karlshorst wandte, wurden die Arbeiter gegen ihren Willen zurückgehalten und sollten statt dessen „für die polnische Regierung arbeiten." Präsident Brack wies die SMAD darauf hin, daß ein solches Vorgehen „jedes Vertrauen der arbeitenden Bevölkerung zu den Arbeitsämtern“ untergrabe und das Ansehen der Roten Armee schädige.

Darüber hinaus protestierten zahlreiche Arbeitsämter in Brandenburg bei der SED-Landesleitung im Herbst 1947 darüber, daß die Anforderungen der sowjetischen Besatzungsbehörde "gemessen an der zu leistenden Arbeit zu hoch gegriffen " seien ${ }^{15}$. Außerdem entsprach der angemeldete Bedarf wohl nicht immer den konkreten Erfordernissen vor Ort, d.h. eine quantitativ geringere Menge an Arbeitskräften wäre oftmals ausreichend gewesen ${ }^{16}$. Die zu hohe Fehlplanung in Verbindung mit dem Materialmangel in zahlreichen Betrieben hatte zur Folge, $\mathrm{daß}$ verpflichtete Arbeitskräfte wieder entlassen werden mußten. So hatte etwa das Kreisarbeitsamt Bernau 100 Baufacharbeiter für die Errichtung eines russischen Erholungsheimes bei Erkner zu stellen; 80 der eingewiesenen Arbeitskräfte konnten wegen Materialmangels erst gar nicht eingestellt werden ${ }^{17}$. Bereits im Frühjahr 1947 hatten Vertreter der DVAS die SMAD gebeten, ihren Einfluß nachdrücklich geltend zu machen, daß sich die „Kräfteanforderungen [...] mit Rücksicht auf den Arbeitermangel auch nur im Rahmen des unbedingt notwendigen Bedarfs bewegen “18. Ferner erwiesen sich zahlreiche von der SMAD bzw. der SMA angeordnete Arbeitseinsätze als äußerst unproduktiv: So waren etwa Verladearbeiten von demontierten Eisenteilen auf dem Potsdamer Güterbahnhof eingestellt und von seiten der SMA die Entladung der Waggons wieder befohlen wor-

12 SAPMO, NY 4090/314, Bl. 39. Vgl. Mai, Der Alliierte Kontrollrat, S. 381, Anm. 316.

13 SAPMO, NY 4090/314, Bl. 43.

14 Zum folgenden: BAB, DQ 2/2064, DVAS-Präsident Brack am 14. 8. 1946 an dic SMAD-Abt. Arbeitskraft.

15 Beispielhaft das Schreiben des Arbeitsamtes Potsdam an den SED-Landesvorstand (Abt. Arbeit und Sozialfürsorge) vom 26. 9. 1947, in: SAPMO, DY 30/IV 2/2.027/21, Bl. 7-10, hier BI. 7.

16 Dies ist den Berichten der Arbeitsämter Prenzlau, Bernau, Kyritz, Teltow-Mahlow, Luckau und Nauen zu entnehmen. Vgl. SAPMO, DY 30/IV 2/2.027/21, Bl. 19.

17 Ebenda, Bl. 20, Bericht des Landesarbeitsamtes Potsdam vom 14. 10. 1947 über Schwierigkeiten der Arbeitsämter mit den sowjetischen Dienststellen.

is BAB, DQ 2/2014, Aktenvermerk über Besprechung mit der SMAD (Schaposchnikow) am 29.5. 1947 in Karlshorst. 
den, da die Demontageware zunächst registriert und mit einer Rostschutzfarbe angestrichen werden mußte ${ }^{19}$. Dadurch sei die Tätigkeit von 50 Arbeitskräften über einen Zeitraum von fünf bis sechs Wochen "umsonst gewesen“, so das zuständige Arbeitsamt in Potsdam. Gegenüber dem brandenburgischen SED-Landesvorstand betonte die Arbeitsverwaltung, daß „die Lust zu derartigen Arbeiten vollkommen schwindet, wenn die Menschen die Nutzlosigkeit ihrer Arbeit täglich vor Augen sehen" 20 . Wenn man bedenke, so die Stellungnahme weiter, daß Arbeitslose nicht zur Verfügung stehen, so daß Arbeiter aus anderen Betrieben herausgezogen werden müßten, könne man die große Verärgerung in den betroffenen Bevölkerungskreisen ermessen.

Die SMAD erteilte vor allem in den ersten beiden Nachkriegsjahren sehr kurzfristige Auflagen, die oftmals nicht mit der DVAS abgestimmt waren. So verlangte etwa der SMAD-Befehl Nr. 178 vom 22. Dezember 1945 die Bereitstellung von 218000 Arbeitern für die Abteilungen der sowjetischen Beutekommissionen innerhalb von zehn Tagen ${ }^{21}$. Die DVAS, die daraufhin alle Landesarbeitsämter unterrichtete, mußte rasch feststellen, daß einige Landesverwaltungen von der Besatzungsmacht bereits informiert worden waren ${ }^{22}$. Zur Kurzfristigkeit der Aufträge kam also noch die fehlende bzw. mangelhafte Koordinierung erschwerend hinzu. Anfang 1947 hatte sich an diesem Zustand wenig geändert: Die Berliner Zentralverwaltung bemängelte nach wie vor, daß sie von einzelnen SMAD-Befehlen „keine direkte Kenntnis erlangt“"23. Die Abteilung Arbeitskraft in Karlshorst wurde daher gebeten, Abschriften von Befehlen, die an die Landesverwaltungen ergangen waren, umgehend an die DVAS weiterzureichen. Nur so schien eine „sofortige Kontrolle“ der einzelnen Befehlsauflagen und deren Durchführung möglich zu sein.

Die Landes- und Provinzialverwaltungen versuchten frühzeitig mit der jeweiligen SMA eine enge Abstimmung herbeizuführen. So gab Garde-Generalmajor Kolesnitschenko der thüringischen Landesregierung am 8. Oktober 1946 die $\mathrm{Zu}$ sage, daß Arbeitskräfteanforderungen durch die einzelnen sowjetischen Kommandanten nicht mehr direkt an die Arbeitsämter ergehen sollten, sondern zentral über die SMA in Weimar an das Landesarbeitsamt geleitet werden, „damit eine einwandfreie Lenkung und Versorgung der Betriebe und die Erfüllung der Befehle besser gewährleistet wird, als das bisher der Fall war. "24 Darüber hinaus sollte den Arbeitsämtern für die "Gestellung von Spezialarbeitern" eine längere Frist eingeräumt werden. Solche Absprachen zwischen DVAS, SMAD und örtlichen sowjetischen Kommandanturen blieben jedoch auch 1948 meist wirkungslos. Karlshorst erkannte zwar die Unzulänglichkeiten der unkoordinierten Be-

14 SAPMO, DY 30/IV 2/2.027/21, Bl. 6, Arbeitsamt Potsdam am 18. 10. 1947 an den SED-Landesvorstand in Potsdam (Abt. Arbeit und Sozialfürsorge).

20 Ebenda.

21 BAB, DQ 2/1503, Bl. 83. Der Befehl wird erstmals erwähnt bei: Zank, Wirtschaft und Arbeit, S. 61 .

22 BAB, DQ 2/2055, Bericht der DVAS-Abt. II vom 3. 1. 1946.

23 BAB, DQ 2/498, Bl. 127 f., hier Bl. 128, DVAS-Abt. I b am 11. 3. 1947 an die SMAD-Abt. Arbeitskraft.

24 ThHStA, Land Thüringen, Ministerium für Wirtschaft und Arbeit, Bd. 3700, Bl. 15f., Aktennotiz des Landesdirektors Gustav A. Müller vom 9.10. 1946 über eine Besprechung bei Kolesnitschenko. 
fehlspraxis, war jedoch nicht bereit, gegen die SMA in den Ländern und die eigenen Dienststellen in den Gemeinden vorzugehen. Im Spätsommer 1948 hatten einzelne Kommandanturen in Mecklenburg-Vorpommern Arbeitskräfte, die zur Erfüllung des Befehls Nr. 209 vorgesehen waren, eigenmächtig für den Aufbau der Werften eingesetzt. Vertreter der DVAS, die in Karlshorst vorstellig wurden, erhielten vom zuständigen SMAD-Mitarbeiter die unbefriedigende Antwort, daß diese Angelegenheit in den Ländern selbst geregelt werden müsse. Die Kommandanten, die gegenüber der Zentrale in Karlshorst verantwortlich seien, hätten vermutlich „nur aus dringenden Gründen diese Anordnung erteilt“25. Dies zeigte beispielhaft, daß für die sowjetische Besatzungsmacht letztlich die Bereitstellung von Arbeitskräften entscheidend war, dagegen blieb die konkrete Durchführung der entsprechenden Befehle der deutschen Arbeitsverwaltung überlassen.

Als zusätzliches Hindernis erwies sich außerdem die Tatsache, daß die sowjetische Besatzungsmacht Arbeitskräfte anforderte, ohne die Versorgung der jeweiligen Betriebe mit Rohstoffen zu beachten. Aufgrund von Rohstoffmangel, besonders von Kohle, konnten etwa die Hüttenwerke ihre Produktion im Herbst 1948 nicht weiter steigern. Dies hatte wiederum zur Folge, daß die Nichterfüllung von Befehlen ohne Konsequenzen blieb oder ein Großteil der angeforderten Arbeitskräfte wieder nach Hause geschickt werden mußte. So benötigte die SMAD für die Formgießereien in Thüringen insgesamt 2000 Arbeitskräfte, von denen nur 872 gestellt werden konnten; die restlichen 1128 Arbeiter wurden wegen des Rohstoffmangels nicht mehr angefordert ${ }^{26}$. Für Sachsen-Anhalt und Sachsen ist eine ähnliche Entwicklung zu beobachten: Die sowjetischen Anforderungen waren oft $\mathrm{zu}$ hoch bemessen und entsprachen damit nicht den Produktionsmöglichkeiten der Betriebe.

Die Landes- und Provinzialverwaltungen hatten auf Anweisung der DVAS regelmäßig Bericht zu erstatten über die Durchführung der einzelnen SMA-Befehle. Obwohl nicht alle Berichte überliefert sind, läßt sich doch ein erster vorläufiger Gesamteindruck formulieren: Arbeitskräfteanforderungen für die Grundstoffund Schwerindustrie konnten in der Regel zur Zufriedenheit der sowjetischen Besatzungsmacht erfüllt werden ${ }^{27}$. Dies gelang jedoch nur über einen längeren Zeitraum, d.h. kurzfristige Auflagen unter vier Wochen ließen sich in der Regel nicht vollständig realisieren. Aus den statistischen Erhebungen der Landesämter geht die berufliche Qualifikation der eingestellten Arbeitskräfte nicht hervor. Als äuBerst problematisch erwies sich allerdings die Bereitstellung von Facharbeitern für einzelne Betriebe der Schwerindustrie, wie die DVAS gegenüber der SMAD-Abteilung Arbeitskraft oftmals einräumen mußte. Diese waren häufig nicht vorhanden, konnten aus der Gruppe der Arbeitslosen auch nicht gewonnen werden oder waren in weniger wichtige Wirtschaftszweige eingewiesen worden ${ }^{28}$.

$25 \mathrm{BAB}, \mathrm{DQ} 2 / 2040, \mathrm{Bl}$. 165, Aktennotiz über eine Besprechung mit der SMAD in Karlshorst am 1. 10.1948 .

26 BAB, DQ 2/498, Bl. 127, DVAS-Abt. I b am 11. 3. 1947 an dic SMAD-Abt. Arbeitskraft.

27 Vgl. BAB, DQ 2/518, Bl. 5-7, Bericht des Landesarbeitsamtes in Potsdam vom 29. 7. 1946; BAB, DQ 2/1785, Bl. 28-36, Bericht des Landesarbeitsamtes in Dresden vom 1.10. 1946.

28 BAB, DQ 2/498, Bl. 128, DVAS-Abt. I b am 11.3. 1947 an SMAD-Abt. Arbeitskraft. 
Einschränkend muß betont werden, daß die Zahl der Arbeitseinweisungen nicht automatisch deckungsgleich war mit der Zahl der Arbeitskräfteanforderungen, d.h. nicht jeder SMAD-Befehl zur Bereitstellung von Arbeitskräftekontingenten für Demontagetätigkeiten oder SAG-Betriebe wurde mit dem Instrument der Zwangsverpflichtung durchgeführt. Dennoch stellten die sowjetischen Anforderungen bis 1949 den entscheidenden Faktor für die Arbeitseinweisungen dar. Entscheidend für den Einsatz dieser Zwangsmaßnahme waren die Dringlichkeit und der Umfang des Auftrages, der Zeitrahmen sowie die konkrete Situation auf dem Arbeitsmarkt in einem Bezirk. Die Arbeitsämter und Landesarbeitsämter registrierten durchaus die Zahl der Arbeitseinweisungen und korrelierten diese immer mit den Arbeitsvermittlungen, nicht jedoch mit den sowjetischen Anforderungen. Dabei zeigten sich Unterschiede zwischen den einzelnen Ländern und Provinzen: So meldete etwa das Landesarbeitsamt Sachsen im Februar 194711646 Zwangseinweisungen; darunter befanden sich 4029 Arbeitslose, gleichzeitig aber 7066 Personen, die bereits in einem Beschäftigungsverhältnis standen ${ }^{29}$. Relativ unbedeutend war dagegen die Zahl der verpflichteten Selbständigen im Handwerk und in der Landwirtschaft (539) sowie von Angehörigen der Freien Berufe (12). Bei einer Gesamtzahl von 70594 Vermittlungen durch die Arbeitsämter lag der Anteil von Zwangseinweisungen bei 16,5 Prozent. In der Mehrzahl traf dies im übrigen die Männer: Hier standen 45073 Vermittlungen 10418 Arbeitsverpflichtungen gegenüber. Insofern erhöhte sich der relative Anteil der Arbeitseinweisungen bei den Männern auf 23,1 Prozent. Dagegen betrug der Anteil von Zwangseinweisungen an den Arbeitsvermittlungen in Mecklenburg-Vorpommern zum selben Zeitpunkt 10,85 Prozent ${ }^{30}$, während er in Thüringen bei 21,5 Prozent lag ${ }^{31}$. Der Unterschied erklärt sich aus den spezifischen Anforderungen in den einzelnen Ländern, die vor allem mit Großprojekten und mit den bereits erwähnten sowjetischen Anforderungen in direktem Zusammenhang standen. Auf dem Land Sachsen ruhte beispielsweise die Hauptlast bei der Versorgung des extrem arbeitsintensiven Uranbergbaus im Erzgebirge mit Arbeitskräften. Da für dieses Arbeitsvorhaben zahlreiche Arbeitskräfte innerhalb kürzester Zeit von der Besatzungsmacht angefordert wurden, konnte die dortige Arbeitsverwaltung nur unter Rückgriff auf die Zwangseinweisung den Anforderungen einigermaßen gerecht werden.

In der zweiten Hälfte des Jahres 1947 ging in der SBZ der Anteil der Arbeitseinweisungen an den Gesamtvermittlungen langfristig zurück ${ }^{32}$ : Von 12,7 Prozent (Juli) auf 11,2 Prozent (August) und 9,8 Prozent (Oktober); der niedrigste Wert wurde im Dezember erreicht (7,7 Prozent). Gegenüber der SMAD-Abteilung Arbeitskraft stellte die DVAS am 30. Dezember 1947 zwar fest, daß die Zahl der Arbeitseinweisungen insgesamt gesehen rückläufig sei, sie betonte aber gleichzei-

29 BAB, DQ 2/1936, Meldung des Landesarbeitsamtes Sachsen über die im Februar 1947 getätigten Zwangseinweisungen von Arbeitskräften.

30 Ebenda, Ministerium für Sozialwesen der Landesregierung Mecklenburg am 19.4. 1947 an die DVAS.

31 Ebenda, Ministerium für Wirtschaft, Arbeit und Verkehr des Landes Thüringen am 8. 5. 1947 an die DVAS.

32 Ebenda, Statistik der DVAS-Abt. I a über die Entwicklung der Zahl der Arbeitseinweisungen im II. Halbjahr 1947. 
tig, daß sich dieses Instrument bei größeren Arbeitsvorhaben „immer noch als notwendig" erweise, „da Arbeitslosenreserven an vollwertigen Arbeitskräften nicht mehr vorhanden sind und infolge des Lohnstopps ein Anreiz, freiwillig eine Arbeitsstelle aufzugeben, um eine andere abseits vom Wohnort anzunehmen, nicht besteht ${ }^{\text {" } 33}$. Die absolute Zahl der Arbeitseinweisungen stabilisierte sich in der SBZ Anfang 1948 und lag zwischen 11950 (Januar) und 14205 (April) - im Dezember 1947 hatte sie bei 14510 gelegen. Da gleichzeitig die Zahl der Arbeitsvermittlungen anstieg, verringerte sich der prozentuale Anteil der Zwangsverpflichtungen: von 6,9 Prozent (Februar) auf 5,5 Prozent (April)34. Dieser Abwärtstrend setzte sich in der Folgezeit weiter fort: Im Juli 1948 wurden $10900 \mathrm{Ar}$ beitseinweisungen registriert (4,9 Prozent) ${ }^{35}$, im Oktober lag der Anteil bereits bei 1,9 Prozent ${ }^{36}$. In der ersten Jahreshälfte 1949 bewegte sich dieser Prozentsatz zwischen 0,2 (April) als tiefstem und 1,0 (Juni) als höchstem Wert ${ }^{37}$.

Die Arbeitsämter verfügten über eine Reihe von Sanktionsmitteln, um ihren getroffenen Maßnahmen Nachdruck zu verleihen. Dazu zählten Geld- und Gefängnisstrafen, die verhängt werden konnten. Angesichts der Mangelsituation und der allgemeinen Notlage nach dem Ende des Zweiten Weltkrieges versprach allerdings ein anderes Instrument sehr viel mehr Erfolg: die Androhung des Entzugs von Lebensmittelkarten bei Nichtbefolgung von Anweisungen der Arbeitsverwaltung. Frühzeitig meldeten jedoch einzelne Arbeitsämter, daß insbesondere in ländlichen Gebieten der Entzug von Lebensmittelkarten "nicht als Strafe" angesehen wurde, da die Versorgung mit lebensnotwendigen Gütern auch anderweitig gesichert werden konnte. So berichtete etwa das Arbeitsamt in Meiningen, schon mehrfach hätten "Arbeitsverweigerer" ausgesagt, daß diese Strafmaßnahme „auf sie keinen Eindruck mache" 38 . Dennoch wurde in der Folgezeit das Sanktionsmittel durchaus eingesetzt. Das Landesarbeitsamt in Halle meldete Ende August 1948, daß im Vormonat 910 Männern und 543 Frauen die Lebensmittelkarten entzogen worden seien $^{39}$. In diesem Monat waren 47263 Arbeitsvermittlungen und darunter 1629 Einweisungen registriert worden. Noch höher hatte die Zahl im Dezember 1947 gelegen: Nach Angaben des Landesarbeitsamtes hatten 1158 Männer und 455 Frauen keine Lebensmittelkarte erhalten. Das thüringische Ministerium für Arbeit und Sozialwesen wies noch am 30. September 1948 alle Ämter für Arbeit und

$33 \mathrm{BAB}, \mathrm{DQ} 2 / 512$.

34 BAB, DQ 2/1063, Statistik der HVAS über die Entwicklung der Zahl der Arbeitseinweisungen von September 1947 bis April 1948 (o.D.).

35 BAB, DQ 2/498, Bl. 287f., DVAS-Abt. I a am 8. 9. 1948 an SMAD-Abt. Arbeitskraft. In diesem Monat war erstmals der Prozentsatz der Arbeitseinweisungen aus der Summe der Vermittlungen in den jeweiligen Amtsbezirken und den Überweisungen in den zwischen- und überbezirklichen Ausgleich gebildet worden, und nicht wie zuvor von der Zahl der Gesamtvermittlungen. Dadurch wurde nach Einschätzung der DVAS das prozentuale Verhältnis „nur unwesentlich berührt."

$36 \mathrm{BAB}, \mathrm{DQ} 2 / 1531, \mathrm{Bl}$. 28, Niederschrift über die Besprechung des DVAS-Abt. I am 30. 10. 1948. Im Ländervergleich bildete Brandenburg das Schlußlicht. Dort betrug der Anteil der Einweisungen noch 5,3 Prozent, bei Männern sogar 7,5 Prozent.

$37 \mathrm{BAB}, \mathrm{DQ} 2 / 1063$, Übersicht der HVAS über die Arbeitseinweisungen von Januar bis Juni 1949 (o.D.).

38 ThHStA, Land Thüringen, Büro des Ministerpräsidenten, Bd. 1678, Arbeitsamt Meiningen am 23. 8. 1945 an das Landesamt für Arbeit in Weimar.

39 LA Magdeburg LHA, Rep K MW, Nr. 10185, BI. 516, Landesarbeitsamt Halle am 31.8. 1948 an den Landesausschuß für den Befehl 234. 
Sozialfürsorge des Landes an, für die Einhaltung der bestehenden gesetzlichen Bestimmungen Sorge zu tragen ${ }^{40}$. Dies deutet auf die mangelnde Effektivität des Sanktionsmittels hin.

In den Kommunen wurden Arbeitskräfte teilweise unter Androhung schwerer Strafen aus einem festen Beschäftigungsverhältnis herausgezogen und für Demontagetätigkeiten verpflichtet. So veröffentlichte beispielweise der Bürgermeister von Wildau am 15. Dezember 1945 einen Befehl Marschall Schukows und kündigte an, daß jedes „Fernbleiben“ bei der Arbeitsverpflichtung nicht nur mit dem Entzug der Lebensmittelkarte, sondern auch mit sofortiger Verhaftung und Aburteilung zu "mindestens" 15 Jahre Zuchthaus geahndet werde ${ }^{41}$. Bei Nachweis von „Unwillen“ drohe sogar die Todesstrafe. Es muß allerdings festgehalten werden, daß ein solcher Sanktionsfall nicht nachweisbar ist. Auch aus anderen Gemeinden Brandenburgs wurde ein unnachgiebiges Vorgehen bei der Bereitstellung von Arbeitskräften für sowjetische Kommandanten gemeldet, wobei sich in zahlreichen Fällen der begrenzte Erfolg bemerkbar machte. So ließ die sowjetische Besatzungsmacht im Dezember 1945 in Zeuthen sämtliche Geschäfte schließen, um alle verfügbaren 1879 Erwerbsfähigen ( 963 Männer und 916 Frauen) erfassen und 400 Arbeitskräfte für Demontageaufgaben verpflichten zu können. Trotz „schärfster Maßnahmen (Abriegelung, Razzien, Entzug von Lebensmittelkarten) konnten von der Gemeinde nur 235 männliche Personen“" gestellt werden, berichtete der dortige Bürgermeister der ZVAS bei einer gemeinsamen Besprechung in Berlin ${ }^{42}$. Von diesen schieden wiederum 42 Personen noch vor Arbeitsbeginn wegen Krankheit bzw. Erwerbsbehinderung aus. Von den verbliebenen 193 Personen seien in den ersten acht Tagen "weitere Kranke sowie mit vordringlichen Arbeiten Beschäftigte" von der Arbeitsverpflichtung wieder entbunden worden, so daß sich der Bestand an einsatzfähigen Arbeitern auf rund 120 reduziert habe. Die ZVAS (Abteilung II a) schlug daraufhin vor, daß die brandenburgische Arbeitsverwaltung die Anforderungen von seiten der SMA zentral erfassen und organisieren sollte. Zur Begründung gab sie an: „Durch die unzusammenhängenden Anforderungen der örtlichen Kommandanturen werden die überbezirklichen Auflagen höherer Kommandostellen für noch dringlichere Arbeiten gestört, ja gefährdet, und auf den zweckdienlichen Einsatz der Mangelberufe kaum Rücksicht genommen." 43

Die Großaufträge von seiten der sowjetischen Besatzungsmacht hatten zum Teil katastrophale Folgen für die Arbeitsmarktlage in einzelnen Kreisen. So berichtete das Kreisarbeitsamt Teltow Ende Mai 1947 über einen akuten Arbeitskräftemangel sowie einen steigenden Arbeitskräftebedarf für sowjetische Demontage- und Reparationsaufgaben ${ }^{44}$. Besondere Schwierigkeiten bereitete der Kabelausbau für die sowjetische Besatzungsmacht, der sehr arbeitsintensiv war. Die mangelhafte Zusammenarbeit zwischen deutschen und sowjetischen Stellen erschwerte die Erfüllung der Befehlsauflagen zusätzlich: Das Kreisarbeitsamt hatte

to ThHStA, Land Thüringen, Ministerium für Wirtschaft und Arbeit, Bd. 3699, Bl. 152.

4 BAB, DQ 2/2035.

42 BAB, DQ 2/2035, Aktennotiz der ZVAS-Abt. II a vom 28. 12. 1945, S. 1.

43 Ebenda, S. 3.

$44 \mathrm{BAB}, \mathrm{DQ} 2 / 1739$, Arbeitseinsatzbericht des Kreisarbeitsamtes Teltow vom 27. 5. 1947, S. 1. 
beispielsweise vorgeschlagen, den Kabelausbau „als eine Sondermaßnahme durchzuführen und die Gemeinden dafür heranzuziehen"45. Die zuständige Kommandantur lehnte dies jedoch mit dem Hinweis auf die anstehende Frühjahrsbestellung in der Landwirtschaft ab. Völlig resigniert unterstrich das Teltower Kreisarbeitsamt, daß es mittlerweile unerläßlich geworden sei, bei der SMAD Schritte zu unternehmen, daß bei dem "katastrophalen Fehlbedarf an Arbeitskräften nicht noch gleichzeitig mehrere Großaufträge hergegeben werden, die außerdem wegen der zu kurzen Termingestellung von vornherein zum Scheitern verurteilt sind."

Die Leiter der Arbeitsämter hatten teilweise auch persönlich mit Sanktionen zu rechnen, falls die sowjetischen Arbeitskräfteforderungen nicht erfüllt werden konnten. So nannte das Landesarbeitsamt in Potsdam der DVAS am 6. Juni 1947 sieben Amtsleiter, die von russischen Kommandanten vorübergehend inhaftiert worden waren ${ }^{46}$. Das Arbeitsamt Westprignitz berichtete am 15. Oktober, daß bei „nicht sofortiger Gestellung der Arbeitskräfte für die Besatzungsmacht [...] die Angestellten des Arbeitsamtes immer der Sabotage beschuldigt und mit Erschießen bedroht" würden ${ }^{47}$. Darüber hinaus scheint die Haftandrohung gegenüber Mitarbeitern der Arbeitsverwaltung keineswegs auf Einzelfälle beschränkt gewesen zu sein. Das NKWD versuchte noch Anfang 1948 die Arbeitsämter für eigene Zwecke einzusetzen: Dem Leiter des Amtes für Arbeit und Sozialfürsorge in Gotha war von seiten des sowjetischen Sicherheitsapparates mitgeteilt worden, daß er einzelne Personen zu sich bestellen solle, die dann das NKWD verhaften wollte. Der Präsident der HVAS protestierte gegen dieses Vorgehen und betonte: „Zum Arbeitsamt muß jeder mit dem unbegrenzten Vertrauen hingehen können, nicht aber damit rechnen, daß er evtl. dort verhaftet werden kann." 48 Ein ähnlicher Fall wurde kurz darauf vom Amtsleiter in Jena gemeldet. In beiden Fällen sind die Leiter der Arbeitsämter offenbar gezwungen worden, „solche Vorladungen auszusprechen, denen die Verhaftung folgte ${ }^{\text {“49. }}$. HVAS-Präsident informierte daraufhin auch die SED-Führung über die Vorfälle und vertrat dabei die Auffassung, daß die sowjetische Besatzungsmacht in solchen Fällen die deutschen Polizeidienststellen, nicht aber die Arbeitsämter einschalten sollte ${ }^{50}$. Die Juristische Abteilung der DVAS war in einem Gutachten Ende Dezember 1947 zum Ergebnis gekommen, daß die Arbeitsämter keinerlei rechtliche Grundlagen besaßen, um Vorladungen vornehmen zu können ${ }^{51}$. Helmut Lehmann, der als Mitglied des Zentralsekretariats zuständig war für sozialpolitische Angelegenheiten, reichte die Beschwerde "mit der Bitte um Vermittlung bei der zuständigen Stelle in Karlshorst" an Walter Ulbricht weiter ${ }^{52}$.

45 Ebenda, S. 2.

t6 BAB, DQ 2/498, Bl. 153.

47 SAPMO, DY 30/IV 2/2.027/21, Bl. 21 f., Arbeitsamt Westprignitz am 15. 10. 1947 an den Minister für Arbeit und Sozialwesen der brandenburgischen Landesregierung.

48 BAB, DQ 2/137, Bl. 64, Brack am 24. 2. 1948 an die SMAD-Abt. Arbeitskraft (Morenow).

49 SAPMO, NY 4182/951, Bl. 274, Brack am 15.6. 1948 an die SED-Abt. Arbeit und Sozialfürsorge (Lehmann).

so Ebenda.

5) Vgl. BAB, DQ 2/1537, Niederschrift über den Verlauf der Arbeitstagung der DVAS (Abt. I b) in Leipzig am 6./7. 1. 1948, S. 29.

52 SAPMO, NY 4182/951, Bl. 273, SED-Hausmitteilung Lehmanns für Ulbricht vom 23.6. 1948. 
Die Arbeitsämter befanden sich oftmals in einem Interessenkonflikt, da sie auf der einen Seite die Befehle der sowjetischen Besatzungsmacht zu erfüllen hatten, auf der anderen Seite aber die Belange der zum Arbeitseinsatz verpflichteten Erwerbstätigen berücksichtigen sollten. Zu letzterem ermahnte sie häufig auch die Berliner Zentralverwaltung, an die sich zahlreiche Betroffene gewandt hatten. Das Kreisarbeitsamt Belzig (Nebenstelle Beelitz) ordnete etwa im Sommer 1946 die Schließung sämtlicher Geschäfte in ihrem Zuständigkeitsbereich an; ausgenommen blieben Bäckereien, Drogerien und Apotheken ${ }^{53}$. Sämtliche freiwerdenden Arbeitskräfte sollten sich umgehend bei einem Demontagebetrieb einfinden; bei Nichtbefolgung der Anweisung drohte eine längere Schließung der Geschäfte. Kurze Zeit später drohte das Arbeitsamt in einer offiziellen Bekanntmachung: „Wer unentschuldigt und ohne Grund fern bleibt, wird der Roten Armee wegen Sabotage zur Bestrafung übergeben." ${ }^{54}$ Einzelne Firmeninhaber wandten sich daraufhin an die DVAS in Berlin und machten deutlich, daß sich die angedrohte Schließung der Geschäfte „sehr störend auf den großen Kundenkreis der umliegenden Dörfer" auswirken werde55. Außerdem sei der Gewinn an zusätzlichen Arbeitskräften durch diese Maßnahme sehr gering, da die betroffenen kleinen mittelständischen Betriebe nur über wenige Angestellte verfügten. Als besonders unglücklich erwies sich jedoch die Vorgehensweise des Arbeitsamtes, die bei den Betroffenen Unmut ausgelöst hatte. So beklagte ein Geschäftsmann gegenüber der DVAS, daß „der Ton dieser Bekanntmachung doch wohl nicht mehr in das heutige demokratische Deutschland paßt, sondern noch recht nach Bataillonsbefehlen anmutet “56. Die Berliner Zentralverwaltung versuchte in diesem Fall zu vermitteln und bat die betroffenen Geschäftsleute um Verständnis für die Arbeitseinsatzpolitik, die auf entsprechende SMAD-Befehle zurückzuführen sei57. Gleichzeitig wurde das Arbeitsamt aufgefordert, die Anforderungen im Konsens mit der Bevölkerung zu erfüllen. So sollten die Geschäftsleute und Gewerbetreibenden zu einer Versammlung eingeladen werden, auf der die Mitarbeiter des Arbeitsamtes die Arbeitsmarktlage und die sowjetischen Auflagen erklären sollten. Die DVAS verurteilte die Vorgehensweise der Arbeitsamtsnebenstelle und schloß mit der Bemerkung: „Wir wollen doch die Gepflogenheiten der Nazizeit nicht aufrechterhalten. "58 Das kritisierte Arbeitsamt reagierte auf die Vorwürfe und betonte gegenüber der DVAS die allgemein angespannte Lage auf dem Arbeitsmarkt im Zusammenhang mit den sowjetischen Arbeitskräfteanforderungen. Da sich keine Freiwilligen gemeldet hätten, sei man gezwungen gewesen, „zu einer uns sehr unliebsamen etwas härteren Maßnahme [zu] greifen" ${ }^{59}$.

53 BAB, DQ 2/1739, Kreisarbeitsamt Belzig (Nebenstelle Beelitz) am 10.7.1946 an Kurt Sch.

54 Ebenda, Kreisarbeitsamt Belzig (Außenstelle Beelitz) am 12.7.1946 an alle Geschäftsleute und Gewerbetreibende.

55 Ebenda, Kurt Sch. am 14. 7. 1946 an die DVAS.

56 Ebenda.

57 BAB, DQ 2/1739, DVAS-Abt. Il am 7.8. 1946 an Kurt Sch. Bei der Weitergabe sowjetischer Befehle durften die SMAD, die SMA oder einzelne Offiziere von den Arbeitsämter nicht einmal genannt werden. BLHA, Ld. Br. Rep. 206, Bd. 3016, Bl. 39, Rundschreiben Nr. 46/1947 des LAA Brandenburg an die Arbeitsämter vom 10.3. 1947, S. 1.

$58 \mathrm{BAB}, \mathrm{DQ} 2 / 1739$, DVAS-Abt. II am 7. 8. 1946 an die Arbeitsamtsnebenstelle Beelitz.

59 Ebenda, Kreisarbeitsamt Belzig (Nebenstelle Beelitz) am 14. 8. 1946 an die DVAS. 


\section{Arbeitskräfte für den Uranbergban im Erzgebirge}

Eines der Haupttätigkeitsfelder der Arbeitsverwaltung bestand bis Anfang der fünfziger Jahre darin, Arbeitskräfte für den Uranbergbau bereitzustellen. Hierbei handelte es sich um eine Sonderform der sowjetischen Anforderungen, genoß doch die Wismut AG innerhalb kürzester Zeit oberste Priorität für die Sowjetunion und ihre Besatzungsbehörden in der SBZ. Gerade in diesem Bereich trug das Instrument der Zwangseinweisung zu einer erheblichen Verschlechterung der Stimmungslage in der Bevölkerung gegenüber der SMAD, der Sowjetunion, mittelfristig aber auch gegenüber der rasch als „Russen-Partei“ abgestempelten SED bei60. Der Arbeitskräftebedarf bei der Wismut AG war enorm: Das Arbeitsamt Aue zählte im März 1948 über 50000 Arbeitnehmer, im September über 70000. Im April 1950 wurden dort bereits über 110000 Arbeitnehmer registriert ${ }^{61}$. Während anfangs das Landesarbeitsamt in Sachsen bei der Versorgung des Uranbergbaus mit Arbeitskräften auf sich alleine gestellt war, trat Ende 1946 eine Veränderung ein, als in zunehmenden Maße Absprachen mit den übrigen Landes- bzw. Provinzialverwaltungen sowie der DVAS erfolgten ${ }^{62}$. Diese Zusammenarbeit war notwendig geworden, da die sowjetischen Arbeitskräfteanforderungen stark angestiegen waren und die sächsische Arbeitsverwaltung nicht mehr in der Lage war, den Bedarf aus dem eigenen Zuständigkeitsbereich zu decken. Die sächsische Landesregierung drängte deshalb gegenüber der DVAS darauf, die übrigen Länder bei der Bereitstellung von Arbeitskräften für die Wismut AG aktiv einzubeziehen ${ }^{63}$. Mit der Erhöhung der Beschäftigtenzahlen im Erzgebirge stellten sich akute Probleme bei der Wohnraum- und Lebensmittelversorgung ein. Die Gemeindeverwaltungen waren oftmals nicht auf diesen Ansturm vorbereitet und standen daher den wachsenden sozialen Konfliktherden hilflos gegenüber ${ }^{64}$.

Die Einbeziehung der übrigen Länder bei der Bereitstellung von Arbeitskräften für die Wismut AG hatte indirekt auch Folgen für das Verhältnis zwischen der jeweiligen SMA und der Landesverwaltung. Die SMA-Vertreter mußten den Uranbergbau bei ihren eigenen Befehlsplanungen berücksichtigen. Letztlich verringerte sich dadurch der Arbeitskräftebestand, der ausschließlich für landesspezifische Demontagetätigkeiten vorgesehen war. Die SMA in Thüringen verhandelte daher mit dem Ministerium für Wirtschaft und Arbeit über eine Zentralisierung der Arbeitsvermittlung, um auf diese Weise Bedarfsplanung und -deckung besser aufeinander abstimmen zu können. Dies erwies sich jedoch auch noch im September 1947 als kaum durchführbar, da die Befehle für den Uranbergbau sowie die Befehle der thüringischen SMA nicht genau kalkulierbar waren ${ }^{65}$.

so Naimark, The Russians in Germany, S. $247 \mathrm{f}$.

61 Karlsch, Allcin bezahlt?, S. 141.

62 BAB, DQ 2/2064, Aktenvermerk über Besprechung der DVAS-Abt. I mit dem Landesarbeitsamt Sachsen am 6./7. 12. 1946.

$63 \mathrm{BAB}, \mathrm{DQ} 2 / 2091$, Ministerium für Arbeit und Sozialfürsorge der Landesregierung Sachsen am 16. 4. 1947 an die DVAS.

64 Karlsch, Allein bezahlt?, S. 142-144; Roeling, Arbeiter im Uranbergbau, S. $108 \mathrm{f}$.

$65 \mathrm{Vgl}$. ThHStA, Land Thüringen, Ministerium für Wirtschaft und Arbeit, Bd. 3597, Bl. 24, Aktennotiz vom 24. 9. 1947 über eine Unterredung mit der SMA (Proschljakow). 
Die Durchführung der SMAD-Befehle zur Bereitstellung neuer Arbeitskräfte für den Erzbergbau war auch ein Thema der in unregelmäßigen Abständen stattfindenden Arbeitstagungen, zu denen die DVAS Vertreter der Landesämter und der Gewerkschaften nach Berlin einlud. Ein Vertreter der sowjetischen Besatzungsmacht, in der Regel von der Abteilung Arbeitskraft, war ebenfalls anwesend. Auf diesen Tagungen versuchte die Berliner Zentralverwaltung die Werbemaßnahmen der Länder zu koordinieren. Im Vorfeld der Konferenz in Neuruppin vom 25. bis 27. September 1947 hatten sich DVAS-Präsident Brack sowie Abschnittsleiter Kreil nach Sachsen begeben, um zuallererst mit der dortigen Landesregierung sowie der Bergwerksleitung in Aue Vorabsprachen zu treffen. Dabei wurde die herausgehobene Position des Arbeitsamtes Aue unterstrichen, das nicht nur die ankommenden Arbeitskräfte registrieren und auf die einzelnen Schachtanlagen verteilen, sondern auch die zeitlich befristet eingestellten Arbeiter wieder entlassen sollte ${ }^{66}$. Diese sogenannte Entpflichtung bedurfte jedoch stets der $\mathrm{Zu}$ stimmung der Bergwerksleitung. Dadurch erhoffte sich die Arbeitsverwaltung, die hohe Fluktuation eindämmen zu können. Darüber hinaus wurde das Arbeitsamt in Aue verpflichtet, der DVAS direkt und regelmäßig Informationen über den Stand der Arbeitskräftewerbung und -lenkung zukommen zu lassen. Um die angespannte Situation auf dem Wohnungsmarkt etwas zu entkrampfen, einigten sich die DVAS-Leitung und die sächsische Landesregierung darauf, zunächst nur noch Arbeitskräfte ohne deren Familien im Arbeitsamtsbezirk anzusiedeln. Dies konnte allerdings nur eine vorübergehende Lösung sein. Im Bezirk Aue bestand der größte Bedarf an Arbeitskräften; so erklärt sich auch die Aufteilung der Befehlsauflage, welche Brack am 8. September 1947 mit dem sowjetischen Leiter der Bergwerksverwaltung, General Malzew, vorgenommen hatte: So sollten 13000 Arbeiter in Aue eingesetzt werden, 3000 in Annaberg und 2000 in Marienberg. Von entscheidender Bedeutung war die sowjetische Zusage, daß seitens der Besatzungsmacht „keine Eingriffe in die Zuweisungen von Arbeitskräften vorgenommen werden. " Die einzelnen sowjetischen Dienststellen sollten dazu eine entsprechende Anweisung erhalten ${ }^{67}$. Eingriffe der Bergbauverwaltung Aue blieben jedoch in der Folgezeit nicht aus: So wurden im Auftrag von General Malzew sowjetische Offiziere in die Umsiedlerlager geschickt, die unter Umgehung der zuständigen Arbeits- und Umsiedlerämter mehrere Transporte in einer Personenstärke zwischen sechs und 900 zusammenstellten und diese nach Aue überführten $^{68}$. Am 16. September fand auf Veranlassung der DWK eine Sitzung statt, an der neben der DVAS, dem sächsischen Landesarbeitsamt und dem FDGB sämtliche Zentralverwaltungen teilnahmen. Nach „ergiebiger Aussprache“ wurde festgelegt, daß die Federführung der gesamten Aufgaben bei der DVAS liegen sollte ${ }^{69}$. Grundsätzlich war vorgesehen, die sowjetischen Anforderungen „örtlich, bezirklich oder im Landesmaßstab zu lösen und nur die im Zonenmaßstab zu lösenden

$66 \mathrm{Vgl}$. BAB, DQ 2/1537, Niederschrift über den Verlauf der Arbeitstagung der DVAS (Abt. I b) vom 25. bis 27. 9. 1947, S. 8 .

67 Ebenda.

$68 \mathrm{Vgl}$. BAB, DQ 2/1995, Niederschrift der DVAS über Besprechung am 13. 10. 1947.

$69 \mathrm{BAB}, \mathrm{DQ} 2 / 1537$, Niederschrift über den Verlauf der Arbeitstagung der DVAS (Abt. I b) in Neuruppin vom 25 . bis 27.9 .1947$, S. 9. 
Aufgaben [...] an die Zentralverwaltungen heranzutragen". Auf den ersten Blick schien diese Entscheidung die zuvor getroffene Absprache wieder aufzuheben, die Arbeitskräftelenkung zur Wismut AG in enger Abstimmung mit den übrigen Ländern und vor allem der DVAS zu organisieren. Letztlich bezog sich diese dezentrale Anweisung aber nicht auf die Bereitstellung der angeforderten Arbeitskräfte, sondern vielmehr auf die Versorgung mit Wohnraum, Lebensmitteln und Bekleidung.

Die Aufteilung der Arbeitskräfteanforderung für den Uranbergbau blieb der DVAS überlassen: Sie hatte am 1. September festgelegt, daß die Länder SachsenAnhalt und Thüringen jeweils 4000 Arbeiter zu stellen hatten, Mecklenburg 3000, Sachsen 2000 und Brandenburg 1000. Außerdem sollten aus den Kreisen der "Umsiedler" und Kriegsheimkehrer 1800 bzw. 1200 Arbeitskräfte bereitgestellt werden ${ }^{70}$. Ende des Monats mußte die DVAS feststellen, daß die einzelnen Landesämter ihre jeweiligen Auflagen nicht annähernd erfüllen konnten. Dies machte den begrenzten Nutzen der engen Absprachen zwischen Berliner Zentralverwaltung und Landesverwaltungen deutlich. Der Erfolg der Lenkungsmaßnahmen war letztlich von einem entsprechenden Arbeitskräfteüberhang abhängig, auf den die Landesarbeitsämter sofort zurückgreifen konnten. Andernfalls mußten durch Auskämmungsaktionen Erwerbstätige aus den Betrieben herausgezogen werden. Dadurch ließ sich zwar die Hortung von Arbeitskräften eindämmen, die dabei eingesetzten Maßnahmen förderten jedoch nicht die langfristige Zusammenarbeit zwischen Arbeitsverwaltung und Betrieben. Darüber hinaus klagten mehrere Landesverwaltungen über die Mehrfachbelastung durch SMAD- sowie SMA-Befehle ${ }^{71}$ : Wie bereits angedeutet, mußten nicht nur Anforderungen der Wismut AG bedient werden, sondern auch arbeitsintensive Demontage- und Reparationsaufgaben in den einzelnen Ländern. Trotz der ausbleibenden Erfolge gingen die Propagandaaktionen in den Ländern mit dem Ziel weiter, die geforderten Arbeitskräfte möglichst schnell zur Verfügung zu stellen. Dabei hatten die Vertreter der Landesämter die undankbare Aufgabe, gegenüber den Leitern der Arbeitsämter auf eine Erfüllung der festgesetzten Auflage zu drängen. Diese brachten - wie etwa in Thüringen - nahezu einmütig zum Ausdruck, daß „es nicht möglich sei, die Kräfte zu stellen"72. Der FDGB-Bundesvorstand unterstützte die Werbemaßnahmen zugunsten der Wismut AG und betonte gegenüber den eigenen Landesvorständen sowie den Zentralvorständen der Industriegewerkschaften, daß „die Gestellung dieser Kräfte ein Erfordernis [ist], dem auch wir uns aus wirtschaftlichen und politischen Gründen nicht verschließen dürfen"73.

$\mathrm{Da}$ in den Ländern nicht genügend Arbeitskräfte zur Verfügung standen, die für den Uranbergbau zu gewinnen waren, entdeckte als erstes die Bergbauverwal-

70 Ebenda, S. 11.

71 SächsHStA, Landesregierung Sachsen, Ministerium für Arbeit und Sozialfürsorge, Bd. 307, Bericht über Vorsprache von Frau Dr. Heinze beim Leiter der SMA (Sektor Arbeit, Löhne und Soziale Fürsorge) am 7.10. 1947.

72 ThHStA, Land Thüringen, Ministerium für Wirtschaft und Arbeit, Bd. 3700, Bl. 468-474, hier B1. 474, Protokoll über die Tagung der Einsatz- und Gruppenleiter der Ämter für Arbeit und Sozialfürsorge am 1. 10. 1947.

73 SAPMO, DY 30/IV 2/2.027/25, Bl. 80, Rundschreiben Nr. 64/47 des FDGB-Bundesvorstandes vom 2. 10. 1947. 
tung Aue ein neues Arbeitskräftepotential: die „Umsiedler“. Auf die fehlende Absprache mit der deutschen Arbeitsverwaltung ist bereits hingewiesen worden. Die von sowjetischen Offizieren angeordnete Überführung aus den Umsiedlerlagern in die Bezirke des Erzbergbaus erwies sich rasch als überhastet, da die Zahl der bergbautauglichen "Umsiedler" relativ gering war und durch die geschlossene Ansiedlung von Familien die Wohnungsnot ${ }^{74}$ erneut verschärft wurde ${ }^{75}$. Während zuvor ein Zuwanderungsstopp für Familien verhängt worden war, hatte die sowjetische Besatzungsmacht diesen Kurs nunmehr selbst durchbrochen. Die DVAS hatte zwar im Sommer 1947 bei der Zentralverwaltung für deutsche Umsiedler (ZVU) eine Überprüfung der Umsiedlertransporte sowie eine Überführung von bergbautauglichen Personen zur Wismut AG angeregt ${ }^{76}$, war aber vom eigenmächtigen Vorgehen einzelner sowjetischer Offiziere völlig überrascht worden. Daraufhin wies die sächsische SMA die Kommandanten der Kriegsgefangenen- und Umsiedlerlager an, alle in den Lagern eintreffenden Personen unter die bereits festgelegte Quarantäne zu stellen. Diese sollten ärztlich untersucht, und ihre Einsatzfähigkeit für den Uranbergbau überprüft werden. Erst nach $\mathrm{Ab}-$ lauf der Quarantänezeit durften demzufolge die bergbautauglich eingestuften "Umsiedler" auf Anweisung des zuständigen Arbeitsamtes „zur Ansiedlung und

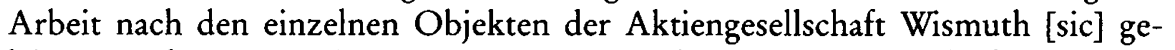
leitet " werden"7. Anweisungen von Vertretern der Wismut AG bedurften der ausdrücklichen Genehmigung von seiten der SMA Sachsen; dadurch sollte das eigenmächtige Vorgehen der Bergbauverwaltung gestoppt werden. Die sächsische Landesverwaltung klagte nicht nur über die unzureichende Abstimmung mit der sowjetischen Besatzungsmacht, sondern hatte offensichtlich auch Probleme mit Arbeitsämtern außerhalb der eigenen Landesgrenzen. So hatte das Arbeitsamt Nordhausen im Juli 194722 ,illegale Grenzgänger" von der Landespolizei übernommen und sie umgehend nach Aue weitergeleitet. Das thüringische Ministerium für Arbeit und Sozialwesen, das vom zuständigen Ministerium in Dresden über das Vorgehen informiert worden war, beanstandete zwar, daß das Arbeitsamt die 22 Personen nach Aue geschickt habe ohne vorliegenden Einweisungsbescheid, ohne ärztliche Untersuchung sowie ohne polizeiliche An- bzw. Abmeldung ${ }^{78}$. Zu weiteren Strafmaßnahmen sah man jedoch keine Veranlassung.

Mit der zunehmenden Arbeitskräftewerbung trat auch die Finanzierungsfrage immer stärker in den Vordergrund. Die Kreisverwaltungen im Erzgebirge waren aufgrund der steigenden Zuwanderung an die Grenzen der finanziellen Belastbarkeit gelangt, mußten sie doch die Kosten der Umsiedlung sowie die der Unterbringung alleine tragen. Die sächsische Landesverwaltung beantragte daher bei

74 Die Sonderabteilung „Erzbergbau“ in Aue kam am 21.11. 1947 zum Ergebnis, daß statistisch gesehen nur $5 \mathrm{qm}$ Wohnraum pro Kopf der Bevölkerung zur Verfügung standen. SächsHStA, SED-Landesleitung Sachsen, Bd. 685, Bl. 74.

$75 \mathrm{BAB}, \mathrm{DQ} 2 / 1995$, Niederschrift der DVAS über Besprechung am 13. 10. 1947.

$76 \mathrm{BAB}, \mathrm{DQ} 2 / 2138$, Abteilungsleiter Donau am 6. 8. 1947 an die ZVU.

7 BAB, DQ 2/1964, Richtlinie des Leiters der Abt. Umsiedler bei der SMA im Land Sachsen, Oberstleutnant Wolodin, und des Leiters des Sektors Arbeit, Löhne und Soziale Fürsorge im Land Sachsen, Danilow, am 23. 10. 1947 an alle Kommandanten der Kriegsgefangenen- und Umsiedlerlager.

$78 \mathrm{BAB}, \mathrm{DQ}$ 2/2138, Ministerium für Arbeit und Sozialwesen des Landes Thüringen am 7.11. 1947 an die DVAS. 
der Zentralfinanzverwaltung, der DVAS und der DWK die Bereitstellung von Sondermitteln in Höhe von 1,5 Millionen RM ${ }^{79}$. Eine einvernehmliche Lösung konnte bei den Reisekosten nie gefunden werden: Dabei ging es um die Frage, ob das Abwanderungs- oder das Zuwanderungsland diese Kosten zu übernehmen hatte. Gegen letzteres wandte sich verständlicherweise die sächsische Landesregierung. Somit mußte die Finanzierungsfrage bei jedem Personentransport ins Erzgebirge neu geregelt werden. Ende 1947 entwickelte sich zwischen den Landesverwaltungen und der Wismut AG eine Kontroverse über die Inhalte der Werbemaßnahmen. Während die deutsche Seite den Standpunkt vertrat, daß die Arbeitsbedingungen "doch tatsächlich so [sind], daß man nichts zu verbergen hat", untersagte die sowjetische Bergwerksverwaltung entsprechende Veröffentlichungen in der Presse oder im Rundfunk ${ }^{80}$. Offensichtlich befürchtete die sowjetische Seite eine öffentlich geführte und vor allem kritische Diskussion über den Uranbergbau in der SBZ. Stellungnahmen einzelner Bergarbeiter gegenüber Mitarbeitern der Arbeitsämter zeigen jedenfalls, daß die Propagandaparolen und die Arbeitsbedingungen in den Schachtanlagen keineswegs übereinstimmten ${ }^{81}$. Ein entscheidendes Problem bei der Beurteilung der Arbeitsbedingungen waren die Unfallziffern in der Wismut AG, und ganz besonders die Zahl der Todesfälle, die unter anderem Rückschlüsse auf den betrieblichen Arbeitsschutz zuließen. Während einzelne Berichte von entlassenen Bergarbeitern auf eine nicht unbedeutende Größenordnung hinwiesen, versuchte die sächsische Landesverwaltung das Thema herunterzuspielen. Das Ministerium für Arbeit und Sozialfürsorge (Abteilung Erzbergbau) registrierte im November 194719 Todesopfer in den Revieren Aue, Annaberg und Marienberg und legte Wert auf die Feststellung, daß im Steinkohlenbergbau die Anzahl der Unfälle und Todesfälle "weit höher" sei82. Als "vollkommen unwahr" wurde außerdem die Meldung bezeichnet, Frauen seien untertage beschäftigt.

Die DVAS beabsichtigte daraufhin, eine Broschüre herauszugeben, mit der die einzelnen Werbemaßnahmen öffentlichkeitswirksam erläutert und umlaufenden Gerüchten entgegengetreten werden sollte. Die Verwirklichung scheiterte jedoch an der mangelnden Kooperationsbereitschaft der sowjetischen Bergwerksleitung, die allen schriftlichen und mündlichen Anfragen ablehnend begegnete ${ }^{83}$. Diese ließ sogar Werbematerial (Plakate und Prospekte) vorab beschlagnahmen. Die von der SMAD angeordneten Propagandaaktivitäten zur Gewinnung neuer Arbeitskräfte für den Erzbergbau wurden somit von der Werksleitung in Aue konterkariert.

$79 \mathrm{BAB}, \mathrm{DQ} 2 / 2091$, Schreiben des Ministeriums für Arbeit und Sozialfürsorge der Landesregierung Sachsen vom 3.11.1947.

80 Ebenda, Ministerium für Arbeit und Sozialwesen des Landes Thüringen am 11.11. 1947 an die DVAS.

81 SAPMO, DY 30/IV 2/2.027/25, Bl. 92, Bericht des Bergarbeiters Norbert Sch., abgegeben im Arbeitsamt Mühlhausen/Thüringen (Nebenstelle Horsmar) am 11. 11. 1947.

82 Ebenda, Bl. 100, Ministerium für Arbeit und Sozialfürsorge der Landesregierung Sachsen am 28. 1. 1948 an das Amt für Arbeit und Sozialfürsorge Mühlhausen/Thüringen.

83 SAPMO, DY 34/20149, Notiz des FDGB-Bundesvorstandes (HA 3: Sozialpolitik) vom 29.1. 1948. 
Obwohl die DVAS bzw. einzelne Landesministerien bei der SMAD die Zusicherung erhalten hatten, daß Arbeitskräfteanforderungen rechtzeitig angekündigt werden sollten, umgingen einige sowjetische Offiziere diese Abmachung und erteilten im Dezember 1947 erneut kurzfristige Aufträge. So erhielt die thüringische Landesverwaltung zunächst den Befehl, im Dezember 800 Arbeiter für Aue zu stellen; kurz darauf wurde ein weiterer Auftrag in Höhe von 2000 Arbeitern eingereicht. Das Landesministerium wies darauf hin, daß „dieses unmöglich sei und überdies jetzt kurz vor Weihnachten eine größere Beunruhigung in der Bevölkerung hervorrufen würde" 84 . Die DVAS wurde gebeten, sich mit der SMAD in Karlshorst in Verbindung zu setzen und eine Verschiebung des Termins bis Ende Januar zu erreichen. Die SMAD lehnte es allerdings ab, im Sinne Thüringens einzuschreiten und eine Aussetzung des Befehls zu erwirken ${ }^{85}$. Auch die mecklenburgische Landesregierung meldete nahezu zeitgleich, daß sie innerhalb von zwei Wochen 3000 Arbeitskräfte für den Erzbergbau bereitzustellen hatte. Gegenüber der SMA in Schwerin machte das Ministerium für Sozialwesen deutlich, daß diese Auflage trotz aller Anstrengungen nicht zu erfüllen sei, da die Arbeitsämter auch noch Arbeitskräfte für die Werften sowie für Meliorationsaufgaben stellen mußten $^{86}$. Das mecklenburgische Landesarbeitsamt schaltete ebenfalls die DVAS ein und erklärte: „Wir möchten ungern mit polizeilichen Maßnahmen die Gestellung für den Erzbergbau durchführen." 87 Der Verzicht auf das Instrument der Zwangseinweisung wurde mit dem Hinweis auf die angebliche westdeutsche Propaganda, aber auch mit dem negativen Stimmungsbild in der ostdeutschen Bevölkerung begründet: „Es ist bekannt, daß die Westzonen eine verstärkte Propaganda gegen den Erzbergbau führen und solche Zwangsmaßnahmen sich nur nachteilig für das politische Leben und unsere demokratische Verwaltung in der Ostzone auswirken werden."

Nachdem mehrere alarmierende Berichte aus Sachsen bei der SED-Führung in Berlin eingegangen waren - auch der SED-Landesvorstand Sachsen hatte sich am 30. Juli 1947 hilfesuchend an das Zentralsekretariat gewandt ${ }^{88}$-, befaßte sich das Zentralsekretariat mit den schlechten Arbeits- und Lebensbedingungen im Erzgebirge. Helmut Lehmann faßte in einer Vorlage für Otto Grotewohl am 12. August 1947 die stellenweise chaotischen Zustände im Uranbergbau kurz und prägnant zusammen: Vielfach würden „körperlich und gesundheitlich ungeeignete Personen " eingewiesen ${ }^{89}$. Die Verpflegung und Unterbringung sei angesichts der schweren Arbeit „völlig unzulänglich“; zugesagte Lebensmittelzuteilungen würden die Arbeitskräfte oftmals nicht erreichen. Hinzu komme, daß „der größte Teil der Beschäftigten berufsfremd“ eingesetzt werde. Die mit der gesundheitlichen Überwachung betrauten Ärzte hätten zudem die Anweisung erhalten, „entgegen ihrer Überzeugung die von ihnen Untersuchten für arbeitsfähig zu erklären, obwohl sie es nicht sind. “ Da die Arbeitsämter laufend neue Arbeitskräfteanforde-

$84 \mathrm{BAB}, \mathrm{DQ} 2 / 2091$, Aktennotiz der Abt. I b vom 3. 12. 1947.

$85 \mathrm{BAB}, \mathrm{DQ} 2 / 2040$, Bl. 108, Niederschrift über Besprechung mit der SMAD am 4. 12. 1947.

86 BAB, DQ 2/2091, Ministerium für Sozialwesen der Landesregierung Mecklenburg am 2. 12. 1947 an die SMA (Abt. Arbeit und Löhne) in Schwerin.

87 Ebenda, Landesarbeitsamt Schwerin am 5. 12. 1947 an die DVAS.

88 SAPMO, DY 30/IV 2/2.027/25, Bl. 5.

89 SAPMO, NY 4090/359, Bl. 4. 
rungen erhielten, und die Zahl der Freiwilligen sehr gering sei, würden Arbeitskräfte „aus den Betrieben und Büros“ zu dieser schweren Arbeit herangezogen. Nach Ansicht Lehmanns blieben die für die SED negativen politischen Auswirkungen nicht auf das Erzgebirge beschränkt, sondern hatten bereits die gesamte SBZ erfaßt.

Im Herbst 1947 setzte allmählich ein begrenzter Lernprozeß ein, zunächst auf deutscher und etwas später auf sowjetischer Seite ${ }^{90}$, der langfristig dazu führte, daß die Arbeitseinweisung immer seltener praktiziert und statt dessen ein Anreizsystem geschaffen wurde. Mit Hilfe einer besseren Entlohnung, eines zusätzlichen Prämiensystems, einer besseren Versorgung mit Wohnraum und Gütern des täglichen Bedarfs sollten Arbeitskräfte für den Uranbergbau gewonnen werden. Die Erfahrungen mit der unzureichenden sozialen Lage vieler Wismut-Arbeiter hatte letztlich zu diesem Politikwechsel geführt. Die Leitung der DVAS-Abteilung I b wies bei einer gemeinsamen Besprechung mit einem Vertreter der sächsischen Landesregierung am 25. August 1947 darauf hin, daß die Vermittlung von Arbeitskräften "möglichst im Wege der Freiwilligkeit mit Hilfe einer umfangreichen Propaganda bewerkstelligt werden" sollte ${ }^{91}$. Die SMAD erkannte zunächst die Notwendigkeit eines Instrumentenwechsels nicht an. Noch Ende August 1947 beklagte sich der Vertreter der sowjetischen Besatzungsmacht Iljuschin darüber, daß die Einweisungen in die Wismut AG „zu langsam vor sich gehen"92. Er zog daraus eine Schlußfolgerung, welche die Rückkehr zu alten Praktiken befürchten ließ: „Wenn durch Propaganda auf freiwillige Meldungen Erfolge erzielt werden, sei es gut, wenn aber nicht, müßte zu Einweisungen geschritten werden."

Einen qualitativen Wandel brachte in dieser Frage erst der SMAD-Befehl Nr. 234 über „Maßnahmen zur Steigerung der Arbeitsproduktivität und zur weiteren Verbesserung der materiellen Lage der Arbeiter und Angestellten in der Industrie und im Verkehrswesen" vom 9. Oktober 194793. Die Einwände, welche die DVAS-Führung und Vertreter der SED in Karlshorst vorgetragen hatten, zeigten offenbar Wirkung: Die SMAD bestand nicht mehr in dem Maße auf dem Instrument der $Z$ wangseinweisung und ließ den verantwortlichen deutschen Stellen vergleichsweise freie Hand bei der Erprobung verschiedener Werbemaßnahmen. Hintergrund für diese Entwicklung bildete das allgemeine sowjetische Interesse, die Arbeitsproduktivität in den Betrieben zu erhöhen. Dabei schien sich auch auf seiten der SMAD die Erkenntnis durchzusetzen, daß dies eher auf dem Weg freiwilliger Anwerbung als über Zwangsmaßnahmen zu erreichen war. Nach dem Willen der sowjetischen Besatzungsmacht sollten im Zusammenhang mit Befehl Nr. 234 unter anderem eine zusätzliche Lebensmittelversorgung eingeführt und die ärztliche Versorgung in den Betrieben verbessert werden. Darüber hinaus diente die Erweiterung des Systems der Stück- und Akkordlöhne zunächst einmal

90 Nach Einschätzung von Karlsch trug ein Brief des FDGB-Landesvorstandes Sachsen vom 15.4. 1947 an die russischen Gewerkschaften wesentlich dazu bei, daß das Problem in Moskau überhaupt wahrgenommen wurde. Karlsch/Zacharov, Ein GULag im Erzgebirge?, S. 27. Der Brief ist abgedruckt in: ebenda, S. 29-32.

91 SAPMO, DY 30/IV 2/2.027/25, Bl. $54 \mathrm{f}$.

92 Ebenda, Bl. 66.

93 Arbeit und Sozialfürsorge 2 (1947), S. $452 \mathrm{f}$. 
der Steigerung der Arbeitsproduktivität, hatte gleichzeitig aber auch eine Anreizfunktion für Arbeitsuchende.

Die DVAS legte Anfang November 1947 einen ersten Maßnahmenkatalog vor, der die angestrebten Änderungen bei der Arbeitskräftelenkung verwirklichen sollte ${ }^{94}$. Darin wurden die Arbeitsämter aufgefordert, mit den örtlichen Kommandanturen der SMA Verhandlungen aufzunehmen, um eine geregelte Auftragserteilung zu erreichen. Der Verzicht auf Arbeitseinweisungen bedinge, daß „die Fristen für Gestellung von Arbeitskräften [...] zeitlich so gestellt werden, daß die Gewinnung dieser Arbeitskräfte auf freiwilliger Basis möglich ist" ${ }^{\text {"95. Auch die }}$ Zusammenarbeit zwischen Arbeitsämtern und Betriebsleitern sollte intensiviert werden. Dazu war vorgesehen, innerhalb eines Arbeitsamtsbezirkes „mit einer den vordringlichsten Bedürfnissen entsprechenden Anzahl von Unternehmern Vereinbarungen zu treffen, daß diese im Benehmen mit ihrer Belegschaft jederzeit auf Abruf dem Arbeitsamt eine Anzahl von Arbeitnehmern zu kurzfristigen Einsätzen zur Verfügung stellen." Zugleich wurden die Arbeitsämter von der DVAS angewiesen, in Zukunft sorgfältig zu prüfen, ob Anforderungen überhöht seien. Mit den vorhandenen Arbeitskräften müsse - so die Berliner Zentralverwaltung "weit sparsamer gewirtschaftet" werden. Bei niedriger Arbeitsproduktivität in einzelnen Betrieben sei die Neuzuführung von Arbeitskräften dort zu verweigern. Abschließend wies jedoch die DVAS nochmals darauf hin, daß Arbeitseinweisungen dann unvermeidbar seien, wenn sich nicht genügend Arbeitskräfte freiwillig melden würden. Bei Verfehlungen müßten aber die "verantwortlichen Personen“ zur Rechenschaft gezogen werden ${ }^{96}$.

Die Versorgung mit Wohnraum erschwerte Ende 1947 in zunehmenden Maße den Zuzug von neuen Arbeitskräften zur Wismut AG97. Der "Wohnungsmarkt“ war zu diesem Zeitpunkt in zahlreichen Städten und Bezirken der SBZ erheblich angespannt ${ }^{98}$. Beim Uranbergbau kam jedoch hinzu, daß der Bedarf nach Wohnungen rapide angestiegen war, was in erster Linie mit dem von der SMAD sowie der Bergwerksleitung forciert betriebenen Ausbau der Schachtanlagen zusammenhing. Während also die Lenkung von Arbeitskräften ins Erzgebirge weitgehend zufriedenstellend verlief, traf dies für die Situation auf dem Wohnungsmarkt überhaupt nicht zu. Es fehlten nicht nur Wohnungen, die bereits vorhandenen waren oftmals unzureichend. Aufgrund der schlechten Stimmungslage im Zusammenhang mit der mangelhaften Versorgung auf diesem konsumptiven Sektor versuchte die Besatzungsmacht in enger Absprache mit der Arbeitsverwaltung, ein Wohnungsbauprogramm für die Wismut-Arbeiter zu entwerfen, von dem man

94 SAPMO, DY 30/IV 2/2.027/21, Bl. 24f., Rundschreiben der DVAS vom 3. 11. 1947 an den Minister für Arbeit und Sozialwesen der Landesregierung Brandenburg.

95 Ebenda, Bl. 24.

96 Ebenda, Bl. 25.

97 Einen Engpaß mußte selbst die IG Bergbau (Revierleitung Aue) in ihrem ansonsten stark geschönten Bericht über die Arbeitsbedingungen im Bergbaugebiet Aue, Annaberg, Marienberg konstatieren. Vgl. BAB, DQ 2/1964, IG Bergbau (Revierleitung Aue) am 29.12. 1947 an das Landesarbeitsamt in Dresden, $\mathrm{S}$. 1.

98 Vgl. allgemein: Hoffmann, Wohnungspolitik in der DDR; in vergleichender Perspektive: Schildt, Wohnungspolitik. 
annahm, daß sich erst 1949 entlastende Wirkungen bemerkbar machen würden 99 . Die sowjetische Besatzungsmacht behielt sich in dieser Frage die Federführung vor und machte rasch deutlich, daß zunächst einmal kurzfristige Maßnahmen zu ergreifen waren. Darunter verstanden Vertreter der sächsischen SMA „eine stärkere Belegung des vorhandenen Wohnraumes" 100 und verwiesen auf das Gesetz Nr. 18 des Alliierten Kontrollrates (Wohnungsgesetz) vom 8. März 1946101, das die Erfassung und Verteilung des knappen Gutes regelte. Nach den Vorstellungen der sowjetischen Besatzungsmacht sollten bei der Erfassung nicht nur das Erzbergbaugebiet, sondern auch die angrenzenden Landkreise systematisch untersucht werden. Verworfen wurde dagegen die Idee, Barackenlager aufzubauen. Diese würden - so die Begründung - „leicht de[n] Eindruck eines Gefangenenlagers" vermitteln ${ }^{102}$.

Sachsen trug trotz Absprachen mit der DVAS sowie den übrigen Landesverwaltungen auch weiterhin die Hauptlast bei der Bereitstellung von Arbeitskräften für den Uranbergbau. Der Präsident des Landesarbeitsamtes in Dresden betonte gegenüber der DVAS, daß das Land Sachsen dazu nicht mehr in der Lage sei: „Die Eingriffe, die in die sächsische Wirtschaft getan werden mußten, sind unverantwortlich. ${ }^{103}$ Die Berliner Zentralverwaltung wurde gebeten, die anderen Länder anzuweisen, „die gegebenen Auflagen unverzüglich zu erfüllen“. Von insgesamt 19000 angeforderten Arbeitskräften hatte nur Sachsen sein Soll fast verdoppeln können, von 2000 auf letztlich 3702. Sachsen-Anhalt konnte von 4000 geforderten Arbeitern nur 394 stellen; Thüringen, Mecklenburg und Brandenburg wiesen einen Erfüllungsstand zwischen 30 und 50 Prozent auf. Die SMAD gab daraufhin die Anweisung heraus, daß die Stellung von Arbeitskräften für Aue Vorrang genießen sollte gegenüber anderen sowjetischen Befehlsauflagen ${ }^{104}$. Aus diesem Grunde wurde auch eine Ausnahmeregelung zugunsten des Kupferschieferbergbaus in Mansfeld wieder zurückgezogen.

Die einzelnen Landesarbeitsämter waren Anfang 1948 bei der Ausführung der SMAD-Befehle für die Wismut AG so weit in Rückstand geraten, daß an die Umsetzung neuer Auflagen von seiten der sowjetischen Besatzungsmacht überhaupt nicht zu denken war. Der damit verbundene Arbeitsaufwand war zudem enorm: So berichtete ein Vertreter des mecklenburgischen Landesarbeitsamtes, daß man insgesamt 12799 Personen auf Bergbautauglichkeit überprüft habe, um schließlich die geforderten 3000 Arbeitskräfte nach Aue zu vermitteln. Von diesen seien nur 2216 Personen am Bestimmungsort eingetroffen, darunter befänden sich 1580 Freiwillige (70 Prozent $)^{105}$. Dies belegte, daß sich zum einen zahlreiche für den Uranbergbau angeworbene Arbeiter während des Transportes wieder absetzten,

99 BAB, DQ 2/2091, Niederschrift über eine Unterredung mit Major Baronjuk am 6.12. 1947 in Aue.

100 Ebenda.

101 Amtsblatt des Kontrollrats in Deutschland, S. 117-121.

102 BAB, DQ 2/2091, Niederschrift über Unterredung mit Major Baronjuk am 6. 12.1947 in Aue.

103 BAB, DQ 2/1785, Bl. 144, Präsident des LAA Sachsen am 12.12. 1947 an die DVAS.

${ }^{104}$ BAB, DQ 2/512, DVAS (Abt. I b) am 19. 12. 1947 an das Landesamt für Arbeit und Sozialfürsorge in Halle/Saale.

105 BAB, DQ 2/1537, Niederschrift über den Verlauf der Arbeitstagung der DVAS (Abt. I b) in Leipzig am 6./7. 1. 1948, S. 6. 
und zum anderen der Anteil der Zwangsverpflichteten nach wie vor nicht unbeträchtlich war. Der mecklenburgische Vertreter ging dennoch davon aus, bis Ende Januar die Auflage erfüllen zu können. Gleichzeitig hatte das nördlichste Land der SBZ in der Zwischenzeit eine weitere Auflage in Höhe von 3000 Arbeitskräften erhalten. Man bemühe sich, so der Mitarbeiter des dortigen Landesarbeitsamtes, den Befehl zu erfüllen, „weise aber jetzt schon darauf hin, es nicht zu können.“ Auf das Instrument der Zwangseinweisung könne nicht mehr zurückgegriffen werden, da zahlreiche Arbeitsamtsleiter erklärt hätten, „in [einem] solchen Falle ihre Ämter niederzulegen." Noch dramatischer hatte sich die Situation in Brandenburg entwickelt, wo von 922 bergbautauglichen Personen, die nach Aue geschickt worden waren, nur 48 Personen ankamen; der Anteil der Freiwilligen betrug hier nur 20 Prozent, in Sachsen-Anhalt sogar nur knapp über 10 Prozent $^{106}$. Die DVAS reagierte auf diese Berichte nur mit dem etwas hilflosen Hinweis, daß die Werbung und Propaganda weiter zu verstärken seien. Nicht nur die DVAS, sondern auch die Landesarbeitsämter und der FDGB-Bundesvorstand erwarteten für das I. Quartal 1948 eine steigende Zahl an Arbeitskräfteanforderungen von seiten der sowjetischen Besatzungsmacht ${ }^{107}$.

Der Wandel von der Arbeitseinweisung zur Freiwilligenwerbung vollzog sich in der Praxis jedoch nur langsam. So meldete etwa der thüringische SED-Landesvorstand der SED-Führung in Berlin am 12. Februar 1948, daß sich unter den insgesamt 4204 Arbeitskräften, die aus Thüringen dem sächsischen Erzbergbau zugewiesen worden waren, 1530 Freiwillige befanden ${ }^{108}$. Die Anzahl der Eingewiesenen betrug demzufolge 2674. Die Arbeitsämter hatten außerdem 2524 Personen registriert, die noch vor der Einweisung in die Westzonen gegangen waren, 428 Arbeitskräfte hatten sich noch während des Transportes in den Westen abgesetzt. In der Folgezeit sank die Zahl der Arbeitseinweisungen weiter: Nach Angaben des sächsischen Ministeriums für Arbeit und Sozialfürsorge befanden sich unter den 7475 Arbeitskräften, die im Laufe des August 1948 aus der gesamten SBZ dem Erzbergbau zugewiesen wurden, 7332 Freiwillige (95,4 Prozent) ${ }^{109}$. Im Dezember lag die Quote bei 96,7 Prozent, wobei die absolute Zahl der zugewiesenen Arbeiter sich nahezu halbiert hatte (3745) ${ }^{110}$. Im Verlauf des Jahres 1948 trug das Land Sachsen erneut mit weitem Abstand die Hauptlast: Von insgesamt 81432 Arbeitern, die zwischen dem 1. Januar und dem 31. Dezember 1948 zur Wismut AG kamen, stellte Sachsen 48739 Arbeiter, Sachsen-Anhalt 9461, Thüringen 9222, Mecklenburg-Vorpommern 7413 und Brandenburg 6597111. Die Arbeitsverwaltung konnte für das I. Quartal wiederum verbesserte Ergebnisse vorlegen ${ }^{12}$ : Das

\footnotetext{
106 Ebenda.

107 SAPMO, DY 34/20149, Bericht der Abt. Arbeitslenkung, Berufsausbildung, Kriegsgefangene, Heimkehrer und Umsiedler vom 11. 1. 1948.

108 SAPMO, DY 30/IV 2/2.027/25, Bl. 101.

109 BAB, DQ 2/1964, Halbmonatsmeldung des Ministeriums für Arbeit und Sozialfürsorge der Landesregierung Sachsen vom 2. 9. 1948 an die HVAS.

$110 \mathrm{BAB}, \mathrm{DQ} 2 / 1914$, Halbmonatsmeldung des Ministeriums für Arbeit und Sozialfürsorge der Landesregierung Sachsen vom 5. 1. 1949 an die HVAS.

111 Ebenda.

112 BAB, DQ 2/1964, Halbmonatsmeldung des Ministeriums für Arbeit und Sozialwesen der Landesregierung Sachsen vom 4. 4. 1949 an die HVAS. Der Bericht enthält auch Angaben über die Entwicklung im I. Quartal 1949.
} 
Auflagensoll von 22500 Arbeitskräften war weit übertroffen worden; insgesamt 34656 Arbeiter hatten für die Arbeit im Uranbergbau gewonnen werden können. Bis auf Brandenburg und Mecklenburg-Vorpommern hatten alle Länder ihre Anforderungen erfüllt, wobei Sachsen mit 19139 Arbeitern zum wiederholten Male die Spitzenposition einnahm. Auch der prozentuale Anteil der Freiwilligen unter den zugewiesenen Arbeitern (99,6 Prozent) konnte die Arbeitsverwaltung zufriedenstellen.

Im Verlauf des Jahres 1948 verbesserte sich zunächst die soziale Lage der Beschäftigten der Wismut AG. Die nunmehr einsetzende Bevorzugung der Bergarbeiter bei der Versorgung mit Konsumgütern hatte eine Magnetwirkung auf Arbeitskräfte auch außerhalb Sachsens. Aufgrund des massenhaften Zuzugs kam es jedoch zu einer erneuten Verschlechterung der Lebensbedingungen ab Mitte $1948^{113}$. Bereits im Herbst 1947 hatte sich die Sogwirkung bemerkbar gemacht, die von der übertariflichen Bezahlung der Bergarbeiter ausging. Dies hing auch mit der herausgehobenen Stellung dieses Berufsstandes innerhalb der Sozialversicherung zusammen ${ }^{114}$, verstärkte sich aber zumindest für die Beschäftigten des Uranbergbaus im Zusammenhang mit dem SMAD-Befehl Nr. 234. So existierte frühzeitig in einzelnen Bezirken des Erzgebirges ein Prämiensystem, „wonach in den meisten Fällen die Tariflöhne bei weitem überschritten " wurden ${ }^{115}$. Nach Angaben der DVAS konnten rund 50 Prozent der in Aue beschäftigten Bergarbeiter "das Mehrfache ihres tariflichen Schichtlohnes" verdienen.

Die Freiwilligenwerbung für die Wismut AG blieb nicht ohne Wirkung auf die Wirtschaftsbranchen, die nicht dem SMAD-Befehl Nr. 153 unterlagen, zunächst in Sachsen und etwas zeitversetzt in den übrigen Ländern der SBZ. Aufgrund der deutlich gestiegenen Löhne und der besseren Lebensmittelversorgung - dies hing unmittelbar mit dem SMAD-Befehl Nr. 234 zusammen - hatten sich offensichtlich zahlreiche Arbeiter zu einem Arbeitsplatzwechsel entschlossen. Diese Entwicklung war von seiten der Arbeitsverwaltung und der SED-Führung durchaus intendiert gewesen, über die Konsequenzen hatte man sich allerdings keine weiteren Gedanken gemacht. Planungen über die Abdeckung des dabei auftretenden Arbeitskräftebedarfs in den Wirtschaftsbranchen, aus denen die Arbeiter abwanderten, existierten nicht. Es hat sogar den Anschein, daß sich bei den an der Arbeitskräftelenkung beteiligten Ressorts auf Zentral- und Landesebene zunächst eine gewisse Ratlosigkeit breit machte. Die Berichte über die Abwanderung erreichten als erstes die sächsische Landesverwaltung. So berichtete ein Vertreter der Industrie- und Handelskammer (IHK) in Aue, daß er „von der gesamten Industrie Meldungen habe, daß Spitzenkräfte in den Erzbergbau abwandern" 116 . Durch eine unterschiedliche Behandlung von Fach- und Hilfsarbeitern versuchte die Leiterin des Landesarbeitsamtes in Dresden, Hildegard

${ }^{113}$ Roeling, Arbeiter im Uranbergbau, S. 118.

$11+$ Vgl. dazu: Hoffmann, Sozialpolitische Neuordnung in der SBZ/DDR, S. 57-63. Vgl. zur historischen Entwicklung der knappschaftlichen Versicherung bis 1945: Geyer, Die Reichsknappschaft.

115 SAPMO, DY 30/IV 2/2.027/25, Bl. 76, DVAS-Präsident Brack am 20. 9.1947 an die Abt. Arbeit und Sozialfürsorge des SED-Zentralsekretariats.

116 SächsHStA, Landesregierung Sachsen, Ministerium für Arbeit und Sozialfürsorge, Bd. 307, Niederschrift über die Besprechung wegen der Abwanderung von Fachkräften aus der Industrie zum Erzbergbau im Arbeitsamt Aue am 15. 3. 1948, S. 1. 
Heinze, eine Problemlösung zu finden. Nach ihren Vorstellungen sollten Facharbeiter, die sich freiwillig für den Uranbergbau meldeten, für die aber vom zuständigen Arbeitsamt kein Ersatz gestellt werden konnte, keine Genehmigung zum Arbeitsplatzwechsel erhalten ${ }^{117}$. Anders sei dagegen bei der Freigabe von Hilfsarbeitern zu verfahren. Dieser Vorschlag erwies sich jedoch als nicht sehr praktikabel, da er eine lückenlose Erfassung der Wanderungsbewegung durch die Arbeitsämter voraussetzte. Das Landesarbeitsamt informierte kurz darauf die sächsische Landesregierung sowie den FDGB-Landesvorstand über die neu eingetretene Entwicklung und betonte, daß die Abwanderung von Fachkräften aus der Industrie „ein bedrohliches Ausmaß $\aleph^{\prime}$ angenommen habe ${ }^{118}$. Heinze kündigte in dem Zusammenhang an, daß sie versuchen werde, bei der SMA Sachsen zu erreichen, daß „die Einstellung von Arbeitskräften in den einzelnen Objekten des Erzbergbaus nur bei Zuweisung des Arbeitsamtes zu erfolgen hat." Es blieb jedoch bei dieser Absichtserklärung; eine konkrete Absprache zwischen der sowjetischen Besatzungsmacht in Sachsen und dem dortigen Landesarbeitsamt ist nicht nachweisbar. $\mathrm{Zu}$ vermuten ist, daß sich die SMA und vor allem die Bergwerksleitung in Aue zu einer solchen Zusicherung nicht bereitfinden wollten. Die unzureichende Zusammenarbeit zwischen sowjetischen und deutschen Dienststellen hatte sich, wie gezeigt werden konnte, bereits zuvor angedeutet, was mit der mangelnden Bereitschaft auf seiten der Wismut AG zusammenhing. Diese Abwanderung zum Erzbergbau setzte sich in der Folgezeit weiter fort und betraf schließlich auch Betriebe der Schwerindustrie, so etwa die Gießereien ${ }^{11}$. Einzelne Arbeitsamtsleiter in Sachsen befürchteten sogar langfristige Auswirkungen für den Stein- und Braunkohlenbergbau: Falls dort keine Besserung für die Bergarbeiter einträte, sei mit einer Wanderungsbewegung hin zur Wismut AG zu rechnen ${ }^{120}$. Den Mangel an Nachwuchskräften führte die Hauptverwaltung Kohle jedoch weniger auf die Abwanderung von Arbeitskräften als vielmehr auf die "Unlust der Jugendlichen zum Bergbauberuf" zurück ${ }^{121}$. Statistische Erhebungen über die Fluktuation vom Kohlen- zum Erzbergbau konnte die Hauptverwaltung nicht vorlegen. Nach Einschätzung der sächsischen Landesverwaltung war jedoch eine "Störung der Kohlenförderung" nicht zu befürchten, da etwa die Steinkohlegruben ebenfalls zu den Bereichen gehörten, die bevorzugt mit Arbeitskräften zu versorgen waren. Ein Arbeitsplatzwechsel konnte zudem nur mit Zustimmung des abgebenden Betriebes stattfinden, berichtete das sächsische Ministerium für Arbeit und Sozialfürsorge der HVAS122. In den ersten neun Monaten des Jahres 1948 hatten in den Arbeitsamtsbezirken

117 Ebenda, S. 2.

118 BAB, DQ 2/2091, LAA Sachsen am 16.3. 1948 an den Ministerpräsidenten, den Minister für Arbeit und Sozialfürsorge, das Ministerium für Handel und Versorgung, das Ministerium für Wirtschaft und Wirtschaftsplanung (Abt. Verkehr) und den FDGB-Landesvorstand (Abt. Wirtschaftspolitik).

119 BAB, DQ 2/1763, Niederschrift über die Amtsleitertagung am 5. 8. 1948 im Arbeitsamt Dresden, S. 6.

120 Ebenda, S. 7.

121 BAB, DQ 2/1995, HVAS-Abt. I b am 13. 9. 1948 an Präsident Brack.

122 Ebenda, Ministerium für Arbeit und Sozialfürsorge (HA Arbeit) der Landesregierung Sachsen am 6. 10. 1948 an dic HVAS. 
Dresden, Lugau und Zwickau insgesamt 57 Fach- und 8 Hilfsarbeiter den Steinkohlenbergbau verlassen und waren zum Erzbergbau abgewandert ${ }^{123}$.

Die Betriebe besaßen ihrerseits durchaus Möglichkeiten, Auflagen der Arbeitsämter abzulehnen bzw. zu reduzieren. Dabei wurden nicht nur die entsprechenden Landesverwaltungen, sondern sogar die Zentralverwaltungen bzw. Hauptverwaltungen der DWK eingeschaltet. Diese versuchten des öfteren bei Auseinandersetzungen zwischen Betrieben und Arbeitsämtern als Vermittler aufzutreten. So berichtete die HVAS am 14. Mai 1948, daß Verhandlungen mit der Betriebsleitung des Kraftwerkes Plessa ergeben hätten, daß dieses Unternehmen „vorläufig“ nur fünf ungelernte bergbautaugliche Arbeiter für Aue zu stellen hatte; auf die restlichen fünf solle dagegen verzichtet werden ${ }^{124}$. Damit war es der Kraftwerksleitung letztlich gelungen, die Anforderung zu halbieren. Diese Verfahrensweise war mitunter aber sehr zeit- und personalaufwendig; außerdem standen Aufwand und Ertrag der Verhandlungen in keinem günstigen Verhältnis. Dennoch bleibt festzuhalten, daß die HVAS bestrebt war, die Erfüllung der Arbeitskräfteauflagen für die Wismut AG im Konsens zwischen allen Beteiligten herbeizuführen.

Um die Arbeitskräftelenkung zu verbessern, schlug der Leiter der HVAS Brack im Mai 1948 vor, bei der DWK einen Sonderbeauftragten für den sächsischen Erzbergbau zu bestellen ${ }^{125}$. Zu dessen Aufgaben sollten die konkrete Planung und Lenkung der Arbeiter, Fragen der Wohnraum- und Lebensmittelversorgung, der Verkehrsverbesserung und die „kulturelle Betreuung“ gehören. Dabei hatte er vor allem die Tätigkeit der kommunalen Behörden, der Landesverwaltungen und der beteiligten Hauptverwaltungen zu koordinieren sowie für die Durchführung von DWK-Beschlüssen zu sorgen. Die DWK-Spitze reagierte jedoch auf diesen Vorstoß nicht weiter, obwohl ein Koordinierungsbedarf mittlerweile deutlich geworden war. Die sächsische Landesregierung unterstützte Brack vehement und bat darum, den Sonderbeauftragten „recht bald zu bestimmen, damit die notwendigen Maßnahmen insbesondere zur Arbeitskräftebeschaffung, aber auch für die Versorgung der Bergarbeiter mit Wohnraum, Kleidung und Hausrat unter Beteiligung aller Länder der Zone durchgeführt werden können" 126 .

Die Fluktuation unter der Belegschaft der Wismut AG war bis Ende der vierziger Jahre stets hoch und lag vermutlich über der durchschnittlichen Quote in der gesamten SBZ. Dies hing mit den Besonderheiten des Uranbergbaus und vor allem mit dem Instrument der Arbeitseinweisung zusammen. Diese konnte, so sah es die „Verordnung über die Sicherung und den Schutz der Rechte bei Einweisungen von Arbeitskräften" vor, nur für sechs Monate erfolgen; in begründeten Ausnahmefällen war eine Verlängerung um weitere sechs Monate möglich. Anschließend mußten die eingewiesenen Arbeitskräfte von den Arbeitsämtern im Erzgebirge entlassen werden und konnten in ihre Heimatorte zurückkehren. Dabei ergaben sich oftmals Anpassungsschwierigkeiten, da die Arbeitsverwaltung die Neuankömmlinge wieder mit Arbeit versorgen mußte. Zwar hatten die arbeits-

123 Ebenda.

124 BAB, DQ 2/1995, HVAS (Donau) am 14. 5. 1948 an HV Encrgiewirtschaft.

125 BAB, DQ 2/2091, HVAS (Brack) am 15. 5. 1948 an den DWK-Vorsitzenden Rau.

126 Ebenda, Ministerium für Arbeit und Sozialfürsorge der Landesregierung Sachsen am 1.6. 1948 an die HVAS. 
rechtlichen Bestimmungen vorgesehen, daß eingewiesene Arbeiter von ihrem ursprünglichen Arbeitgeber wieder einzustellen waren. Eine Garantie gab es letztlich aber nicht, so daß in einzelnen Betrieben die Arbeitslosenzahl wieder leicht anzusteigen drohte. So meldete das mecklenburgische Ministerium für Sozialwesen der HVAS, zahlreiche Arbeitsämter würden sich darüber beklagen, daß „von der Entpflichtung der Arbeitskräfte die Abgabeämter keine Nachricht erhalten.“ Dies habe zur Folge, daß „die zurückgekehrten Arbeitskräfte tage- und wochenlang ohne Beschäftigung in ihren Heimatorten sind, bis sie es für richtig finden, sich beim zuständigen Amt für Arbeit wieder anzumelden" 127 .

Das Präsidium der HVAS erwartete für das 2. Halbjahr 1948 einen weiteren Anstieg des Bedarfs an Arbeitskräften für den sächsischen Erzbergbau, der zwischen 15 und 20 Prozent über dem des ersten Halbjahrs liegen werde ${ }^{128}$. Erstmals wurde erwogen, bei der Vermittlung Frauen zu berücksichtigen. Gespräche mit der Abteilung Arbeitskraft in Karlshorst hatten offensichtlich ergeben, daß die SMAD ein „besonderes Interesse“ daran zeigte, im Rahmen der Werbemaßnahmen „die Lebensweise nicht rosiger" zu machen, „als sie tatsächlich ist." Es sei vielmehr zweckmäßig, sich auf eine sachliche Beschreibung der Arbeits- und Lebensverhältnisse zu beschränken, "damit keine Enttäuschungen eintreten" ${ }^{129}$. Diese Position mußte die deutschen Vertreter einigermaßen überraschen, hatte doch die SMAD bis zu diesem Zeitpunkt eine Darstellung der Verhältnisse im Uranbergbau in der Öffentlichkeit kategorisch abgelehnt. Erstaunlich war außerdem, daß Karlshorst SAG-Betriebe bei der Abstellung von Arbeitskräften für die Wismut AG nicht ausnehmen wollte. Inwieweit dies jedoch nur eine Absichtserklärung war, mußte die Praxis der Arbeitsverpflichtung noch zeigen.

Aus Sicht des sächsischen Landesarbeitsamtes hatte sich Mitte des Jahres 1948 die Freiwilligenwerbung spürbar verbessert; der von der HVAS prognostizierte Anstieg des Arbeitskräftebedarfs hatte sich wohl noch nicht eingestellt. Auch die Bergwerksleitung in Aue teilte diese Einschätzung, wies aber gleichzeitig darauf hin, daß „das nicht bedeuten soll, daß die Gestellung von Arbeitskräften für den Erzbergbau eingestellt werden kann"130. Erhöhte Entlohnung und zusätzliche Versorgung mit Lebensmitteln boten offensichtlich genügend Anreize, so daß sich die Situation insgesamt leicht entspannt hatte. Das Problem der Gewinnung neuer Arbeiter für die Wismut AG sei ,im Hinblick auf die augenblickliche Lage nicht sehr akut [...], da die Leute ohne besondere Werbung in den Bergbau strömen“" 131 , so die Einschätzung eines Ministerialdirektors des Landesarbeitsamtes. Die sowjetische Besatzungsmacht überließ es weitgehend der deutschen Arbeitsverwaltung, Arbeitskräfte in den sächsischen Erzbergbau zu lenken. Für sie war nur die annähernde Erfüllung der Auflagen entscheidend, damit die Gewinnung des uranhaltigen Gesteins gesteigert werden konnte. Daneben bestanden aber massive Si-

127 Ebenda, Ministerium für Sozialwesen der Landesregierung Mecklenburg am 4.6. 1948 an die HVAS.

128 BAB, DQ 2/2049, Bl. 138, Protokoll der Präsidiumssitzung am 18.6. 1948.

129 Ebenda.

130 BAB, DQ 2/1763, Niederschrift über dic Amtsleitertagung am 5. 8. 1948 im Arbeitsamt Dresden, S. 7 .

131 BAB, DQ 2/1762, Bericht der DVAS-Abt. I b über die Amtsleitertagung am 9./10. 7. 1948 des LAA Dresden im Mittweida. 
cherheitsbedenken auf seiten der sowjetischen Besatzungsmacht gegenüber zwei Personengruppen: entlassene politische Strafgefangene, darunter fielen in erster Linie NS-Belastete, sowie Westmigranten. Diesen wurde der Zugang kategorisch verwehrt. Ein sowjetischer Offizier faßte dies im Sommer 1948 gegenüber Vertretern der sächsischen Arbeitsverwaltung kurz zusammen: „Ehemalige politische Inhaftierte sollen nicht für den Erzbergbau eingesetzt werden. Personen, die aus der Westzone herüberkommen, sind nicht zum Einsatz für den Erzbergbau zu vermitteln, da der Spionageverdacht vorliegt. " ${ }^{132}$ Allerdings bestanden in dieser Frage unterschiedliche Positionen: So erklärte ein Vertreter der Bergwerksleitung in Aue, daß auch Arbeitskräfte aus den westlichen Besatzungszonen in den Erzbergbau vermittelt werden könnten ${ }^{133}$. Die Nachfrage nach Arbeitskräften wog dabei schwerer als die Furcht vor der Einschleusung vermeintlicher Westagenten. Festzuhalten bleibt, daß sich die Arbeitskräftewerbung für die Wismut AG primär auf die SBZ konzentrierte. Darüber hinaus gewannen die angesprochenen Sicherheitsbedenken die Oberhand, je weiter die Blockbildung in Europa und die damit zusammenhängende wirtschaftliche und politische Teilung Deutschlands voranschritt.

Für die Arbeitsverwaltung gerieten im Sommer 1948 zwei Bevölkerungsgruppen in den Mittelpunkt des Interesses, die bisher bei der Rekrutierung vernachlässigt worden waren: Frauen und Jugendliche. Aufgrund der arbeitsrechtlichen Bestimmungen sowie der Kriterien für die Bergbautauglichkeit blieben die weibliche Bevölkerungsgruppe sowie die Jugendlichen von dieser Tätigkeit bis dahin ausgeschlossen. Der Politikwechsel ging auf die sowjetische Besatzungsmacht zurück, wobei betont werden muß, daß bereits zu diesem Zeitpunkt Frauen zu leichten Arbeiten etwa in der Verwaltung eingesetzt worden waren. Dagegen blieb die Untertagearbeit nach wie vor eine Männerdomäne; daran änderte sich auch in der Folge nichts. Neu war dagegen der Versuch, Frauen in größerem Umfange für Verwaltungsarbeiten zu gewinnen. Dadurch hätten wiederum Männer für die körperlich schwere Arbeit in den Schachtanlagen freigesetzt werden können. Die sowjetische Bergwerksleitung hatte allerdings völlig illusorische Vorstellungen: „Es können beliebig viele Frauen nach Aue geschickt werden, jedoch werden nur $30 \%$ auf das Auflagesoll angerechnet. "134 Die eingestellten Frauen sollten die gleichen Löhne und gleiche Verpflegung erhalten wie ihre männlichen Kollegen. Die HVAS informierte das Landesarbeitsamt in Dresden umgehend über den neuen Kurs ${ }^{135}$. Die Berliner Hauptverwaltung hatte aber erhebliche Zweifel an der Ankündigung der Wismut AG, daß die Unterbringung der Frauen „vorwiegend“ in Einzelquartieren garantiert werde, stand dies doch im krassen Widerspruch zu den bisherigen Berichten über die Wohnverhältnisse im Erzbergbaugebiet. Einzelne Schachtanlagen der Wismut AG lehnten jedoch die Einstellung von Frauen $\mathrm{ab}$, angeblich um die Verbreitung von Seuchen im Vorfeld zu verhindern ${ }^{136}$. Das

132 BAB, DQ 2/1763, Niederschrift über die Amtsleitertagung am 5. $8.1948 \mathrm{im}$ Arbeitsamt Dresden, S. 7.

${ }^{133}$ Ebenda, Bericht über die Amtsleitertagung in Halle/Saale am 10. 8. 1948, S. 1.

$13+$ Ebenda, S. 2.

$135 \mathrm{BAB}, \mathrm{DQ} 2 / 2091$, Schreiben Krügers vom 16. 8. 1948 an das sächsische Landesarbeitsamt.

136 BAB, DQ 2/1995, Arbeitsamt Aue am 10.9. 1948 an das Ministerium für Arbeit und Sozialfürsorge der Landesregierung Sachsen. 
Arbeitsamt Aue berichtete, daß einige ärztliche Untersuchungs- und Betreuungsstellen nicht nur Schwangerschaftsfälle, sondern auch Geschlechtskrankheiten festgestellt hätten. Die Ambulatorien im Erzbergbaugebiet verzeichneten „diese Fälle in großem Ausmaß"137. Dadurch stieg die Rate der Fehlvermittlungen sowie der Arbeitsentpflichtungen, so daß das Arbeitsamt anregte, daß „vor Zuweisung von Frauen zum Erzbergbau die Untersuchung auf Geschlechtskrankheiten und Schwangerschaft durchgeführt werden muß und ein entsprechender Vermerk auf den Papieren zu stehen hat". Die HVAS übernahm diesen Vorschlag138. Da die Frage der wohnlichen Unterbringung nicht so rasch gelöst werden konnte, schlug die SMA Sachsen vor, die Zuweisung von Frauen ins Erzbergbaugebiet vorerst zu beenden, ohne allerdings das Gesamtsoll der zu stellenden Arbeitskräfte zu reduzieren ${ }^{139}$. Die sowjetische Bergwerksleitung in Aue hob schließlich nach Rücksprache mit Karlshorst die von der SMAD der DWK erteilte Anweisung auf, nach der die Länder die Auflagen für den Erzbergbau zu 30 Prozent mit Frauen abdecken konnten, und senkte den Anteil auf 5 Prozent ${ }^{140}$. Nach den Meldungen einzelner Arbeitsamtsbezirke betonte die HVAS, daß die Versorgung der eingewiesenen Frauen nicht allein eine Aufgabe der sächsischen Landesverwaltung sei, und unterstrich die Bedeutung von ärztlichen Eingangsuntersuchungen, die auch auf männliche Arbeitskräfte ausgedehnt werden sollten. Strittig war dagegen die Finanzierungsfrage; nach Ansicht der HVAS mußte die Zentralfinanzverwaltung die erforderlichen Mittel bereitstellen. Zur Begründung gab ihr Präsident Brack an: „Einen Seuchenherd einzudämmen ist immer billiger, als wenn man ihn ausbreiten läßt." ${ }^{141}$

Darüber hinaus befürwortete die sowjetische Bergwerksleitung die Vermittlung von Jugendlichen nach Aue, die kurz vor der Vollendung des 18. Lebensjahres standen ${ }^{142}$. In dem Zusammenhang war geplant, eigene Aus- und Weiterbildungskurse einzurichten. Die Angaben der HVAS, daß die SMAD beabsichtigte, 5000 Jugendliche im Alter von 16 bis 21 Jahren zu kurzfristigen und 2000 Lehrlinge im Alter von 14 bis 16 Jahren zu einer dreijährigen Ausbildung in der Wismut AG unterzubringen, waren jedoch deutlich überhöht ${ }^{143}$. Tatsächlich sollten vielmehr 2350 Jugendliche für eine dreijährige und nur 2400 für eine kurzfristige Ausbildung eingesetzt werden. Im August 1948 gab es offensichtlich keinen Lehrling. Gleichzeitig registrierte die IG Bergbau aber eine Reihe von Jugendlichen, die das 18. Lebensjahr noch nicht erreicht hatten. Sie schätzte die Gesamtzahl der im Uranbergbau beschäftigten Jugendlichen auf 10000 (18-21 Jahre) bzw. 20000

137 Ebenda.

$138 \mathrm{BAB}, \mathrm{DQ} 2 / 1950$, Aktennotiz über Besprechung mit der SMAD am 1. 10. 1948.

$139 \mathrm{BAB}, \mathrm{DQ} 2 / 1762$, Niederschrift über den Verlauf der Arbeitstagung der DVAS (Abt. I b) in Bad Kösen am 5./6. 10. 1948, S. 2.

140 SächsHStA, Landesregierung Sachsen, Ministerium für Arbeit und Sozialfürsorge, BD. 396, Vermerk über Vorsprache beim Vertreter von General Malzew, Oberst Domaschnikow, am 18. 10. 1948 in Aue.

$141 \mathrm{BAB}, \mathrm{DQ}, 2 / 1762$, Niederschrift über den Verlauf der Arbeitstagung der DVAS (Abt. I b) in Bad Kösen am 5./6. 10. 1948, S. 3.

$142 \mathrm{BAB}, \mathrm{DQ} 2 / 1763$, Bericht über die Amtsleitertagung in Halle/Saale am 10. 8. 1948, S. 3.

${ }_{143}$ SAPMO, DY 30/IV 2/16/111, Bl. 206-211, hier Bl. 206, Bericht des FDGB-Bundesvorstandes (HA 10: Jugend) vom 30. 8. 1948. 
(21-25 Jahre) ${ }^{144}$. Am 27. September veröffentlichte die HVAS (HA Ausbildung und Umschulung) „Richtlinien für die Werbung und Einstellung von Jugendlichen zur Ausbildung im Erzbergbau bei der Wismut AG“145. Demzufolge durften nur Jugendliche ab dem vollendeten 17. Lebensjahr eingestellt werden, die ein ärztliches Zeugnis über ihre Bergbautauglichkeit vorweisen konnten und nicht in der Ausbildung für einen „Mangelberuf“ standen. Erst Ende November gab die Leitung der Wismut AG die Zusage, für die Ausbildung Lehrkräfte, Bekleidung und Unterkünfte bereitzuhalten ${ }^{146}$. Die HVAS erteilte daraufhin eine Anweisung, nach der die Werbung von Jugendlichen, insbesondere in den ländlichen Regionen, fortzusetzen war. Die Massenorganisationen wurden weniger zur Werbung von Arbeitskräften eingebunden - dies blieb eine Aufgabe der Arbeitsverwaltung und der Werber - als vielmehr zur Mobilisierung der eigenen Klientel mit dem Ziel, die Produktion in der Wismut AG zu steigern. So legte der FDGB-Kreisvorstand Wismut am 21. Februar 1949 einen Aktionsplan für eine Schachtanlage in Annaberg vor, die zum "Jugendschacht" ernannt worden war ${ }^{147}$.

Mitte Oktober 1948 legte die Wismut AG einen Plan zur Verbesserung der Arbeitskräftewerbung vor ${ }^{148}$. Demzufolge sollten die Werber nicht mehr ohne Absprache mit der Arbeitsverwaltung ausschwärmen und ihrer Tätigkeit nachgehen, sondern jeweils einem Arbeitsamt zugeteilt werden. Während der Werber ausschließlich für das Arbeitsamt tätig zu sein und für die Einhaltung der Auflagen Sorge zu tragen hatte, sollte das betreffende Arbeitsamt von der Bergwerksleitung einen Plan erhalten, für welche Schachtanlagen die Arbeitskräfte abzustellen waren. Dadurch sollten die Arbeitsämter enger in die Werbung mit einbezogen und die bestehende Rivalität zwischen Arbeitsämtern und Werbern aufgehoben werden. Eine reibungslose Zusammenarbeit stellte sich jedoch nicht ein. Im Gegenteil: Die Länder mußten nach wie vor die ihnen gestellten Auflagen erfüllen und erblickten in der Tätigkeit der Werber eine Konkurrenz. Gegenseitige Abwerbungen waren offensichtlich keine Seltenheit. So leitete das Landesarbeitsamt Schwerin die Beschwerde eines Transportbegleiters weiter, der berichtet hatte, daß sich Werber der Wismut AG „an seinen Transport herangemacht und versucht hätten, Arbeitskräfte für bestimmte Objekte zu werben“ "149. Die HVAS kritisierte „derartige Werbemethoden“, die darauf hinausliefen, daß „eine erhebliche Anzahl von Arbeitskräften, durch die Mühe und Arbeit ihrer Arbeitsämter [des Landesarbeitsamtes Schwerin] geworben und auf den Weg gebracht, nunmehr den Werbern angerechnet werden und der Sollerfüllung der Länder" verlorengingen. Auch die sowjetische Bergwerksleitung in Aue wollte dem dadurch entstandenen Planungs- und Lenkungschaos ein Ende bereiten. Major Baranjok kündigte Anfang November 1948 an, daß die einzelnen Schachtanlagen „ab sofort“ ihre Wer-

144 Ebenda, Bl. 207.

$145 \mathrm{BAB}, \mathrm{DQ} 2 / 1964$.

146 BAB, DQ 2/1964, Aktenvermerk Bracks vom 1. 12. 1948.

147 SAPMO, DY 30/IV 2/16/112, Bl. 1-4.

148 SächsHStA, Landesregierung Sachsen, Ministerium für Arbeit und Sozialfürsorge, Bd. 396, Vermerk über die Vorsprache beim Vertreter von General Malzew, Oberst Domaschnikow, am 18. 10. 1948 in Aue.

${ }^{149} \mathrm{BAB}, \mathrm{DQ} 2 / 1964$, Abteilungsleiter Donau am 20.11. 1948 an das Ministerium für Arbeit und Sozialfürsorge in Dresden. 
bungstätigkeit territorial abgrenzen würden: „Jedem Objekt wird in Übereinstimmung mit den Landesämtern ein besonderes Werbegebiet zugewiesen. “150 In $\mathrm{Zu}$ kunft seien „wilde" Werbungen notfalls mit polizeilichen Mitteln zu unterbinden.

Die Wirtschaftsstruktur des Bezirkes Aue wurde wesentlich geprägt vom Uranbergbau, der eine nicht unerhebliche Magnetwirkung auf dem Arbeitsmarkt ausübte ${ }^{151}$. Die frühzeitig festgestellte Abwanderung von Arbeitskräften zur Wismut AG setzte sich weiter fort und wurde positiv beeinflußt durch die verhältnismäßig guten Arbeits- und Lebensbedingungen. Sowohl die Arbeitsämter als auch die HVAS hatten wiederholt darauf aufmerksam gemacht, daß die Tätigkeit der Arbeitsverwaltung durch diese Wanderungsbewegung erheblich belastet wurde. Deshalb schlugen Mitarbeiter der Berliner Hauptverwaltung nach einer Überprüfung des Arbeitsamtes in Aue vor, daß im Interesse der Entwicklung des Erzbergbaus und im Interesse der Industriebetriebe, die eine Abwanderung von Arbeitskräften verzeichneten, eine andere Strukturpolitik notwendig sei. Das bedeutete letztlich eine aufwendige Auslagerung der Betriebe, die nicht unmittelbar zur Wismut AG gehörten. Das Ministerium für Arbeit und Sozialfürsorge in Dresden wurde gebeten, entsprechende Konzepte mit den zuständigen Landesministerien auszuarbeiten. Obwohl dieser Plan in der Folgezeit öfters wieder aufgegriffen wurde, hatte er doch sehr geringe Realisierungschancen. $\mathrm{Zu}$ berücksichtigen waren dabei aus Sicht der Landesverwaltungen nicht nur die Kosten für die Verlagerung der Industriebetriebe in andere Bezirke außerhalb der Erzbergbauregion, sondern auch die anfallenden Kosten für den Aufbau einer neuen Infrastruktur sowie die finanziellen Aufwendungen für die Wohnraumversorgung, die auf diese Weise nur auf andere Bezirke abgewälzt wurden.

Eine große Belastung für den wirtschaftlichen Aufbau in der SBZ stellte die "Transportkrise“ 152 dar, die nach Einschätzung von Wolfgang Zank noch gravierender war als der Kohlenmangel. Für die Arbeitskräftelenkung verstärkte sich dieses Problem im Zusammenhang mit dem Wohnraummangel, da Wismut-Arbeiter oftmals fern der Schachtanlagen untergebracht waren und täglich einen stundenlangen Anfahrtsweg zur Arbeitsstätte auf sich nehmen mußten, den sie darüber hinaus auch noch stellenweise ohne Verkehrsmittel zurückzulegen hatten. Ein gut ausgebautes Verkehrsnetz mit regelmäßig verkehrenden Autobussen bzw. Personenzügen existierte aber im Herbst 1948 noch nicht ${ }^{153}$. Einzelne Bergarbeiter beklagten sich sogar bei der ,Berliner Zeitung' über die zu langen Anfahrtswege in völlig überfüllten Zügen ${ }^{154}$. Die HVAS nahm solche Beschwerden als willkommenen Anlaß für die Überprüfung des Arbeitsamtes Aue ${ }^{155}$. Dadurch

150 BAB, DQ 2/2090, Bericht der HVAS vom 10. 11. 1948, S. 6.

151 Ebenda, S. If.

152 Zank, Wirtschaft und Arbeit, S. 23. Im Gegensatz zu Zank und Karlsch relativiert Kühr die Bedeutung der Verkehrsreparationen sowic die Folgen für die industrielle Produktion. Im Zeitraum zwischen 1945 und 1950 habe vielmehr der Gütermangel den Mangel an Transportkapazitäten überlagert. Vgl. Kühr, Die Reparationspolitik der UdSSR und die Sowjetisierung des Verkehrswesens, S. $8 \mathrm{f}$.

153 SächsHStA, Landesregierung Sachsen, Ministerium für Arbeit und Sozialfürsorge, Bd. 396, Vermerk über die Vorsprache beim Vertreter von General Malzew, Oberst Domaschnikow, am 18. 10. 1948 in Aue.

${ }_{154}$ BAB, DQ 2/2090, Leserbrief von Max C. (o.D., vermutlich Herbst 1948).

155 Ebenda, Vermerk Donaus (HVAS) vom 19. 10. 1948. 
wurde die politische Verantwortung auf die kommunale Ebene abgewälzt; ein Ausbau und eine Verbesserung des Verkehrssystems wurde dagegen nicht gezielt in Angriff genommen, zumal eine entsprechende Investitionsplanung nur in enger Absprache mit der sowjetischen Besatzungsmacht möglich gewesen wäre.

Aufgrund der zeitlich befristeten Einweisungen war die Fluktuation bei der Wismut AG relativ hoch. Nach wie vor galt: Nach Ablauf von sechs Monaten mußten die eingewiesenen Arbeiter wieder entlassen werden; nur in begründeten Ausnahmefällen war eine Verlängerung auf zwölf Monate möglich. Dies war in der „Verordnung über die Sicherung und den Schutz der Rechte bei Einweisungen von Arbeitskräften" vom 2. Juni 1948 festgeschrieben worden. Jede Arbeitskraft benötigte vor der Rückkehr in die Heimatgebiete eine schriftliche Entpflichtung vom zuständigen Arbeitsamt im Erzbergbaugebiet. Beim sächsischen Landesarbeitsamt und dem Arbeitsamt in Aue erfolgten zwischen dem 11. Juni 1948 und dem 20. Januar 1949 insgesamt 7734 Entlassungen; außerdem lagen Ende Januar 1949 weitere 1034 schriftliche Gesuche auf Freistellung vom Uranbergbau vor ${ }^{156}$. Die Zahl der Arbeitskräfte, die bereits vor dem 14. Juli 1948 verpflichtet worden waren und nunmehr eine Freistellung anstrebten, konnte dagegen nicht angegeben werden. Zur Sicherung des Arbeitskräftebestandes schlug die Bergwerksleitung Aue vor, die Fristenregelung für die Arbeitseinweisung in den Uranbergbau auszusetzen ${ }^{157}$. Das sächsische Landesarbeitsamt befürchtete sogar ein Ansteigen der Entlassungsanträge, falls sich die gesetzlich eingeräumte Möglichkeit unter der Belegschaft weiter herumsprechen sollte. In dem Zusammenhang wurde eine grundsätzliche Verlängerung der Arbeitsdauer von sechs auf zwölf Monate verlangt ${ }^{158}$. Das sächsische Ministerium für Arbeit und Sozialwesen versuchte in dieser Frage eine Lösung herbeizuführen und schlug eine Einteilung in drei Kategorien vor, nach der die Freistellung geregelt werden sollte ${ }^{159}$. Diese Regelung wurde sowohl mit der HVAS als auch mit der SMAD abgestimmt. Demzufolge endete für Arbeitskräfte, die vor Inkrafttreten der Verordnung vom 2. Juni 1948 eingewiesen worden waren, die Arbeitszeit am 15. Januar 1949. Arbeitskräfte, die einen Arbeitsvertrag abgeschlossen hatten, konnten unter Beachtung der Kündigungsfrist von 14 Tagen ihre Entpflichtung beantragen. In die letzte Gruppe fielen die Arbeitskräfte, die weder einen Arbeitsvertrag noch einen Einweisungsbefehl vorweisen konnten und ebenfalls nach Einhaltung der gesetzlichen Frist kündigen durften. Eine einheitliche Regelung setzte sich jedoch nicht durch ${ }^{160}$, was vermutlich auf den mangelnden Kooperationswillen der sowjetischen Bergwerksleitung zurückzuführen war, da diese primär ein Interesse am Fortbestand der eigenen Belegschaft hatte. Hierbei zeigte sich zum wiederholten Male der Sonderfall der Wismut AG, die der ostdeutschen Verwaltung weitgehend entzogen war. Das galt nicht nur bei Fragen der inneren Sicherheit, sondern eben auch bei zahlreichen

156 Ebenda, Ministerium für Arbeit und Sozialfürsorge der Landesregierung Sachsen am 27. 1. 1949 an die HVAS.

157 Vgl. ebenda.

158 Ebenda.

159 BAB, DQ 2/1995, Ministerium für Arbeit und Sozialwesen des Landes Thüringen am 5. 3. 1949 an den FDGB-Landesvorstand (IG Bergbau) in Dresden.

160 Ebenda, Ministerium für Arbeit und Sozialwesen der Landesregierung Sachsen am 31. 5. 1949 an die HVAS. 
arbeits- und sozialrechtlichen Angelegenheiten. Insofern waren die Landesverwaltungen und die HVAS bei ihren Vorstößen immer auf das Entgegenkommen der sowjetischen Dienststellen angewiesen. Bei den betroffenen Wismut-Arbeitern führte diese Vorgehensweise aber dazu, daß sich die Zahl derer vermehrte, die wegen „Bummelantentum“ umgehend entlassen wurden ${ }^{161}$. Dies schien für viele Bergarbeiter der einzige Weg zu sein, um eine fristgerechte Entpflichtung erwirken zu können.

Die sächsische Landesregierung zeigte sich Anfang 1949 in verstärktem Maße unzufrieden über die Tätigkeit der Werber sowie über deren Zusammenstellung der Arbeitskräftekontingente. So seien Transporte von Berlin nach Aue gesandt worden, bei denen 80 Prozent als bergbauuntauglich eingestuft und zurückgeschickt werden mußten ${ }^{162}$. Sachsen lehnte es daher ab, in Zukunft die Fahrtkosten zu übernehmen, und fand Unterstützung bei der HVAS. Die Berliner Hauptverwaltung vertrat die Auffassung, daß diese Kosten von der Wismut AG getragen werden sollten. Während sich die sächsische Landesverwaltung dafür aussprach, ärztliche Untersuchungen vor Transportbeginn durchzuführen, um dadurch die Quote der als bergbauuntauglich eingestuften Arbeiter zu senken, lehnten einige Arbeitsämter diesen Vorschlag aus Kostengründen ab. Sie verwiesen auf die angespannte Haushaltslage in den Kommunen, die solche Voruntersuchungen letztlich nicht zulassen würden. Die Zahl der Fehlvermittlungen blieb nach Einschätzung der HVAS „außerordentlich groß ${ }^{163}$. Die ärztliche Untersuchung der sich freiwillig gemeldeten und der eingewiesenen Arbeiter sei stellenweise „sehr mangelhaft" gewesen, sonst hätte es nicht vorkommen können, „daß man sogar Personen mit Prothesen als bergbautauglich erklärt." Die HVAS untersagte daraufhin den Arbeitsämtern, mit der Wismut AG Verträge abzuschließen, in denen eine „Kopfprämie" für jeden Eingewiesenen festgelegt wurde ${ }^{164}$. Dadurch sollten wilde und unseriöse Werbemethoden unterbunden werden, die auch das öffentliche Erscheinungsbild der Arbeitskräftewerbung nachteilig beeinflußten. Vor allem ging es aber um die Steigerung der Effektivität der Werbemaßnahmen und die prozentuale Senkung des Anteils der als untauglich eingestuften Arbeitskräfte.

Die Auflagenerteilung von seiten der sowjetischen Besatzungsmacht blieb für die deutsche Arbeitsverwaltung unkalkulierbar und brachte somit die eigenen Pläne zur Arbeitskräftelenkung ständig durcheinander. So erhielt etwa das thüringische Ministerium für Arbeit und Sozialwesen für das erste Quartal 1949 eine Auflage in Höhe von 4000 und für das zweite Quartal eine Auflage in Höhe von 5000 Arbeitskräften 165 . Wenige Tage später teilte das Landesarbeitsamt in Thüringen mit, daß die erste Auflage um weitere 3500 Personen erhöht worden sei166. Die HVAS wurde gebeten, Gespräche mit der SMAD aufzunehmen, damit Auflagen "wieder ordnungsgemäß" von Karlshorst aus über die DWK an die Länder erteilt

\footnotetext{
161 Ebenda.

$162 \mathrm{BAB}, \mathrm{DQ} 2 / 2090$, Aktenvermerk der HVAS vom 12. 2. 1949.

163 Ebenda, Niederschrift der HVAS vom 14. 2. 1949, S. 3.

164 Ebenda, S. 5 f.

$165 \mathrm{BAB}, \mathrm{DQ} 2 / 2091$, Ministerium für Arbcit und Sozialwesen der Landesregierung Thüringen am 4. 3. 1949 an die HVAS.

166 Ebenda, Aktenvermerk der HVAS-Abt. I a vom 9. 3. 1949.
} 
würden ${ }^{167}$. Dadurch erhofften sich einzelne Landesregierungen, Versuchen der Wismut AG, die Auflagen nochmals zu erhöhen, besser begegnen zu können. Diesem Wunsch kam die Berliner Hauptverwaltung jedoch nicht nach, die offensichtlich eine Konfrontation mit der SMAD vermeiden wollte.

Einzelne Arbeitsämter registrierten auch noch 1949 einen kausalen Zusammenhang zwischen Arbeitseinweisung zur Wismut AG und Westflucht. Dies war offensichtlich ein entscheidender, aber nicht der alleinige Faktor für die ansteigende Abwanderung in den Westen, die von den Kommunalverwaltungen festgestellt wurde. Neben der drohenden Verpflichtung für den Uranbergbau war die Wirtschaftsstruktur in den jeweiligen Kreisen und damit das Arbeitsplatzangebot von besonderer Bedeutung. So berichtete der Leiter des Arbeitsamtes Grimmen, daß die Abwanderung von Arbeitskräften in seinem Amtsbezirk so groß sei, daß sich sogar die Bevölkerungszahl merklich vermindert habe ${ }^{168}$. Er führte dieses Phänomen darauf zurück, daß keine größeren Industriestandorte existierten und vor allem die Jugendlichen keine berufliche Zukunft für sich mehr sahen. Aus Sicht der Arbeitsverwaltung, hier waren HVAS, Landes- und Arbeitsämter einer Meinung, mußte ein Ausbildungsprogramm für Jugendliche rasch entwickelt werden. Dies drohte aber an der mangelnden Bereitschaft sowohl der Industriebetriebe als auch kleinerer Handwerksbetriebe zu scheitern. Die Abteilung II (Nachwuchsplanung) der HVAS berichtete, daß sich auch volkseigene Betriebe der Verantwortung entziehen würden, Jugendliche auszubilden ${ }^{169}$. Aus diesen Gründen blieb es vorerst bei der Absichtserklärung, zumal die Arbeitsämter in diesem Bereich personell schwach besetzt waren. Damit zeigte sich erneut, daß die Rekrutierung von Arbeitskräften aufgrund von sowjetischen Befehlen nach wie vor ein zentrales Beschäftigungsfeld für die Angestellten der Arbeitsverwaltung war.

Gleichzeitig bemühte sich die Arbeitsverwaltung intensiv darum, die Freiwilligenwerbung auszuweiten und zu verbessern. Beispielsweise ließ das Arbeitsamt Potsdam nach eigenen Angaben an 80 Säulen und in sämtlichen Straßenbahnen der Stadt Plakate kleben. Außerdem wurden in den städtischen Lichtspieltheatern Werbefilme vorgeführt ${ }^{170}$. Im Zentrum der einzelnen Werbemaßnahmen standen die Löhne und Zusatzversorgungen (Lebensmittel) im sächsischen Erzbergbau; Nachteile bei der Wohnraumversorgung wurden dagegen nicht angesprochen ${ }^{171}$. Nachdem in den ersten Nachkriegsjahren ein Mangel an Papier vorherrschend gewesen war, der eine ausgedehnte Plakatierung unmöglich gemacht hatte, konnten sich die Arbeitsämter nunmehr über eine unzureichende Belieferung mit Werbematerial nicht beklagen. Bis zum Sommer 1949 wurde auch in anderen Städten der SBZ die Kinowerbung für die Freiwilligenwerbung intensiviert. Dabei appellier-

167 Ebenda, Ministerium für Arbeit und Sozialwesen der Landesregierung Thüringen am 4. 3. 1949 an die HVAS.

168 BAB, DQ 2/2063, Bericht der HVAS (Abt. I a) über die Amtsleitertagung am 5./6. 3. 1949 in Ludwigslust, S. 2.

169 Ebenda, S. 3.

170 BAB, DQ 2/2063, Protokoll der Sitzung des Beratungsausschusses des Arbeitsamtes Potsdam am 7. 3. 1949, S. 2.

171 Vgl. BAB, DQ 2/2090, Handzettel des Arbeitsamtes Randow: „Die Antifaschistischen Partcien rufen auf zur Arbeit, die dem Frieden und dem Fortschritt dient!" Der Handzettel war vom SEDund FDGB-Kreisvorstand sowie dem CDU-Kreisverband Randow unterzeichnet worden. 
ten die Werbetexter in den Arbeitsämtern auch an nationale Empfindungen: "Jeder, der sich zur Mitarbeit im Erzbergbau meldet, hilft dem Vaterlande aus der Not." 172 Aus anderen Kreisen der SBZ sind ähnliche Appelle überliefert. So rief etwa der Antifa-Block des Kreises Güstrow die männlichen Bewohner auf: „Erfülle auch Du Deine vaterländische Pflicht und komme zum Erzbergbau!" 173

Die SED-Führung hatte sich bei der Erfüllung der sowjetischen Arbeitskräfteanforderungen auffallend zurückgehalten und überließ diese undankbare Aufgabe der Arbeitsverwaltung. Dadurch lief sie nicht Gefahr, in die Kritik von seiten der sowjetischen Besatzungsmacht einbezogen zu werden. Nur bei der Realisierung des SMAD-Befehls Nr. 234 und dem damit zusammenhängenden Instrumentenwechsel schaltete sich das Zentralsekretariat etwas stärker ein und wies darauf hin, daß nur in Ausnahmefällen Einweisungen vorgenommen werden sollten. In der Folgezeit beschränkte sich die SED-Führung darauf, den Aufbau einer eigenen Betriebsparteiorganisation zu überwachen. Darüber hinaus ließ sich das Zentralsekretariat über die weitere Entwicklung im Erzbergbau informieren. So mußte etwa die Abteilung für Arbeit und Sozialfürsorge im Frühjahr 1949 zur Kenntnis nehmen, daß ein Großteil der 3000 bis 4000 Bauarbeiter, die zum Bau von Wohnblocks für die Wismut AG eingestellt worden waren, als Bergarbeiter eingesetzt worden seien ${ }^{174}$. Da zudem die Zulieferung von Baumaterialien ins Stocken geriet $^{175}$, wurden die für die Bauvorhaben bereitgestellten Finanzmittel eingefroren, und das gesamte Vorhaben kam zunächst zum Erliegen ${ }^{176}$. Die Abteilung des SED-Zentralsekretariats kritisierte die angeblich ungenügende Gewerkschaftsarbeit und forderte eine "verstärkte Schulungsarbeit “" ${ }^{177}$. Darüber hinaus sollte die IG Bergbau im Gebiet der Wismut AG finanziell stärker unterstützt werden. Ferner wurde vorgeschlagen, eine zonale Kommission aus Vertretern des Zentralsekretariats, der HVAS, der IG Bergbau, der IG Bau und der IG Eisenbahn zu bilden, die „für alle Angelegenheiten der Wismut AG“ zuständig sein sollte. Die Vorschläge der ZS-Abteilung bewegten sich in den gewohnten Bahnen: Intensivierung von Schulung und Überwachung sowie Bildung neuer Gremien mit einem unscharfen Aufgabenprofil. Angesichts der Abwanderung bzw. Abwerbung von Baufacharbeitern zur Wismut AG hielt die IG Bau „eine Bindung von Fachkräften in so hohem Maße für die Bauwirtschaft im Hinblick auf die im Zweijahrplan gestellten Aufgaben [für] nicht vertretbar" ${ }^{178}$. Nicht auf zentraler, sondern auf regionaler Ebene erfolgte letztlich die Bildung einer Wohnungsbaukommission, die sich aus Vertretern der Wismut AG, des SED-Landesvorstandes, des Landesvorstandes der IG Bau, des Beauftragten der IG Bau Johanngeorgenstadt und der VVB Bau zusammensetzte. In diesem Gremium sollten konkrete Absprachen getroffen werden; allerdings konnten sich die Kommissionsmitglie-

$172 \mathrm{BAB}, \mathrm{DQ} 2 / 2092$, Amt für Arbeit und Sozialfürsorge der Lutherstadt Wittenberg am 16. 6. 1949 an die Firma Niethardt-Werbung.

173 BAB, DQ 2/2090, Aufruf des Antifa-Blocks des Kreises Güstrow (vermutlich Sommer 1949).

${ }_{174}$ SAPMO, DY 30/IV 2/2.027/2, Bl. 69-71, Aktennotiz über eine Besprechung der Abt. Arbeit und Sozialfürsorge mit Vertretern der Gewerkschaften und der HVAS am 10. 5. 1949.

175 BAB, DQ 2/2090, Situationsbericht der IG Bau vom 13. 5. 1949, S. 1.

176 Ebenda, Aktenvermerk Herms (o.D.), S. 1.

177 Ebenda, S. 2.

178 BAB, DQ 2/2090, Situationsbericht der IG Bau vom 13. 5. 1949, S. 1. 
der bereits auf der ersten Sitzung nicht über die tarifliche Bezahlung der angeworbenen Bauarbeiter einig werden ${ }^{179}$.

Trotz dieser anfänglichen Schwierigkeiten wurden die Planungen zur Verbesserung des Wohnungsbaus im Erzgebirge vorangetrieben, um den wachsenden Bedarf nach Wohnraum einigermaßen abdecken zu können. Dadurch stieg automatisch die Nachfrage nach Bauarbeitern ${ }^{180}$, die allerdings nicht so rasch befriedigt werden konnte. So meldete das Ministerium für Arbeit und Sozialwesen der sächsischen Landesregierung, daß von 5200 angeforderten Arbeitskräften für den Wohnungsbau in Johanngeorgenstadt nur 1182 gestellt werden konnten, darunter befanden sich 84 Arbeitseinweisungen ${ }^{181}$. Festzuhalten bleibt, daß 1949 in zunehmenden Maße Arbeitskräfte für das Erzbergbaugebiet gewonnen wurden, die zu einem erheblichen Teil nicht direkt in die Gruben der Wismut AG, sondern für den Aufbau bzw. die Verbesserung der Infrastruktur eingesetzt wurden (vor allem Wohnungs- und Straßenbau). Das Landesarbeitsamt Sachsen vermittelte beispielsweise in den ersten zwei Wochen 2011 Freiwillige zum Erzbergbau sowie die bereits erwähnten 1182 Arbeiter für den Wohnungsbau ${ }^{182}$.

Einzelne Landesverwaltungen gingen im Frühjahr 1949 zu einer Prämierung der Arbeitsämter bei der Werbung für den Uranbergbau über. Prämienzahlungen hatte es bis zu diesem Zeitpunkt nur für die Werber gegeben, die der Wismut AG direkt unterstanden. Dagegen waren die Werbeaktivitäten einzelner Arbeitsämter keiner systematischen Untersuchung oder Anleitung durch die HVAS bzw. die Landesarbeitsämter unterworfen. Dies änderte sich nunmehr partiell: So veröffentlichte etwa das thüringische Ministerium für Arbeit und Sozialwesen in einer Rundverfügung die Ergebnisse sämtlicher Arbeitsämter des Landes und wollte dadurch wohl auch einen Wettbewerb innerhalb der Verwaltung in Gang setzen ${ }^{183}$. Die Prämien wurden an die Mitarbeiter vergeben, die sich bei der Anwerbung neuer Arbeitskräfte zwischen dem 1. Januar und dem 30. April besonders hervorgetan hatten. Es gab Auszeichnungen für die drei erfolgreichsten Arbeitsämter in Höhe von 400,- bis 600,- DM und Einzelprämierungen in Höhe von 50,- bis 100,- DM. Das Ministerium der Landesregierung Thüringen gab in dem Zusammenhang auch noch Richtlinien für die Einzelwerbung von Arbeitern für den Erzbergbau heraus ${ }^{184}$.

Obwohl der Chef der SMAD-Abteilung Arbeitskräfte Morenow im Mai 1949 angekündigt hatte, daß die „Zeit der Mobilisation von Arbeitskräften für die Wismut AG [...] vorbei“ sei ${ }^{185}$, machte sich dies bei den Arbeitsämtern nicht sofort bemerkbar. Hier gingen nach wie vor sowjetische Anweisungen zur Stellung von Arbeitern für den Uranbergbau ein. So wurden alle Länder der SBZ (außer Sach-

179 Ebenda, Niederschrift (Abschrift vom 12.5. 1949) über die erste Besprechung der Kommission Wohnungsbau bei der Wismut AG, S. 2.

180 BAB, DQ 2/1763, Protokoll über die Amtsleitertagung am 13./14. 5. 1949 in Chemnitz, S. 7.

181 BAB, DQ 2/2090, Ministerium für Arbeit und Sozialwesen der Landesregierung Sachsen (HA Arbeit) am 18. 5. 1949 an die HVAS.

182 Ebenda, Ministerium für Arbeit und Sozialwesen der Landesregierung Sachsen am 18. 5. 1949 an die HVAS.

183 BAB, DQ 2/2091, Rundverfügung Nr. 5 vom 11. 5. 1949.

184 Ebenda.

$185 \mathrm{BAB}, \mathrm{DQ} 2 / 1303, \mathrm{Bl} .12-23$, hier Bl. 22, Bericht der HVAS über die Arbeitsministerkonferenz am 31. 5. 1949 in Berlin. 
sen) verpflichtet, innerhalb eines Monats 21600 Arbeitskräfte zu stellen, darunter 3000 Baufacharbeiter und 1600 Jugendliche über 18 Jahre, die für die Arbeit im Bergbau umgeschult werden sollten ${ }^{186}$. Die HVAS führte noch Anfang Juni in jedem Land eine Tagung durch, um die einzelnen Arbeitsämter zu mobilisieren ${ }^{187}$. Im Rahmen eines Wettbewerbs sollten anschließend Prämien für die erfolgreichsten Ämter verteilt werden. Gleichzeitig wurde die sächsische Landesregierung aufgefordert, die „notwendigen Vorbereitungen“ für die Unterbringung der ankommenden Arbeiter zu treffen. Die Landesverwaltungen informierten daraufhin die Arbeitsämter, die die Arbeitskräfteanforderung an die Bürgermeister in ihrem Kreis weiterleiten sollten ${ }^{188}$. Darüber hinaus nahmen zahlreiche Kreisverwaltungen die Freiwilligenwerbung wieder auf und veröffentlichten entsprechende Aufrufe in ihren amtlichen Mitteilungsblättern ${ }^{189}$. Die einzelnen Landesämter nahmen die erteilten Auflagen allerdings nicht widerspruchslos hin, sondern versuchten stellenweise, sich dieser Aufgabe zu entziehen. Dazu verwiesen etwa die Arbeitsamtsleiter aus Mecklenburg auf den Rückgang der Zahl der vollarbeitsfähigen Arbeitslosen sowie die laufenden Verpflichtungen für die Werftenindustrie ${ }^{190}$. Somit hatten die Landesverwaltungen Praktiken entwickelt, um der Auflagenerfüllung nicht mehr nachkommen zu müssen: Unter Berufung auf tatsächliche oder vermeintliche Zwangslagen gelang es letztlich den Ländern, sowjetische Befehle zu unterlaufen, ohne Sanktionen befürchten zu müssen. Im Land Brandenburg wurden beispielsweise bis zum 17. Juni 1949605 Arbeitskräfte für den Erzbergbau abgestellt ${ }^{191}$, obwohl das Land eine ursprüngliche Auflage von 4800 hatte, die aber bis zum Ende des Monats erst erfüllt sein mußte. Noch schlechter war das Zwischenergebnis in Sachsen-Anhalt: Hier konnten die Arbeitsämter nur 232 Arbeitskräfte melden, bei einer Auflage von 6500192. Diese Zahlen ließen frühzeitig erkennen, daß an eine Erfüllung der Anforderungen nur ansatzweise zu denken war. Aus diesem Grunde strebte die HVAS auch den Aufbau eines Anreizsystems für die Arbeitsämter an. Die Werbemaßnahmen der einzelnen Arbeitsämter wurden aber immer noch durch die sicherheitspolitischen Bedenken der Wismut AG eingeschränkt. Ein Vertreter der sowjetischen Bergwerksleitung verlangte etwa gegenüber dem Landesarbeitsamt in Potsdam, daß Zeitungsartikel über den Erzbergbau vor der Veröffentlichung der SMA vorzulegen seien. Die brandenburgische Arbeitsverwaltung bat die HVAS, Rücksprache mit Karlshorst zu nehmen, da andernfalls „die Werbung durch die Presse kolossal behindert“ werde ${ }^{193}$.

186 BAB, DQ 2/2090, Fernschreiben der HVAS vom 3. 6. 1949 an das Ministerium für Arbeit und Sozialfürsorge der Landesregierung Sachsen.

187 Ebenda, Bericht der HVAS über Amtsleitertagung am 7.6. 1949 in Potsdam. Am selben Tag fand auch in Schwerin eine Amtsleitertagung statt. Vgl. ebenda.

188 Vgl. BAB, DQ 2/2092, Rat des Landkreises und Leiter des Amtes für Arbeit und Sozialfürsorge Wernigerode am 17.6. 1949 an den Rat der Gemeinden.

189 Ebenda, Mitteilungsblatt für den Kreis Haldensleben vom 23.6. 1949. Vgl. ebenda, Bekanntmachung für den Kreis Ballenstedt vom 17.6.1949.

$190 \mathrm{BAB}, \mathrm{DQ} 2 / 2090$, Bericht der HVAS vom 20.6. 1949.

191 Ebenda, S. 2.

192 BAB, DQ 2/2044, Bl. 13f., Bericht der HVAS vom 20. 6. 1949 über die Dienstreise nach SachsenAnhalt (13.-17.6. 1949).

193 BAB, DQ 2/2090, telefonische Durchsage aus Potsdam am 27. 6. 1949. 
Sowohl die SMAD als auch die HVAS machten mehrmals deutlich, daß sie eine Rückkehr zur Zwangseinweisung ablehnten; die Zuteilung hatte nach wie vor auf freiwilliger Basis zu erfolgen. Arbeitseinweisungen sollten nur in Ausnahmefällen vorgenommen werden ${ }^{194}$. Damit wurde der bisherige Kurs, der spätestens seit dem SMAD-Befehl Nr. 234 galt, erneut bestätigt. HVAS-Abteilungsleiter Karl Litke legte im Zusammenhang mit der laufenden Arbeitskräfteanforderung eine eigentümliche Kalkulation vor, die unter anderem die Hilflosigkeit der Berliner Hauptverwaltung deutlich machte: „Es hätte möglich sein müssen, die Auflage zu erfüllen, wenn man bedenkt, daß wir in der Zone 20000 Gemeinden haben. Wenn jede Gemeinde nur einen Mann gestellt hätten, wäre die Auflage zu schaffen gewesen." 195 Die sowjetische Besatzungsmacht war jedoch in dieser Frage kein monolithischer Block: Anders als die SMAD vertrat die SMA in Thüringen eine gegensätzliche Position und forderte, daß verstärkt Arbeitsverpflichtungen vorgenommen werden müßten, „da sonst die Erfüllung der Auflage nicht gewährleistet sei“"196. Interessanterweise beschloß daraufhin der SED-Landesvorstand, daß sich „die Partei nunmehr öffentlich von dieser Aktion aus politischen Gründen zurückziehen werde" 197 . Offensichtlich befürchtete die Hegemonialpartei, unter der Bevölkerung an Akzeptanz zu verlieren. Dagegen sollte die Freiwilligenwerbung weiterhin durchgeführt und unterstützt werden.

Das SED-Politbüro beschäftigte sich auf seiner Sitzung am 21. Juni 1949 mit der Bereitstellung von Arbeitskräften für den Erzbergbau und beauftragte das Kleine Sekretariat, gemeinsam mit der Abteilung Arbeit und Sozialfürsorge eine Beschlußvorlage auszuarbeiten ${ }^{198}$. Eine solche Vorlage ist jedoch in den Akten nicht mehr aufzufinden. Darüber hinaus tauchte das Thema auch in den Beschlußprotokollen der SED-Führung nicht mehr auf. Dennoch kann dies nicht als Zeichen dafür gewertet werden, daß Politbüro und Sekretariat des ZK keinerlei Interesse am Fortgang der Aktion gezeigt haben. Ende Juni erhielt die SEDFührung vom HVAS-Präsidenten Brack einen ernüchternden Bericht über den Ablauf der Werbeaktion ${ }^{199}$. Der Termin für die Erfüllung des Auflagensolls war mittlerweile - so die Einschätzung Bracks - völlig unrealistisch geworden. Er kritisierte in dem Zusammenhang nicht nur die Blockparteien und Massenorganisationen, sondern auch die sowjetische Militärverwaltung, die oftmals keine Unterstützung geleistet habe, etwa bei der Bereitstellung von Transportmitteln. Die Parteiführung wurde gebeten, an die Landesvorstände entsprechende Anweisungen zu erteilen, um die Arbeit der Landesministerien "in weitestgehendem Maße“ zu unterstützen.

194 SAPMO, DY 30/IV 2/2.027/25, Bl. 159, Aktenvermerk Bracks über cine Besprechung mit dem Ministerium für Arbeit und Sozialfürsorge in Halle am 23.6. 1949.

195 BAB, DQ 2/2044, Bl. 80f., Aktennotiz der HVAS (Abt. I a) vom 20.6. 1949 über eine Besprechung mit der SMAD in Karlshorst.

196 Ebenda, Bl. 11, Bericht der HVAS vom 20. 6. 1949.

197 Ebenda, Bl. 12.

198 SAPMO, DY 30/IV 2/2/28.

199 SAPMO, DY 30/IV 2/2.027/25, Bl. 155, HVAS (Brack) am 27.6. 1949 an dic Abt. Arbeit und Sozialfürsorge (Lehmann). 
Das sächsische Ministerium für Arbeit und Sozialwesen rief die Arbeitsämter des Landes am 1. Juli 1949 nochmals auf, Sofortmaßnahmen für die Werbung von Arbeitskräften für die Wismut AG zu ergreifen ${ }^{200}$. Dazu sollten alle männlichen Arbeitslosen im Alter von 18 bis 55 Jahren auf die Bergbautauglichkeit untersucht werden. Arbeitskräfte, die beschäftigungslos und bergbautauglich waren, konnten zur Arbeit im Uranbergbau verpflichtet werden, sofern sie sich nicht freiwillig meldeten. Die Werbetätigkeit wurde fortgesetzt, ohne daß von seiten der sowjetischen Besatzungsmacht oder der HVAS neue Fristen aufgestellt wurden. Gleichzeitig führte die Berliner Hauptverwaltung ihre Kontrolltätigkeit in den Ländern weiter durch und kritisierte die Tätigkeit der Landesämter sowie der einzelnen Werber ${ }^{201}$, ohne daß jedoch Sanktionen verhängt wurden. Einen offenen Konflikt konnte die HVAS mit den Ländern nicht riskieren, da sie auf deren Mithilfe nach wie vor angewiesen war. Als neues Hindernis erwies sich 1949 die forcierte Werbung für die Volkspolizei202, deren Mannschaftsstärke ausgebaut werden sollte. Dadurch ergab sich eine Konkurrenzaktion für die Anwerbung von Freiwilligen zur Wismut $\mathrm{AG}^{203}$. Gleichzeitig änderte die HVAS ihre Werbestrategie: In $\mathrm{Zu}$ kunft sollten nicht mehr öffentliche Versammlungen abgehalten werden, deren Nutzen von zahlreichen Arbeitsamtsleitern angezweifelt wurde, sondern ausgewählte Personenkreise, die als weitgehend mobil galten, gezielt angesprochen werden. Dazu gehörten nach Einschätzung des HVAS-Mitarbeiters Krüger „Umsiedler", Landarbeiter und "geeignete Personen aus Betrieben“204.

Zusammenfassend läßt sich feststellen, daß es auch Mitte 1949 keine reibungslose Zusammenarbeit zwischen sowjetischer Besatzungsmacht und deutscher Arbeitsverwaltung gab. Dies lag vor allem am eigenmächtigen Handeln der Wismut AG, die immer noch sowjetische Offiziere zu einzelnen Arbeitsämtern entsandte, um deren Tätigkeit zu überprüfen bzw. eigene Anweisungen zu erteilen ${ }^{205}$. Obwohl Karlshorst des öfteren deutlich gemacht hatte, daß Arbeitskräfteanforderungen für den sächsischen Erzbergbau nur über die SMAD zentral vergeben werden sollten ${ }^{206}$, schien sich die sowjetische Bergwerksleitung in Aue nicht daran halten zu wollen. Da die Aufsicht über die Wismut AG nicht bei der SMAD, sondern beim Ministerium für innere Angelegenheiten in Moskau lag207, vermochte Karlshorst an dieser Vorgehensweise kaum etwas zu ändern. So entwickelte sich die sowjetische Bergwerksleitung rasch zu einem autonomen Faktor, der von der SMAD offensichtlich nicht gesteuert werden konnte, sondern seine Anweisungen allem Anschein nach direkt aus Moskau bezog. Die fehlende Absprache zwischen

$200 \mathrm{BAB}, \mathrm{DQ} 2 / 2090$.

$201 \mathrm{BAB}, \mathrm{DQ} 2 / 2090$, Bericht der HVAS (Abt. I a) vom 4. 7. 1949.

202 Vgl. Wenzke, Auf dem Weg zur Kaderarmee, S. 214-220. Diese Werbung hatte bereits 1948 eingesetzt, entwickelte sich jedoch erst im Laufe des Jahres $1949 \mathrm{zu}$ einem Problem für die Arbeitsverwaltung.

${ }^{203} \mathrm{BAB}, \mathrm{DQ} 2 / 2092$, Bericht der HVAS (Abt. I a) vom 7. 7. 1949 über dic in Brandenburg durchgeführten Besprechungen, S. 2.

${ }^{20+}$ Ebenda, Bericht der HVAS (Abt. I a) vom 6. 7. 1949, S. $3 \mathrm{f}$

20.5 Einzelne Beispiele in: BAB, DQ 2/2092, Bcricht der HVAS (Abt. I a) vom 8. 7. 1949 über die Werbung von freiwilligen Arbeitskräften für den Erzbergbau Sachsen im Lande Thüringen, S. 2 f.

$206 \mathrm{BAB}, \mathrm{DQ} 2 / 1950$, Aktennotiz über eine Besprechung mit der SMAD (Schaposchnikow) am 27. 7. 1949, S. 1.

${ }^{207}$ Karlsch, Der Aufbau der Uranindustrien, S. 11. 
Karlshorst und Wismut AG läßt sich anschaulich an der strittigen Frage der Werbungskosten zeigen. Während die SMAD vorschlug, daß die einzelnen Landesämter mit den jeweiligen Objekt-, d.h. Schachtleitungen diese Kosten abrechnen sollten ${ }^{208}$, sah sich die Leitung der Wismut AG nicht daran gebunden ${ }^{209}$. Ähnlich verhielt es sich bei der Arbeitskräftewerbung: Trotz Absprachen zwischen SMAD und HVAS warb die Bergwerksleitung Aue in eigener Regie. So kämmten sowjetische Offiziere Heimkehrerlager nach bergbautauglichen Arbeitskräften durch $^{210}$.

Bis zur Gründung der DDR hatten sich die Arbeits- und Lebensbedingungen im Uranbergbau erheblich verbessert. Dieser zog mittlerweile Arbeitskräfte aus der gesamten SBZ wie ein Magnet an: Die ins Erzgebirge zuziehenden Arbeiter erhofften sich nicht nur eine bessere Entlohnung, sondern auch eine deutlich verbesserte Versorgung mit Wohnraum und Lebensmitteln. Bis auf den Wohnraum gelang es den kommunalen und zentralen Verwaltungen weitgehend, diese Erwartungen zu erfüllen. Dagegen blieb der Wohnungsbau ein Sorgenkind der Arbeitsund Wohnungsämter ${ }^{211}$. Insofern kam es auch noch 1949 häufig vor, daß WismutArbeiter enttäuscht abwanderten, weil sie für ihre Familien keine ausreichenden Unterbringungsmöglichkeiten angeboten bekamen. Der Rückgang der Zwangseinweisungen ${ }^{212}$ und die Normalisierung des Verhältnisses zwischen sowjetischer Bergwerksleitung und deutscher Belegschaft, das lange Zeit aufgrund der rüden Vorgehensweise der Besatzungsmacht stark belastet gewesen war, verbesserte das negative Erscheinungsbild der Wismut AG in der Öffentlichkeit nur langsam. Deutlich geworden ist auch, daß trotz aller Abstimmungsprobleme die sowjetischen Arbeitskräfteanforderungen im großen und ganzen erfüllt werden konnten, auch wenn die wirtschaftlichen und sozialen Folgelasten erheblich waren. Grundsätzlich ist der Feststellung Karlschs zuzustimmen, daß der Uranbergbau im Erzgebirge keine Form des Gulags war213. Obwohl die Wismut AG ein „Staat im Staat" 214 war und der Zugang streng kontrolliert wurde, konnte doch eine vollständige hermetische Abriegelung zu keinem Zeitpunkt erreicht werden. Dies zeigen die zahlreichen Beschwerdebriefe von Bergarbeitern, die das Erzgebirge ohne Rücksprache oder Genehmigung der Bergwerksleitung wieder verließen und in

${ }^{208} \mathrm{BAB}, \mathrm{DQ} 2 / 156, \mathrm{Bl}$. 117, HVAS am 2. 8. 1949 an das Ministerium für Arbeit und Sozialpolitik der Landesregierung Sachsen-Anhalt.

209 BAB, DQ 2/517, Ministerium für Arbeit und Sozialwesen der Landesregierung Brandenburg am 15. 9.1949 an die HVAS.

210 BAB, DQ 2/2092, Bericht der HVAS (Abt. I a) vom 4. 8. 1949.

211 Die Wohnungsnot im Erzbergbaugebiet hatte auch der Minister für Arbeit und Sozialfürsorge der Landesregierung Sachsen, Walther Gäbler, erkannt. ACDP, III/035/045, Protokoll über die 54. Sitzung des Ausschusses für Arbeit und Sozialfürsorge am 27. 10. 1949, S. 4.

212 Im Sommer 1949 gab es immer noch vereinzelt Meldungen über Arbeitseinweisungen. Vgl. SAPMO, NY 4182/988, Bl. 2, Mitteilung der Instrukteurgruppe des Parteivorstandes vom 3.8. 1949 an das Kleine Sekretariat. Vgl. außerdem SAPMO, NY 4036/738, Bl. 4-11, Bericht von Herbert G. (Berliner Rundfunk) vom 18. 8. 1949. Das Landesamt für Arbeit und Sozialpolitik in Halle berichtete, daß ein Teil der registrierten Einweisungen als freiwillige Werbung bewertet werden müßte: Einige Eingewiesene hätten um die Zwangsverpflichtung gebeten, „weil dadurch der Arbeitsplatz und die Wohnung sichergestellt bleiben." BAB, DQ 2/2105, Ministerium für Arbeit und Sozialpolitik der Landesregierung Sachsen-Anhalt am 2. 8. 1949 an die HVAS.

213 Karlsch, Ein GULag im Erzgebirge?, S. 28.

$21+$ Vgl. Karlsch, „Ein Staat im Staate“. 
ihre Heimatorte zurückkehrten. Darüber hinaus hatte die nach Westen offene Grenze eine nicht unerhebliche Ventilfunktion, die auch dazu beitrug, das repressive System der Arbeitseinweisung langfristig zu lockern.

\section{Aufhebung von Arbeitseinweisungen durch Arbeitsgerichte}

Gegen Arbeitseinweisungen konnten die Betroffenen beim Landesarbeitsamt oder dem zuständigen Arbeitsgericht Einspruch einlegen. Erst die „Verordnung über die Sicherung und den Schutz der Rechte bei Einweisungen von Arbeitskräften" vom 2. Juni 1948 schuf eigene Beschwerdeausschüsse, die über diese Einsprüche zu entscheiden hatten. Dadurch entzog die DWK den Arbeitsgerichten den bisherigen Arbeitsbereich, die nur noch bei Klagen gegen die Festsetzung des Trennungsgeldes und Härteausgleichs tätig werden konnten. Hintergrund dafür bildeten mehrere Klagen, die im Laufe des Jahres 1947 bei Arbeitsgerichten gegen die Zwangsverpflichtung zum Uranbergbau erhoben worden waren. Die Abteilung I b der DVAS wies darauf hin, daß damit eine „planmäßige Arbeitslenkung zukünftig nicht mehr möglich“ wäre. Die Entscheidung darüber, „ob eine Arbeitskraft rechtmäßig für ein Arbeitsvorhaben eingewiesen wurde", läge dann beim Arbeitsgericht und nicht mehr bei der Arbeitsverwaltung ${ }^{215}$. Auch die Juristische Abteilung der Berliner Zentralverwaltung vertrat den Standpunkt, daß die "gegenwärtige Rechtslage" die Überprüfung einer Arbeitseinweisung durch das Arbeitsgericht verbiete, und verwies auf eine Dienstanweisung zum Kontrollratsbefehl Nr. 3216. Während die DVAS einhellig diese Meinung vertrat ${ }^{217}$, ließen sich einige Arbeitsgerichte nicht davon abhalten, gegenteilige Urteile zu fällen. Sogar der Präsident des Thüringischen Oberverwaltungsgerichts gab einer Klage statt und erklärte, daß eine Rechtsgrundlage für eine „zwangsweise Einweisung $E r$ werbstätiger [...] vorerst" nicht bestehe ${ }^{218}$. Damit brach der alte Rechtsstreit über die Frage wieder aus, ob das im Befehl des Alliierten Kontrollrats verbriefte Recht zur Zwangseinweisung nur für Arbeitslose oder auch für Erwerbstätige galt. Der Präsident des Thüringischen Oberverwaltungsgerichts unterstellte der Arbeitsverwaltung nicht zu Unrecht, daß die steigenden Arbeitskräfteanforderungen die Arbeitsämter in die Zwangslage versetzt hätten, „Arbeitskräfte für den Bergbau zu stellen, die sie unter Zugrundelegung des geltenden Rechts offenbar nicht in voller Zahl beschaffen" konnten ${ }^{219}$. Nach Auffassung des Gerichts waren DVAS und SMAD aufgerufen, „für solche Eingriffe in Freiheit und Rechte der Werktätigen eine ausreichende Rechtsgrundlage zu schaffen". Solange wurde die Entscheidung über laufende Anfechtungsklagen ausgesetzt. Die Juristische Abteilung der

215 BAB, DQ 2/1767, Abt. I b am 7. 7. 1947 an Abt. III.

216 Ebenda, Juristische Abt. am 11.7. 1947 an Abt. III a.

217 Ebenda, Abt. III a am 17. 7. 1947 an Abt. I. Eine etwas modifizierte Stellungnahme gab die Abt. I b ab: Sie betonte, daß bereits der Kontrollratsbefehl Nr. 3 den Arbeitsämtern das Recht zur Einweisung erteilt habe und somit ein Kontrollrecht von seiten der Arbeitsgerichtsbarkeit zu keinem Zeitpunkt bestanden habe. Vgl. ebenda, Abt. I b am 26. 7. 1947 an Abt. III a.

$218 \mathrm{BAB}, \mathrm{DQ} 2$ 2/91, Präsident des Thüringischen Oberverwaltungsgerichts am 23.9. 1947 an das Ministerium für Wirtschaft, Arbeit und Verkehr in Weimar.

219 SAPMO, DY 30/IV 2/2.027/25, Bl. 88-90, Präsident des Thüringischen Oberverwaltungsgerichts am 6. 12. 1947 an den Ministerpräsidenten des Landes Thüringen. 
DVAS stimmte letztlich der Argumentation des Oberverwaltungsgerichts in einem Punkt zu: „Zuzugeben ist [...], daß der Befehl Nr. 3 des Kontrollrats als Rechtsgrundlage für die Zwangseinweisung von Erwerbstätigen nicht völlig zweifelsfrei ist." 220 Dies besage jedoch nicht, daß es keine rechtliche Grundlage für die Einweisung von Arbeitskräften gäbe. Die Juristen der DVAS verwiesen in dem Zusammenhang auf einzelne Bestimmungen des SMAD-Befehls Nr. 3 und vertraten damit eine wenig überzeugende Rechtsposition. Offensichtlich waren sie von den juristischen Winkelzügen ebenso wenig überzeugt, stellten sie doch selbst die Veröffentlichung einer Verordnung in Aussicht, die in diesem Punkte Klarheit bringen sollte 221 .

\section{Arbeitskräfte für den Stein- und Braunkoblenbergbau}

Bei der Zuteilung von Arbeitskräften waren der Stein- und Braunkohlenbergbau der Wismut AG nachgeordnet. Gleichwohl zählten auch diese Betriebe zu den laut SMAD-Befehl Nr. 153 „wichtigsten Wirtschaftszweigen“, die die Versorgung der Gesamtwirtschaft sowie der Bevölkerung mit Brennstoffgütern sicherzustellen hatten. Zunächst prägten jedoch Fragen der Eigentumsform sowie der Zuordnung zu bestimmten Zentralverwaltungen die Debatte über den Wiederaufbau des Bergbaus in der SBZ. Nach Auffassung des 1. Vizepräsidenten der Deutschen Zentralverwaltung für Brennstoffindustrie, Gustav Dahrendorf, stellte die Verstaatlichung des Bergbaus „eine zwingende Notwendigkeit“ dar ${ }^{222}$. Da zentralstaatliche Institutionen noch nicht bestanden bzw. keinerlei Kompetenzen besaßen, plädierte der Sozialdemokrat, der sich im Februar 1946 aus Protest über die bevorstehende $Z$ wangsvereinigung in den Westen absetzte ${ }^{223}$, für entsprechende Gesetzesregelungen auf Landesebene. Daher sollten die Länder und Provinzen den Bergbau in treuhänderische Verwaltung übernehmen. Bereits im September 1945 wurde in Sachsen der Kohlenbergbau der Landesverwaltung unterstellt und damit faktisch enteignet ${ }^{224}$. Enteignung und Verstaatlichung betrafen im übrigen auch andere Bereiche der Großindustrie. Dieser größere Zusammenhang kann an dieser Stelle nicht weiter vertieft werden ${ }^{225}$, muß aber mit berücksichtigt werden, da sich dadurch die Rahmenbedingungen für die weitere ökonomische Entwicklung erheblich wandelten. Für die Deutsche Zentralverwaltung der Brennstoffindustrie waren die landesspezifischen Regelungen nur Übergangslösungen; sie strebte eine weitere Zentralisierung des Bergbaus an. Nur so könne "jederzeit“ Auskunft gegeben werden über den Zustand der einzelnen Gruben und Brikett-

22c BAB, DQ 2/91, Juristische Abt. am 2.1. 1948 an Präsident Brack, S. 1.

221 Vgl. Werner Holling, Die Rechtsgrundlagen der Arbeitseinweisung und die Zustimmung des Arbeitsamtes bei Arbeitsplatzwechsel, in: Arbeit und Sozialfürsorge 3 (1948), S. 6-9. Auch DVASPräsident Brack deutete dies an: BAB, DQ 2/91, Präsident Brack am 6.1.1948 an den Ministerpräsidenten des Landes Thüringen.

222 SAPMO, NY 4182/1184, Bl. 62, Notiz Dahrendorfs vom Oktober 1945 zur Frage der Verstaatlichung des Bergbaus.

223 Biographische Angaben zu Dahrendorf in: SBZ-Handbuch, S. 884.

${ }^{22+}$ Staritz, Die Gründung der DDR, S. 117.

225 Vgl. Weber, Geschichte der DDR, S. 113-115. Für Sachsen neuerdings: Kluge/Halder, Die befohlene Wirtschaftsordnung in Sachsen 1945/46; Halder, „Prüfstein ... für die politische Lauterkeit der Führenden"? 
fabriken sowie über die „vorhandenen und notwendigen Arbeitskräfte“226. Während Präsident Ferdinand Friedensburg einen entsprechenden Entwurf für einen SMAD-Befehl einbrachte, der den Bergbau ihm persönlich unterstellen sollte ${ }^{227}$, sprachen sich die beiden Vizepräsidenten Albert Bergholz und Gustav Sobottka gegen diesen Vorschlag aus 228.

Frühzeitig gab die Zentralverwaltung der Brennstoffindustrie gegenüber der ZVAS den Arbeitskräftebedarf für den Bergbau in der SBZ bekannt und bat um Unterstützung ${ }^{229}$. Eine ausführliche Zusammenstellung des Fachverbandes des Deutschen Braunkohlenbergbaus in Halle/Saale listete insgesamt 11890 Arbeitskräfte auf, die von den einzelnen Bergbaubetrieben angefordert wurden ${ }^{230}$. Darunter befanden sich allerdings nur 1898 fachlich qualifizierte Bergarbeiter und 1542 angelernte Kräfte sowie 6323 Hilfsarbeiter. Regionale Schwerpunkte waren Sachsen-Anhalt (4960 Arbeitskräfte), Brandenburg (3307) und Sachsen (3092). Dagegen meldete Thüringen einen Bedarf in Höhe von 531; Mecklenburg-Vorpommern verfügte über keine nennenswerten Gruben des Braun- oder Steinkohlenbergbaus und konnte deshalb auch keinen Arbeitskräftebedarf anmelden ${ }^{231}$. Die ZVAS versuchte den Bedarf teilweise durch überbezirklichen Ausgleich abzudecken: So wurde das Landesarbeitsamt in Potsdam gebeten, „den Arbeitsämtern Ihres Bezirkes aufzugeben, etwa dort vorhandene, ausgleichsfähige Kräfte [...] zu überweisen "232. Als besonders langwierig und oftmals aussichtslos erwies sich die Suche nach Facharbeitern, die entweder in der geforderten Anzahl nicht vorhanden oder bereits für andere dringliche Arbeiten eingesetzt waren. Der Bürgermeister von Fürstenberg (Oder) reagierte auf die Aufforderung der ZVAS, Arbeitskräfte zur Verfügung zu stellen, mit dem Hinweis, daß die gewünschten Fachkräfte „hier überhaupt nicht vorhanden sind“233. In einem Rundschreiben an die Landesarbeitsämter vom 10. Dezember 1945 sprach sich die Berliner Zentralverwaltung dafür aus, ,aus den Reihen der Umsiedler einen erheblichen Teil des Bedarfs zu decken" ${ }^{234}$. Angesichts der zu diesem Zeitpunkt chaotischen Lage in den Flüchtlingslagern sowie der Ungewißheit über den weiteren Vertriebenenzustrom war daran allerdings noch nicht zu denken. Die Rekrutierung von „Umsiedlern" für den Braun- und Steinkohlenbergbau erfolgte somit eher zufällig und hing im wesentlichen von der Eigeninitiative der einzelnen Grubenleitungen ab, Arbeitskräfte in den Lagern anzuwerben, oder von den Vertriebenen selbst, die sich nach Verlassen der Auffanglager freiwillig melden konnten. Eine koordinierte Planung und Lenkung durch die Arbeitsverwaltung war dagegen Ende 1945 kaum durchführbar. Die Zuweisung von Arbeitskräften konnte in der anvisierten Grö-

\footnotetext{
226 SAPMO, NY 4182/1184, Bl. 42-46, hier Bl. 43, Vizepräsident Gustav Sobottka am 13. 2. 1946 an den Leiter der Verwaltung der Brennstoffindustrie und Energie der SMAD (J. Kurmaschew).

227 Ebenda, Bl. 57, Entwurf Friedensburgs (März 1946).

228 Ebenda, B1. 55, Notiz Sobottkas vom 8. 3. 1946

${ }^{229} \mathrm{BAB}, \mathrm{DQ} 2 / 1881$, Bl. 1, Zentralverwaltung der Brennstoffindustrie am 17.10. 1945 an die ZVAS.

230 Ebenda, Bl. 2.

231 Eine Liste der führenden Betriebe aus den einzelnen Wirtschaftszweigen, die die DVAS-Abt. I b im Zusammenhang mit dem SMAD-Befehl Nr. 234 zusammenstellte, führte nur eine Braunkohlengrube für das Land Mecklenburg in Malliß mit 124 Beschäftigten an: BAB, DQ 2/1711.

23. BAB, DQ 2/1881, Bl. 3, ZVAS am 1. 11. 1945 an das Landesarbeitsamt von Brandenburg.

${ }_{233}$ Ebenda, Bl. 15f., Bürgermeister von Fürstenberg (Oder) am 5. 12. 1945 an die ZVAS.

$23+$ Ebenda, Bl. 17.
} 
Benordnung nicht durchgeführt werden, da zahlreiche Kreise über einen akuten Arbeitskräftemangel klagten 235 und die Unterbringungsmöglichkeiten für anreisende Arbeiter aufgrund der kriegsbedingten Zerstörungen oftmals stark eingeschränkt waren ${ }^{236}$.

Trotz vielfältiger Bemühungen kam eine koordinierte und abgestimmte Bedarfsplanung im Braun- und Steinkohlenbergbau nicht zustande. Das war der unzureichenden Zusammenarbeit zwischen den Bergwerksleitungen und den Landesverwaltungen auf der einen und der ZVAS/DVAS bzw. der Zentralverwaltung der Brennstoffindustrie auf der anderen Seite geschuldet. Vor allem die Berliner Zentralverwaltungen erhielten erst verspätet einen Überblick über die entsprechende Nachfrage von Arbeitskräften und konnten somit den zwischenbezirklichen Ausgleich nicht mehr rechtzeitig einleiten. Vizepräsident Sobottka schätzte den Bedarf Anfang des Jahres 1946 auf 12000 bis 15000 ein. Es sei „dringend notwendig, Maßnahmen zu ergreifen, um dem Braunkohlenbergbau Arbeiter zuzuführen" ${ }^{237}$. Andernfalls verringere sich die notwendige Abraummenge an Kohle, die Voraussetzung war für eine langfristige Sicherstellung der Energieversorgung sowohl der Betriebe als auch der Privathaushalte. Des weiteren wies Sobottka auf die fehlenden Unterbringungsmöglichkeiten für die angeworbenen Arbeiter hin. Eine durchgehende Trennung von Braun- und Steinkohlenbergbau wurde bei der Planung nicht vorgenommen: die Zentralverwaltungen faßten beide Bereiche des Bergbaus oftmals zusammen; es kam allerdings auch vor, daß der Bedarf voneinander getrennt angegeben wurde 238 .

Für die beiden Zentralverwaltungen in Berlin kam erschwerend hinzu, daß die sowjetische Besatzungsmacht in den Ländern bzw. Provinzen eigene Befehle zur Produktionssteigerung erteilte, die auch Anweisungen zur Bereitstellung von Arbeitskräften für die einzelnen Gruben enthielten ${ }^{239}$. Dadurch konnte es mitunter zu Überschneidungen mit Planungen seitens der DVAS bzw. der Zentralverwaltung der Brennstoffindustrie kommen. Dieses strukturelle Problem ließ sich jedoch zu keinem Zeitpunkt zufriedenstellend lösen, da es offensichtlich auch Abstimmungsschwierigkeiten zwischen der SMAD in Karlshorst und den SMA in den Ländern gab. Bei den gemeinsamen Unterredungen mit Vertretern der DVAS mahnte die SMAD-Abteilung Arbeitskraft des öfteren eine Kontrolle der Bergbaubetriebe an. So sollten die innerbetrieblichen Arbeitsbedingungen durch Arbeitsschutzinspektoren geprüft werden ${ }^{240}$. Auf diese Weise erhofften sich die sowjetischen Vertreter eine Senkung des Krankheits- und Unfallstandes sowie langfristig eine bessere Ausnutzung des Produktionsfaktors, Arbeit‘.

${ }^{235}$ Ebenda, Bl. 19, Provinzialamt für Arbeit und Sozialfürsorge von Sachsen-Anhalt am 13.12. 1945 an die ZVAS.

${ }^{236}$ Ebenda, Bl. 21, Landesarbeitsamt Dresden am 27. 12. 1945 an die ZVAS.

${ }^{237}$ SAPMO, NY 4182/1184, Bl. 11-15, hier BI. 12, Bericht Sobottkas vom 14. 1. 1946 an Walter Ulbricht.

${ }^{238}$ So gab Sobottka den Bedarf beim sächsischen Steinkohlenbergbau im Januar 1946 mit 1000 Arbeitskräften an. Vgl. BAB, DQ 2/2134, Bl. 1, Deutsche Zentralverwaltung der Brennstoffindustrie am 23. 1. 1946 an DVAS.

239 BAB, DQ 2/518, Bl. 3 f., Befehl des Stellvertretenden Chefs der SMA der Provinz Brandenburg Nr. 11 vom 24. 1. 1946.

2+0 BAB, DQ 2/3923, Bl. $17 \mathrm{f}$., Bericht über die Besprechung mit Morenow in Karlshorst am 2. 2. 1946. 
In der Folgezeit ergriff die DVAS die Initiative und lud den Vizepräsidenten und weitere Sachbearbeiter der Zentralverwaltung der Brennstoffindustrie sowie Mitarbeiter sämtlicher Landesarbeitsämter zu einer Aussprache ein, um die Stellung von Arbeitskräften für den Braunkohlenbergbau besser abstimmen zu können. Mittlerweile hatte sich nach Angaben von Vizepräsident Sobottka der kurzfristige Bedarf auf 18000 erhöht, langfristig seien sogar 30000 Arbeiter erforderlich ${ }^{241}$. In dem Zusammenhang schlug er vor, daß sich die Arbeitsämter sehr viel stärker der Versorgung dieses Wirtschaftszweiges mit Arbeitskräften zuwenden sollten. Dabei könnten - so Sobottka - auch Berufsfremde eingesetzt werden; Arbeiter aus ländlichen Gebieten seien „am besten geeignet“. Darüber hinaus sollte die Schwerarbeiterkarte nicht mehr von den Ernährungsämtern, sondern von den Betrieben „als kurzfristige Zusatzkarte“ mit einer Laufzeit von acht Tagen vergeben werden ${ }^{242}$. Eine Verbesserung der Kontrolle und eine Unterbindung von Mißbrauch wurde damit angestrebt. Ähnliche Ziele verfolgte Sobottka mit seinen Vorschlägen zur Wohnraumfrage: Hier sollten Werkswohnungen, die von „Werksfremden“ belegt waren, zugunsten angeworbener oder zugewiesener Arbeiter geräumt werden. Bei der Frage nach der Rekrutierung neuer Bevölkerungsgruppen für den Bergbau waren sich die Teilnehmer der Konferenz einig darüber, daß die Frauen für den Arbeitseinsatz in diesem Bereich „,in der Regel“" ausschieden. Statt dessen wurde die „Auswechselung“ von Arbeitskräften favorisiert, d.h. der Abzug von bergbautauglichen Arbeitern aus Bereichen der Leicht- und Konsumgüterindustrie und deren Ersetzung durch Frauen bzw. bergbauuntaugliche Arbeitskräfte ${ }^{243}$. Eine systematische Auskämmung der Betriebe durch die Arbeitsämter war zu diesem Zeitpunkt jedoch nicht geplant; ein solcher Schritt hätte vermutlich Unruhe unter den Belegschaften hervorgerufen.

Innerhalb des Alliierten Kontrollrates existierten 1946 Überlegungen, ein Gesetz zur Frauenarbeit im Bergbau zu verabschieden, das die Beschäftigung unter Tage grundsätzlich gestatten sollte. Arbeitsschutzrechtliche Bestimmungen hatten dies in Deutschland vor 1945 nahezu ausgeschlossen, und die DVAS sowie die SED-Führung stellten sich hinter dieses Verbot. Die Autorenschaft für den Gesetzentwurf läßt sich sehr wahrscheinlich auf die sowjetischen Vertreter im Kontrollrat zurückführen, die an ihren Plänen jedoch nicht lange festhielten. Nach einem Telefonat mit einem Vertreter der SMAD-Abteilung Arbeitskraft notierte Max Herm von der DVAS: „Abtlg. Arbeitskraft lehnt diesen Befehl in vorliegender Form ab. "244 Auch die Abteilung Frauen beim SED-Zentralsekretariat wandte sich gegen eine Aufhebung des Verbots von Frauenarbeit im Untertagebau. Es müsse möglich sein, „den Mangel an Bergarbeitern auf andere Weise zu beheben insbesondere durch Umschulung von männlichen Arbeitskräften“"245. Einen ähnlichen Vorschlag unterbreitete der FDGB-Vorstand, der außerdem auf die gesundheitlichen Risiken aufmerksam machte246. Damit hatte sich auf deutscher

${ }^{241} \mathrm{BAB}, \mathrm{DQ} 2 / 2054$, Niederschrift der DVAS-Abt. II über die Aussprache am 6. 2. 1946, S. 1.

242 Ebenda, S. 2.

243 Vgl. ebenda, S. 3

${ }^{244} \mathrm{BAB}, \mathrm{DQ} 2 / 1517$, handschriftlicher Zusatz Herms auf dem Entwurf des Kontrollratgesetzes.

${ }^{245}$ SAPMO, DY 30/IV 2/17/26, Bl. 109, Briefentwurf an den Alliierten Kontrollrat.

$246 \mathrm{BAB}, \mathrm{DQ} 2 / 1517$, FDGB-Vorstand am 27. 11. 1946 an den Alliierten Kontrollrat. 
Seite eine breite Opposition gebildet, die die sowjetischen Vertreter im Alliierten Kontrollrat offenbar zum Einlenken bewog. Der Plan wurde fallengelassen und der Chef der SMAD-Abteilung Arbeitskraft Morenow beeilte sich, dem SEDFrauensekretariat mitzuteilen, daß der Kontrollrat „einen ähnlichen Befehl, der die Verwendung von Frauen Untertage im Bergbau gestatten würde, nicht ausgearbeitet hat und auch nicht mit der Ausarbeitung desselben beschäftigt ist" ${ }^{\text {"247 }}$. Die arbeitsrechtlichen Bestimmungen blieben in dieser Angelegenheit eindeutig: Zwar gestattete das Gesetz Nr. 32 des Alliierten Kontrollrats vom 10. Juli 1946 die Beschäftigung von Frauen bei „Bau- und Wiederaufbauarbeiten“248. Von entscheidender Bedeutung für die SBZ wurde aber der SMAD-Befehl Nr. 39 vom 19. Februar 1947, der die Beschäftigung von Frauen mit „schweren und gesundheitsschädlichen Arbeiten" klar verbot ${ }^{249}$. Ein dem Befehl hinzugefügtes Verzeichnis enthielt insgesamt 36 Berufe bzw. Tätigkeiten, die von dem Verbot betroffen waren, darunter auch der Untertagebergbau. Ausnahmeregelungen waren nur mit Einverständnis der betrieblichen Arbeitsschutzkommissionen und der Gewerkschaften möglich und mußten von den Ämtern für Arbeitsschutz in den Ländern und Provinzen genehmigt werden.

Schwerpunkte der Lenkung von Arbeitskräften in den Braunkohlenbergbau waren anfangs Klettwitz in Sachsen-Anhalt sowie das Gebiet um Senftenberg, das den höchsten Bedarf angemeldet hatte. Mitarbeiter der DVAS unternahmen bereits Mitte Februar 1946 erste Dienstreisen in diese Regionen, um sich einen Eindruck über die Lebens- und Arbeitsbedingungen zu verschaffen. Meldungen über eine schlechte Versorgung mit Wohnraum und vor allem mit Lebensmitteln hatten in dieser Phase keinen Seltenheitswert ${ }^{250}$. Aus Sicht der Arbeitsverwaltung stand einer Steigerung der Arbeitsleistung jedoch auch die Altersgliederung der Belegschaften entgegen. Aufgrund der Einziehung zur Wehrmacht war es bereits im Verlauf des Zweiten Weltkrieges ${ }^{251}$ zu einer allgemein beklagten Überalterung 252 gekommen; dieser Prozeß hielt auch nach Kriegsende an. Die Versorgungslage war 1946 allerdings nicht in allen Braunkohlerevieren unzureichend. Ein Mitarbeiter der Zentralverwaltung der Brennstoffindustrie betonte nach dem Be-

${ }^{247}$ SAPMO, DY 30/IV 2/17/26, B1. 111, Morenow am 12.12. 1946 an das SED-Zentralsekretariat (Frauensekretariat).

${ }_{248}$ Amtsblatt des Alliierten Kontrollrats in Deutschland, S. 166.

${ }^{249}$ Arbeit und Sozialfürsorge 2 (1947), S. 143-145.

250 Vgl. BAB, DQ 2/1881, Bl. 27-31, Niederschrift der ZVAS-Abt. II über die Dienstreise am 15./ 16. 2. 1946 .

251 Vgl. zu den Folgen für das Niederlausitzer Braunkohlenrevier: Hübner, Arbeiter und sozialer Wandel, S. 35-41.

252 Diesen Trend illustriert auch der Altersaufbau der Mitglieder in der Ruhr-Knappschaft zwischen 1933 und 1943. So stieg der Anteil der Mitglieder, die über 50 Jahre alt waren, von 4,6 (1933) auf 13,8 Prozent (1943). Dagegen fiel der Anteil derjenigen, die zwischen 20 und 29 Jahre alt waren, von 34,45 (1933) auf 15,95 Prozent (1943), wobei dieser Abwärtstrend im wesentlichen schon 1939 erreicht worden war (15,66 Prozent). Relativ konstant blieb dagegen die Gruppe der 30 bis 39jährigen, deren Anteil zunächst von 34,11 Prozent (1933) auf 39,87 (1938) anstieg, um dann wieder kontinuierlich auf 34,20 Prozent (1942) abzusinken. Der Anteil der Altersgruppe zwischen 40 und 49 Jahre erhöhte sich von 19,36 Prozent (1933) auf 31,27 (1942). Interessant ist außerdem, daß die Gruppe der unter 19jährigen, die 1918 noch einen prozentualen Anteil von rund 25 hatte, bereits 1926 auf knapp 10 Prozent abgesunken war; der niedrigste Wert lag hier 1943 bei 5,22 Prozent. Alle Angaben aus: Geyer, Die Reichsknappschaft, S. 394 (Tabelle 25). 
such der Gruben im Raum Bitterfeld, daß die Arbeiter dort „bestens versorgt“ seien $^{253}$.

Zwischen den beiden Zentralverwaltungen verlief die Zusammenarbeit nicht reibungslos. Die ZVAS-Abteilung II beanstandete im Februar 1946, immer noch keinen „listenmäßigen Bedarfs[nachweis]“ erhalten zu haben. Um eine zuverlässige Grundlage für die Arbeitskräftelenkung gewinnen und „die Zuweisung nach dem Grade der Dringlichkeit ordnen zu können“, sei es erforderlich, die einzelnen Braunkohlengruben mit dem jeweiligen Bedarf genau mitzuteilen ${ }^{254}$. Eine solche Absprache wurde immer dringlicher, zumal die gesteuerte Binnenwanderung an Bedeutung gewinnen sollte. So plante die Arbeitsverwaltung, 300 Bergarbeiter, die berufsfremd in Mecklenburg-Vorpommern untergebracht waren, nach Sachsen zu entsenden 255 . Letztlich konnte das Landesarbeitsamt in Schwerin jedoch nicht verhindern, daß sich ein großer Teil dieser Beschäftigtengruppe selbst auf die Arbeitsplatzsuche machte und in die britische Zone abwanderte. Der Präsident der Deutschen Zentralverwaltung der Brennstoffindustrie betonte daraufhin die krisenhafte Situation im Braun- und Steinkohlenbergbau und wies die Schuld bei der ausgebliebenen Zuteilung neuer Arbeitskräfte den Landesarbeitsämtern zu256. Die ZVAS reagierte auf diese Kritik und gab den Landes- und Provinzialämtern die Anweisung, die Heranziehung von Bergarbeitern für Demontagetätigkeiten außerhalb des Bergbaus zu unterlassen ${ }^{257}$. Gleichzeitig wies die ZVAS in einer Stellungnahme darauf hin, daß die bisherige unzureichende Deckung des Arbeitskräftebedarfs ,keineswegs seine Ursache in einem Versagen der Ämter der Arbeit [hat], sondern [...] in der allgemeinen arbeitsmarktpolitischen Lage und in den gestiegenen Anforderungen durch die SMA für Demontagezwecke begründet“ sei258.

Anders als beim Uranbergbau setzte sich beim Braun- und Steinkohlenbergbau sehr viel früher die Erkenntnis durch, daß Arbeitskräfte auf dem Wege der Freiwilligkeit und nicht durch $\mathrm{Z}$ wangsmittel zu gewinnen seien. Diese unterschiedliche Behandlung hing vornehmlich mit den hohen sowjetischen Anforderungen zusammen, die im Falle des sächsischen Erzbergbaus dominant waren. In den übrigen Bereichen des Bergbaus war das Interesse der Besatzungsmacht bedeutend geringer und damit der Gestaltungsspielraum der deutschen Stellen entsprechend größer. Das heißt allerdings nicht, daß SMAD bzw. SMA diesem Teil der Grundstoffindustrie keinerlei Bedeutung beimessen wollten. Im Gegenteil: Gerade im Winter 1945/46 und 1946/47 stand die Sicherung der Versorgung der SBZ mit Kohle ganz oben auf der sowjetischen Agenda ${ }^{259}$. Der DVAS sowie den Landes-

$253 \mathrm{BAB}, \mathrm{DQ} 2 / 2054$, Reisebericht Roeseners vom 25. 2. 1946.

${ }^{254} \mathrm{BAB}, \mathrm{DQ} 2 / 1881, \mathrm{Bl}$. 27 31, hier Bl. 31, Niederschrift der ZVAS-Abt. II über die Dienstreise am 15./16. 2. 1946.

255 BAB, DQ 2/2054, Landesarbeitsamt Mecklenburg-Vorpommern am 21. 3. 1946 an die ZVAS.

256 Ebenda, Präsident Friedensburg am 30. 3. 1946 an die ZVAS, S. 1.

257 BAB, DQ 2/2064, Kreil (Abt. II) am 4. 4. 1946 an die Landes- und Provinzialämter für Arbeit und Sozialfürsorge von Sachsen, Thüringen, Brandenburg und Sachsen-Anhalt.

258 BAB, DQ 2/2054, ZVAS-Abt. II (Kreil) am 9. 4. 1946 an Präsident Friedensburg, S. 1.

259 Ähnliche Versorgungsengpässe gab es im übrigen auch in den westlichen Besatzungszonen. Im Ruhrkohlenbergbau wurde etwa die Versorgung der Bergarbeiter mit Lebensmitteln Anfang 1947 durch ein einkommensabhängiges Punktesystem verbessert, um langfristig eine Produktionssteigerung zu erreichen. Vgl. Abelshauser, Der Ruhrkohlenbergbau, S. 38-42. 
arbeitsämtern wurde im wesentlichen nur die Höhe der Kohlenförderung vorgegeben; konkrete Arbeitskräfteanforderungen für einzelne Gruben wurden dagegen äußerst selten erteilt. Somit konnte die deutsche Arbeitsverwaltung relativ autonom über die Wahl der Instrumente bei der Rekrutierung von Arbeitskräften entscheiden. Für den Fachverband des Braunkohlenbergbaus in der Provinz Sachsen stand außer Frage, daß Zwangsmittel nicht eingesetzt werden sollten: „Der gesamte Bergmannsstand würde dadurch zur Z $\mathrm{Z}$ wangsarbeit degradiert werden. [...] Durch den Zwang würde man das Standesgefühl vernichten." 260 Statt dessen müsse versucht werden, „durch entsprechende Propaganda“ Freiwillige für den Beruf des Bergmanns zu gewinnen. Daher seien die Bergarbeiter - so der Vertreter des Fachverbandes - bei der Entlohnung sowie der Arbeitszeitregelung gegenüber anderen Berufen zu bevorzugen. Diese Vorschläge fanden die ungeteilte Zustimmung des Provinzialamtes für Arbeit und Sozialfürsorge.

Der Arbeitskräftebedarf konnte im Frühjahr 1946 nicht befriedigt werden. Zahlreiche Arbeitsämter meldeten, daß wegen der ungeklärten Unterbringungsfrage ein „Heranziehen von auswärtigen Kräften [...] gegenwärtig nicht ratsam erscheint" 261 . Das brandenburgische Landesarbeitsamt setzte seine Hoffnungen darauf, nach Beendigung der Demontagen den Bedarf „rein örtlich“ abdecken zu können. Auch das Provinzialamt für Arbeit und Sozialfürsorge von SachsenAnhalt berichtete, daß die Anforderungen der Bergbaubetriebe nicht zu erfüllen seien $^{262}$. Präsident Friedensburg von der Deutschen Zentralverwaltung der Brennstoffindustrie richtete nunmehr direkte Arbeitskräfteanforderungen an die einzelnen Landes- bzw. Provinzialverwaltungen ${ }^{263}$ und riskierte damit einen offenen Konflikt mit der ZVAS, die sich übergangen fühlen mußte. Die quantitativ größte Auflage hatte Sachsen-Anhalt (4712), gefolgt von Brandenburg (3775); Sachsen sollte insgesamt 2970 und Thüringen 633 Arbeiter stellen. Diese Vorgehensweise führte allerdings dazu, daß Landesämter die ihnen gestellten Auflagen an benachbarte Landesarbeitsämter weiterleiteten. Das Provinzialamt für Arbeit und Sozialfürsorge von Sachsen-Anhalt verband sein Ersuchen an das thüringische Landesamt sogar mit einem Ultimatum: „Sofern Sie diese Kräfte nicht stellen, wird meinerseits bei der Deutschen Zentralverwaltung der Brennstoffindustrie [...] der Antrag auf Sperrung der Lieferungen an Sie gestellt werden müssen.“264 Allem Anschein nach hatte die ZVAS gegen die Initiative von Friedensburg nichts einzuwenden. Dieser forderte die ZVAS am 5. Juni sogar explizit auf, „sich nachdrücklich dafür einzusetzen und die nachgeordneten Dienststellen wiederholt eindringlich darauf hinzuweisen, daß eine Abziehung von Arbeitskräften aus der Brennstoffindustrie zu Demontagezwecken auf keinen Fall vorgenommen werden darf“265. Da Friedensburg mittlerweile die Unterstützung der SMAD gewon-

260 LA Magdeburg LHA, Rep. K MW, Nr. 10576, Bl. 135-143, hier B1. 140, Bericht des Provinzialamtes für Arbeit und Sozialpolitik in Halle/Saale über eine Besprechung am 6. 3. 1946.

261 BAB, DQ 2/1881, Bl. 51 f., Landesarbeitsamt Potsdam am 18. 4. 1946 an die ZVAS.

${ }^{262}$ LA Magdeburg LHA, Rep. K MW, Nr. 10576, Bl. 135-143, hier Bl. 135, Bericht vom 6. 3. 1946.

263 BAB, DQ 2/1881, Bl. 53-55.

${ }^{264}$ ThHStA, Land Thüringen, Ministerium für Wirtschaft und Arbeit, Bd. 3700, Bl. 72, Schreiben vom 25. 5. 1946. Ein gleichlautendes Schreiben ging auch an die Landesämter für Arbeit und Sozialfürsorge in Dresden, Schwerin und Potsdam. Vgl. BAB, DQ 2/1881, Bl. 56, 57 und 60.

$265 \mathrm{BAB}, \mathrm{DQ} 2 / 2054$. 
nen hatte ${ }^{266}$, war aus Sicht der ZVAS offener Widerspruch zwecklos. Das geschilderte eigenmächtige Vorpreschen des Provinzialamtes für Arbeit und Sozialfürsorge in Halle/Saale wurde dagegen von der ZVAS am 4. Juli gestoppt ${ }^{267}$. Zur Bedarfsdeckung schlug die Berliner Zentralverwaltung vor, die "laufenden Umsiedlertransporte weitgehendst heranzuziehen". Da eine Erfassung und Lenkung der bergbautauglichen Arbeitskräfte aufgrund anderslautender Befehle der SMA nicht vorgenommen werden konnte, sollte dies in den Auffang- und Quarantänelagern nachgeholt werden.

Die Grubenleitungen zeigten sich oftmals unzufrieden über die berufliche Qualifizierung der Arbeitskräfte, die ihnen von seiten der Arbeitsverwaltung zugewiesen worden waren. So betonte die Anhaltische Kohlenwerke AG, daß der Bedarf an ungelernten Arbeitskräften gedeckt sei ${ }^{268}$. Darüber hinaus sei es "nicht zweckmäßig“, Arbeiter zuzuweisen, die „die von uns gestellten Berufsangaben bzw. -kenntnisse nicht besitzen." Des weiteren klagte die Werksleitung darüber, daß die Überalterung der Belegschaften eher verstärkt als gebremst werde. Die Anhaltische Kohlenwerke AG sah sich deshalb nicht mehr in der Lage, Arbeiter aufzunehmen, „die älter sind wie von uns angegeben, da die Bergmannsarbeit doch eine bestimmte Beweglichkeit und auch körperliche Anstrengung erfordert."

DVAS-Präsident Brack wollte den Arbeitskräftemangel im Bergbau mittelfristig durch eine gezielte Verbesserung des Wohnungsbaus, der Ausstattung mit adäquater Berufskleidung, der Löhne sowie der Leistungen aus der Sozialversicherung beheben. Dadurch - so die Überlegung - sollten Anreize für einen freiwilligen Arbeitsplatzwechsel geschaffen werden. Die Überalterung wollte er mit einer Intensivierung der Lehrlingsausbildung stoppen ${ }^{269}$. Der Oberste Chef der SMAD veröffentlichte am 20. November 1946 den Befehl Nr. 323, der Maßnahmen zur Erhöhung des Kohlenabbaus und der Brikettproduktion enthielt ${ }^{270}$. Diese reichten von der Entlohnung bis zum Wohnungsbau. Damit machte auch die sowjetische Besatzungsmacht deutlich, daß dringender Handlungsbedarf bestand. Neben einer Festlegung der Fördermenge enthielt der Befehl auch genaue Anweisungen zur Versorgung der Steinkohlengruben in Zwickau-Oelsnitz mit Arbeitskräften: Im IV. Quartal 1946 sollten 750 Arbeiter und im Laufe des Jahres 1947 insgesamt 2750 Arbeiter neu eingestellt werden. Die Planung der DVAS zur Erfüllung dieser Auflage bewegte sich in gewohnten Bahnen: „Die Abdeckung der im Befehl vorgesehenen Kräfte soll aus den weniger beanspruchten Bevölkerungskreisen und Berufsschichten erfolgen wie Umsiedler, Landarbeiter usw." 271 Außerdem sei der Fraueneinsatz zu fördern'272. Per Fernschreiben wurden die Landesarbeitsämter

266 BAB, DQ 2/2054, Stellvertretender Leiter der Verwaltung der Brennstoffindustrie und Energie der SMAD (Fedjaew) am 5. 6. 1946 an Friedensburg.

$267 \mathrm{BAB}, \mathrm{DQ} 2 / 2054$.

268 BAB, DQ 2/1881, Bl. 71 f., hier Bl. 72. Anhaltische Kohlenwerke AG am 5. 9. 1946 an das Landesarbeitsamt in Potsdam.

$269 \mathrm{BAB}, \mathrm{DQ} 2 / 2240$, Präsident Brack am 22. 10. 1946 an SMAD (Morenow).

$270 \mathrm{BAB}, \mathrm{DQ} 2 / 962$.

$271 \mathrm{BAB}, \mathrm{DQ} 2 / 2135, \mathrm{Bl} .12$, Aktenvermerk der DVAS-Abt. I vom 29. 11. 1946.

272 Der Beschäftigtenanteil der Frauen im gesamten Bergbau (inklusive Erzbergbau) betrug im zweiten Quartal 1948 4,9 Prozent; 5068 Frauen standen 102796 Männern gegenüber. Dabei wurden die Frauen nur zu körperlich leichteren Arbeiten, d.h. nur über Tage herangezogen. Die regionale 
über die neu erteilte Anforderung informiert ${ }^{273}$. Dabei verpflichtete die DVAS das sächsische Landesarbeitsamt, die Stellung des ersten Kontingents von 750 Arbeitern zu übernehmen, falls die übrigen Landesämter nicht ausreichend Arbeitskräfte zuweisen könnten. Wenige Tage später wies die DVAS in einem Rundschreiben auf ein weiteres Arbeitskräftepotential hin, das ausgeschöpft werden sollte: die Arbeitslosen und die Kriegsheimkehrer ${ }^{274}$. Die Landesverwaltung in Sachsen, die bereits für Oktober 711 und für November rund 600 Arbeiter gemeldet hatte, war offenbar davon überzeugt, auf die Hilfestellung der übrigen Länder nicht angewiesen zu sein ${ }^{275}$. Daher verzichtet die DVAS darauf, die Landesarbeitsämter stärker einzubinden und deren Werbungsaktivitäten für den Bergbau zu überprüfen.

Der SMAD-Befehl Nr. 323 war für die Belegschaften nicht folgenlos. Besonders der brandenburgische Justizminister tat sich in dieser Angelegenheit hervor und erließ für seine Justizverwaltung eine Rundverfügung, die den Grubenleitungen die Möglichkeit einräumte, gegen „Arbeitsschwänzer und Verletzer der Arbeitsdisziplin" Sanktionen zu verhängen: Vom öffentlichen Tadel bis zum Entzug der Lebensmittelkarten für zusätzliche Verpflegung oder die Verkürzung des Urlaubs um die Zahl der „ohne triftige Gründe versäumten Tage“276. Das Strafmaß konnte sogar noch weiter erhöht werden. In „schweren Fällen“ komme der Befehl Nr. 16 über die Bestrafung von Sabotage- und Diversionsakten als Grundlage in Betracht. Die DVAS wurde offensichtlich erst aufgrund der Berichterstattung im ,Tagesspiegel' über die Vorgehensweise des Landesjustizministers informiert. Nach Rückfrage machte die dortige Justizverwaltung noch präzisere Angaben zur Höhe der zu verhängenden Strafen: Diese könnten „in besonders schweren Fällen“ auf 15 Jahre Gefängnis festgesetzt, „bei nachgewiesener Sabotage sogar auf Todesstrafe erkannt werden"277. Gegen diese Befehlsauslegung wandte sich die Juristische Abteilung der DVAS: Es sei zweckmäßig, den Justizminister der

Verteilung war unterschiedlich: Sachsen-Anhalt meldete 3161 weibliche Beschäftigte im Bergbau, Brandenburg 1484. Vgl. BAB, DQ 2/2054, Aktenvermerk der HVAS-Abt. I b vom 30. 6. 1948. Die Angaben zur Beschäftigtenzahl schwankten mitunter beträchtlich und hingen sehr stark von der jeweiligen Bezugsgröße ab. So ermittelte eine weitere Übersicht der HVAS für 1948 insgesamt 209550 beschäftigte Personen im Bergbau, darunter 17450 Frauen. Vgl. BAB, DQ 2/137, Bl. 430 f. Die unterschiedlichen Angaben erklären sich möglicherweise daraus, daß im letzten Falle sehr viel mehr Nebenbetriebe mit eingerechnet wurden. Die Verteilung auf die einzelnen Bergbauzweige sah wie folgt aus:

\begin{tabular}{lrr}
\hline & Männer & Frauen \\
\hline Steinkohle & 22100 & 650 \\
Braunkohle & 105200 & 11200 \\
Erzbergbau & 45300 & 4700 \\
Salzbergbau & 19500 & 900 \\
\hline
\end{tabular}

Quelle: BAB, DQ 2/137, Bl. 430.

${ }^{273} \mathrm{BAB}, \mathrm{DQ} 2 / 2135, \mathrm{Bl}$. 13, DVAS am 30. 11. 1946 an die Landesarbeitsämter.

274 Ebenda, Bl. 18-21, hier Bl. 18, Rundschreiben der DVAS-Abt. I vom 4. 12.1946 an alle Landesund Provinzialämter für Arbeit und Sozialfürsorge.

$275 \mathrm{BAB}, \mathrm{DQ} 2 / 2064$, Aktenvermerk der DVAS-Abt. I über eine Besprechung mit dem Landesarbeitsamt Sachsen am 6./7. 12. 1946, S. 1.

276 BAB, DQ 2/2054, Rundverfügung Nr. 4/VI vom 24. 12. 1946. Darüber berichtete „Der Tagesspiegel" am 24. 1. 1947. Vgl. ebenda.

277 Ebenda, Aktenvermerk vom 31.1. 1947 (vermutlich vom Landesarbeitsamt in Potsdam) an die DVAS. 
Landesregierung Brandenburg darauf hinzuweisen, „daß der Wortlaut des SMABefehls den scharfen Hinweis im letzten Absatz der Rundverfügung nicht rechtfertigt" ${ }^{278}$.

Anfang Februar 1947 startete die DVAS eine neue Initiative, um die Versorgung des Bergbaus mit Arbeitskräften langfristig zu sichern. Den Landes- und Provinzialämtern wurde in einem Rundschreiben mitgeteilt, daß den einzelnen Gruben „noch immer nicht ausreichende Arbeitskräfte zur Verfügung stehen, um die dringend nötigen Fördermengen zu erzielen "279. Die Arbeitsämter erhielten in dem Zusammenhang die Aufgabe, „den Ansprüchen der Gruben auf Gestellung der notwendigen Arbeitskräfte restlos zu entsprechen." Zur Kontrolle sollten die Landesarbeitsämter Sachbearbeiter abstellen, denen eine koordinierende Funktion zukam. Darüber hinaus hatte die Arbeitsverwaltung in den Kreisen und Städten ihre Propagandatätigkeit, bei der die Betonung der verbesserten Lohn-, Arbeits- und Versorgungsbedingungen im Vordergrund stehen sollte, zu intensivieren. Auf diese Weise würden sich - so die Einschätzung der DVAS - „genügend freiwillige Arbeitskräfte für die Arbeitsaufnahme im Kohlenbergbau finden" lassen280. Gleichzeitig wurde zum wiederholten Male die Freiwilligkeit der Arbeitskräftegewinnung betont. Zwangseinweisungen seien überflüssig und unter Berücksichtigung der anzustrebenden Arbeitsleistungen in den Gruben auch unerwünscht. Dagegen sei jedoch die „sofortige Zuweisung arbeitsloser oder berufsfremd eingesetzter Bergfachkräfte" nach wie vor zulässig. Um sich mit der Zentralverwaltung der Brennstoffindustrie und der IG Bergbau besser abstimmen zu können, lud die DVAS am 15. Februar zu einer Besprechung ein. DVAS-Abschnittsleiter Kreil unterstrich in seiner Begrüßung, daß „die Notwendigkeit der ausreichenden Versorgung des Kohlenbergbaus mit Arbeitskräften wohl niemals

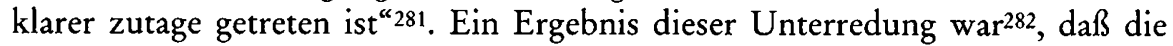
Zentralverwaltung der Brennstoffindustrie nach wie vor die Aufgabe hatte, den konkreten Arbeitskräftebedarf in den Gruben zu ermitteln und anschließend der DVAS mitzuteilen. Dagegen sollten die Arbeitsämter für die Zuweisung der Bergarbeiter verantwortlich bleiben. Der Dualismus, der sich zwischen beiden Zentralverwaltungen entwickelt hatte, bestand somit weiter fort. $\mathrm{Zu}$ den Aufgabengebieten der DVAS zählte außerdem die Regelung der Wohnraumfrage für die zuziehenden Arbeiter und deren Familien. In dem Zusammenhang wurde vorgeschlagen, „die SMA's um Freigabe beschlagnahmter, für militärische Zwecke aber nicht mehr benutzter Unterkünfte anzugehen." Der Lehrlingsausbildung sollte sich wiederum verstärkt die Zentralverwaltung der Brennstoffindustrie zuwenden. Die ausreichende Versorgung mit Wohnraum stellte auch noch Mitte 1947 ein weitgehend ungelöstes Problem dar, wie die DVAS offen einräumen mußte283.

Nachwuchsfragen im Bergbau standen fortan im Zentrum der gemeinsamen Planungen von DVAS und Zentralverwaltung der Brennstoffindustrie, zu denen

${ }_{278}$ Ebenda, Juristische Abt. am 8. 2. 1947 an Abt. III (Herm).

279 BAB, DQ 2/546, Rundschreiben Nr. 131 vom 11. 2. 1947, S. 1.

280 Ebenda, S. 2.

281 BAB, DQ 2/2054, Aktenvermerk der DVAS-Abt. I b vom 15. 2. 1947, S. 1.

282 Vgl. zum folgenden: ebenda, S. 3.

${ }^{283}$ SAPMO, DY 30/IV 2/2.027/25, Bl. 1 f., Aktenvermerk der DVAS-Abt. I b vom 14. Juli 1947. 
auch Vertreter der Zentralverwaltung der Industrie und der IG Bergbau hinzugezogen wurden. Die DVAS-Mitarbeiterin Heinze, die zuvor das Landesarbeitsamt in Dresden geleitet hatte und daher über ausgezeichnete Fachkenntnisse verfügte, beschrieb den Stand der Aus- und Weiterbildung für den Bergbauberuf in äußerst düsteren Farben: Der Anteil der Jugendlichen betrage nur 1,47 Prozent; die Arbeitsämter hätten im gesamten Bergbau 5469 Jugendliche gezählt ${ }^{284}$. Um die Überalterung der Belegschaften zu verhindern, sei es aber notwendig, die Anzahl auf 10000 zu erhöhen. Die Zurückhaltung zahlreicher Grubenleitungen, neue Lehrlinge einzustellen, hing offensichtlich auch damit zusammen, daß diese vollständig zur Belegschaft hinzugezählt wurden, obwohl sie noch nicht unter Tage eingesetzt werden durften ${ }^{285}$. Da die Belegschaftsgröße über die auferlegte Produktionshöhe entschied, reduzierte das automatisch das Interesse auf seiten der Bergbauwerke, Lehrlinge auszubilden, die erst nach einer dreijährigen Ausbildung richtig einsatzfähig waren. Ein Mitarbeiter der Zentralverwaltung der Brennstoffindustrie schlug deshalb vor, bei der SMAD zu erreichen, daß die Anzahl der Lehrlinge bei der Festlegung der Produktion nicht angerechnet werde. Die verstärkte Lehrlingsausbildung hatte nicht nur die Funktion, jüngere Jahrgänge für den Bergbau zu gewinnen, sondern auch die Aufgabe, den oftmals angesprochenen Facharbeitermangel besser in den Griff zu bekommen ${ }^{286}$.

Anfangs hatten sich durchaus Erfolge bei der Werbung für den Braun- und Steinkohlenbergbau eingestellt. Während der ersten beiden Monate 1947 stieg etwa im Steinkohlenrevier Zwickau-Oelsnitz die Belegschaft (ohne die kaufmännischen Angestellten) um 795 auf insgesamt $17659 \mathrm{an}^{287}$. Während sich zuvor die ungeklärte Wohnraumfrage als Hemmschuh erwiesen hatte, traten nunmehr die stellenweise wieder aufgenommenen Demontagen als neue Hindernisse auf. Die Kohlenförderung wurde vor allem dadurch behindert, daß die sowjetische Besatzungsmacht Teile des Maschinenparks konfiszieren ließ. Diese Demontagen hatten zwar schon in der unmittelbaren Nachkriegszeit eingesetzt, gewannen aber nun eine neue Qualität. Die durch den Befehl Nr. 323 angestrebte Produktionssteigerung war nämlich ohne eine Neuausstattung der Bergbaugruben mit technischen Geräten undurchführbar. Einzelne Landesarbeitsämter formulierten deutlich den kausalen Zusammenhang: „Eine Steigerung der Koblenproduktion läßt sich daher durch den neuen Einsatz von Bergarbeitern nicht herbeiführen, wenn nicht zu gleicher Zeit die demontierten Betriebe wieder betriebsfähig gemacht werden." 288 Der DVAS lagen sogar Berichte einzelner Arbeitsämter vor, die von einem Ansteigen der Arbeitslosenzahlen ausgingen. So war beispielsweise im Kreis Calau ein nicht näher quantifizierter, aber doch „erheblicher Teil“ der in Bergbaugruben beschäftigten Arbeiter beschäftigungslos geworden, weil die SMA Brandenburg Demontagen wieder aufgenommen hatte289. Das brandenburgische Landesarbeitsamt wurde gebeten, dafür Sorge zu tragen, daß arbeitslose Bergar-

${ }^{284} \mathrm{BAB}, \mathrm{DQ} 2 / 2054$, Bericht über Sitzung am 11. 3. 1947, S. 1.

285 Ebenda, S. 4.

${ }^{286}$ SAPMO, DY 30/IV 2/2.027/25, Bl. 1 f., Aktenvermerk der DVAS-Abt. I b vom 14. 7. 1947.

${ }^{287}$ BAB, DQ 2/2135, Bl. 81, DVAS am 11. 3. 1947 an SMAD-Abt. Arbeitskraft (Morenow).

$288 \mathrm{BAB}, \mathrm{DQ} 2 / 2133, \mathrm{Bl}$. 32, Bericht des Referats Wohnungsfürsorge, Wohnungshygiene und Siedlung in Potsdam vom 21.3.1947 [Hervorhebung im Original].

${ }^{289}$ Ebenda, Bl. 60, Abteilungsleiter Kreil am 15.4. 1947 an das Landesarbeitsamt in Potsdam. 
beiter nicht berufsfremd eingesetzt würden. In dem Zusammenhang plädierte die DVAS für eine überbezirkliche Vermittlung: So bestünde etwa in Sachsen-Anhalt ein "größerer ungedeckter Bedarf“. Der Leiter der Hauptabteilung Industrie im sächsischen Wirtschaftsministerium, Gerhart Ziller, faßte in einem Bericht das Ausmaß der Demontagen und deren Auswirkungen auf den wirtschaftlichen Aufbau in der SBZ zusammen. Dabei warnte er nicht nur vor den Gefährdungen für die Energieversorgung, sondern auch vor den politischen Folgewirkungen. Diese bezogen sich zum einen auf die Beschäftigten in den Kohlengruben: „Wir werden mit starken Depressionserscheinungen unter den Bergarbeitern zu rechnen baben, wenn man die Demontage in der vorgenannten Form durchführt." 290 Ziller rechnete zum anderen mit entsprechenden Meldungen in der gesamten westlichen Presse, vor der man die neuerlichen Demontagen nicht habe verbergen können. Nachdem die SED-Führung über die Demontagen unterrichtet worden war, sprachen Wilhelm Pieck, Otto Grotewohl, Walter Ulbricht und Max Fechner das Thema am 28. August bei Marschall Wassili D. Sokolowski291 an. Diese Intervention verlief aber erfolglos: Der Oberste Chef des SMAD bezeichnete die Demontagen als "Restdemontage[n]“ und beharrte auf der eigenen Vorgehensweise ${ }^{292}$.

Im Laufe des Sommers 1947 stieg der Arbeitskräftebedarf im Bergbau weiter. Allein die Braunkohlengruben benötigten zusätzlich 12100 Arbeitskräfte, vor allem in Sachsen-Anhalt (4700)293. Der sächsische Steinkohlenbergbau meldete einen erneuten Bedarf von 2000 Arbeitskräften an. Im Gegensatz zu den fast gleichzeitig eingereichten Forderungen für den Uranbergbau ( 3000 bis zum 30.8. sowie 17000 Arbeiter bis zum 31. 10. 1947) waren die Auflagen für den Kohlenbergbau mit keiner Frist verbunden ${ }^{294}$. Auf einer Arbeitsbesprechung am 16. September 1947 im Hause der Zentralverwaltungen ließ sich die DVAS, die die Zentralverwaltung der Brennstoffindustrie offensichtlich nicht eingeladen hatte, die Federführung bei der Bereitstellung von Arbeitskräften für den Bergbau bestätigen ${ }^{295}$. Beim Steinkohlenbergbau, der in der SBZ nicht so personalintensiv war, konnte der Bedarf bis Ende 1947 abgedeckt werden ${ }^{296}$; durch nicht vorhersehbare Entlassungen und Kündigungen reduzierten sich allerdings die Nettozugänge auf fast die Hälfte (994)297.

Zusätzliche Probleme bei der Arbeitskräftelenkung traten in den Bergbaugruben im grenznahen Gebiet zu Polen auf, so etwa beim Werk Hirschfelde. Teile der Kohlengruben befanden sich nämlich auf polnisch verwaltetem Gebiet, wo deut-

290 Bericht Zillers über neue Demontagen im Kohlenbergbau vom 24. 8. 1947, in: Badstübner/Loth, Wilhelm Pieck, S. 144-147, hier S. 146 [Hervorhebung im Original].

${ }^{291}$ Vgl. zu Sokolowski die Kurzbiographie in: Foitzik, SMAD, S. 478.

292 Brief des SED-Zentralsekretariats an die Landessekretariate der SED vom 29. 8. 1947, in: Badstübner/Loth, Wilhelm Pieck, S. $159 \mathrm{f}$. 293 BAB, DQ 2/2136, DVAS-Präsident Brack am 26. 7. 1947 an die Zentralverwaltung der Brennstoff-
industrie.

294 SAPMO, DY 30/IV 2/2.027/25, Bl. 60-64, hier Bl. 60, Niederschrift der DVAS über eine Sitzung der Abt. I b mit Vertretern des FDGB-Bundesvorstandes, der IG Bergbau, der Abt. IV und der Abt. Kultur der DVAS.

$295 \mathrm{BAB}, \mathrm{DC}$ 15/581, Bl. if., Ergebnisprotokoll vom 19. 9. 1947.

$296 \mathrm{BAB}, \mathrm{DQ} 2211537$, Niederschrift über den Verlauf der Arbeitstagung der DVAS (Abt. I b) in Leipzig am 6./7. 1. 1948, S. 25.

${ }^{297} \mathrm{BAB}, \mathrm{BQ} 2 / 2135, \mathrm{Bl} .109$, Zentralverwaltung der Brennstoffindustrie am 12.11. 1947 an die DVAS. 
sche Bergarbeiter nach wie vor beschäftigt waren. Rechtsgrundlage bildete offensichtlich ein Vertrag zwischen Polen und der SMAD, der das in der SBZ liegende Werk Hirschfelde verpflichtete, „dem Tagebau Turow auf Verlangen die Möglichkeit zur Verwendung deutscher Arbeitskräfte zu geben"298. Darüber hinaus sollte Hirschfelde die Lohn-, Krankenversicherungs- und Unfallversicherungskosten tragen sowie für den An- und Abtransport der Arbeiter zuständig sein. Die polnische Verwaltung erhielt dagegen die Aufgabe, Maßnahmen für einen "normalen“ Arbeitsschutz zu ergreifen. Der FDGB-Bundesvorstand sprach sich dafür aus, die für die SBZ geltenden Arbeitsschutzbestimmungen auch auf den Tagebau Turow zu übertragen. Diese Forderung bezog sich sowohl auf die Einrichtung von Sanitätsstellen und den Einsatz der Betriebsärzte als auch auf die Wahl von Bevollmächtigten für die Sozialversicherung299. Die Übernahme deutscher Rechtsvorschriften auf das polnische Werk ließ sich jedoch kaum realisieren. Selbst Mitarbeitern der Zentralverwaltung der Brennstoffindustrie war die Besichtigung der Arbeitsstätten nicht gestattet; dies wurde nur einigen Betriebsratsmitgliedern genehmigt, die besondere Ausweise erhielten. Da die Werksleitung von Turow bestrebt war, die ungefähr 300 deutschen Bergleute sukzessive durch polnische Arbeitskräfte zu ersetzen, erübrigte sich bald eine umfassende bilaterale Regelung 300 .

Die Fluktuation von Arbeitskräften zum Erzbergbau erfaßte auch den Steinkohlenbergbau. Dieser befand sich zwar laut sowjetischen und deutschen Anweisungen in derselben Dringlichkeitsstufe wie der Uranbergbau, konnte aber die Abwanderung nicht verhindern, die mit den allmählich verbesserten Arbeits- und Lebensbedingungen ursächlich zusammenhing. Die HVAS schaltete sich in dieser Frage ebenfalls ein und betonte, daß ein Arbeitsplatzwechsel nur mit vorheriger Zustimmung des bisher zuständigen Arbeitsamtes zulässig sei. Das sächsische Landesarbeitsamt wurde gebeten, das Arbeitsamt in Aue anzuweisen, „bei der Einstellung freiwilliger Kräfte aus dem Zwickauer Steinkohlengebiet besonders auf das Vorliegen einer Genehmigung des Arbeitsplatzwechsels zu achten"301. Gleichzeitig sollte das abgebende Arbeitsamt in Lugau weitere Anträge auf Arbeitsplatzwechsel ablehnen. Einzelne Werksleitungen wandten sich hilfesuchend an die Steinkohlenverwaltung in Zwickau, da die Abwanderung im Laufe des Sommers 1949 nicht abriß302. Die DWK-Hauptverwaltung Kohle, der die Gruben unterstanden, bat ihrerseits die HVAS, „möglichst umgehend dafür zu sorgen, daß weitere Abgänge aus dem Steinkohlenbergbau im Interesse der Erfüllung des Volkswirtschaftsplanes vermieden werden " ${ }^{303}$. In seinem Antwortschreiben wies jedoch Litke darauf hin, daß die Arbeitsämter zwar grundsätzlich Widerspruch gegen eine Abwanderung zur Wismut AG erheben könnten. Dies habe jedoch keine rechtlichen Folgen: „Eine gesetzliche Möglichkeit, den Arbeitsplatzwechsel

${ }^{298} \mathrm{BAB}, \mathrm{DQ} 2 / 1881$, Bl. 152, Zentralverwaltung der Brennstoffindustrie am 14. 1. 1948 an die DVAS.

249 Ebenda, Bl. 154, FDGB-Bundesvorstand am 30.1.1948 an die DVAS (Herm).

300 Ebenda, Bl. 151, Zentralverwaltung der Brennstoffindustrie im Februar 1948 an die DVAS.

301 BAB, DQ 2/2135, Bl. 111, HVAS-Abt. I b am 8. 7.1948 an das Landesarbeitsamt in Dresden.

302 BAB, DQ 2/2134, Bl. 25, Karl-Marx-Werk Zwickau am 3. 8. 1949 an die Steinkohlenverwaltung Zwickau.

${ }^{303}$ Ebenda, Bl. 27, HV Kohle am 9. 8. 1949 an die HVAS. 


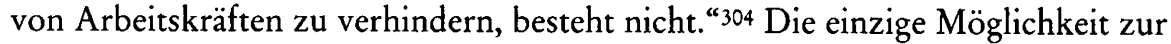
Eindämmung der Fluktuation sah der HVAS-Mitarbeiter darin, das sächsische Landesamt für Arbeit und Sozialfürsorge zu beauftragen, „keine besonderen Werbemaßnahmen, die zum Ziel haben, freiwillige Arbeitskräfte aus den Betrieben der Steinkohlenindustrie für die Wismut AG anzuwerben, durchzuführen.“

\section{Kalibergban}

Der Kalibergbau stellte einen Zweig des Bergbaus in der SBZ dar, der regional vor allem auf das Land Thüringen begrenzt blieb. Mit dem Befehl Nr. 9 vom 9. Januar 1946 legte der Oberste Chef der SMAD den Produktionsplan für den Abbau von Kalisalz fest, aus dem in erster Linie Phosphat-Düngemittel hergestellt wurden, die letztlich in der Landwirtschaft zum Einsatz kamen. Entscheidend für die Arbeitsverwaltung war die Anlage zum SMAD-Befehl, der konkrete Angaben für die Bereitstellung von Arbeitskräften enthielt ${ }^{305}$. Demzufolge hatte Thüringen insgesamt 4260 Arbeiter zur Verfügung zu stellen ${ }^{306}$; Sachsen-Anhalt verfügte über drei kleinere Kaliwerke ${ }^{307}$, für die 380 Arbeitskräfte benötigt wurden. Die sowjetische Besatzungsmacht wurde nahezu regelmäßig über den Stand der Arbeitskräftegewinnung informiert. So berichtete Landesdirektor Brack, daß bis zum 26. Januar 1083 Arbeiter bereitgestellt werden konnten ${ }^{308}$. Nicht nur die SMAD, sondern auch die SMA von Sachsen-Anhalt zeigte sich frühzeitig unzufrieden über die Erfüllung der von ihr aufgestellten Produktionspläne. Die SMA Sachsen-Anhalt übermittelte dem Präsidenten der Provinz am 9. Februar den Befehl Nr. 40, in dem die Auflagen nochmals angemahnt wurden ${ }^{309}$. Technische Schwierigkeiten - den Gruben fehlten in der Anfangszeit häufig Maschinen und Sprengstoff - sowie eine verspätete Bekanntgabe des Befehls Nr. 9 hatten letztlich dazu geführt, daß der Kaliabbau erst langsam anlaufen konnte ${ }^{310}$. Die Landesverwaltungen waren zunächst auf sich allein gestellt. Das thüringische Landesamt für Arbeit und Sozialfürsorge führte mehrere Besprechungen mit den Leitern der Arbeitsämter ${ }^{311}$ sowie mit den Betriebsleitern der einzelnen Gruben ${ }^{312}$ durch. Dabei wurden ähnliche Problemlagen wie beim Braun- und Steinkohlenbergbau deutlich: eine schlechte Versorgung mit Wohnraum sowie mit Transportmitteln

30+ BAB, DQ 2/2134, Litke am 23. 8. 1949 an die HV Kohle. $305 \mathrm{BAB}, \mathrm{DQ} 2 / 2165$. Die Anlage war von der Industrie-Verwaltung der SMAD zusammengestellt
worden.

306 Dabei handelte es sich um die Gruben der Wintershall AG (Kaiseroda, Heiligenroda, SachsenWeinmar und Glückauf), der Preussag (Bleicherode), der Burbach-Kaliwerke (Volkenroda) sowie der Vereinigten Kaliwerke AG Salzdethfurth (Sollstedt).

307 Dazu gehörten die Gruben der Preussag in Staßfurt und Klein Schierstedt sowie der BurbachKaliwerke $A G$ in Krügershall.

308 ThHStA, Land Thüringen, Ministerium für Wirtschaft und Arbeit, Bd. 3651, Bl. 21 .

$309 \mathrm{Vgl}$. BAB, DQ 2/2165. $310 \mathrm{BAB}, \mathrm{DQ} 2 / 2165,2$. Vizepräsident von Sachsen-Anhalt, Ernst Thape, am 18. 2. 1946 an die SMA
in Halle/Saale.

311 ThHStA, Land Thüringen, Büro des Ministerpräsidenten, Bd. 1678, Landesdirektor Brack am 12. 2. 1946 an den Präsidenten des Landes Paul.

312 Ebenda, Besprechung des Präsidenten Paul mit den Direktoren und Betriebsräten der Kalibergwerke in Thüringen am 19.2. 1946. 
(Bus und Bahn). Darüber hinaus beklagten zahlreiche Betriebsräte die schlechte Ernährungslage und das Fehlen von Arbeitskleidung313.

Auf Nachfrage der Zentralverwaltung der Industrie befaßte sich die ZVAS ungefähr ab März 1946 intensiver mit der Deckung des Bedarfs an Arbeitskräften für den Kalibergbau. Vereinbart wurde zunächst jedoch nur die Durchführung von gemeinsamen Dienstreisen in die „Bedarfsgebiete“314. Dagegen verschärfte Landesdirektor Brack die Gangart gegenüber den thüringischen Arbeitsämtern: Es gelte, die Produktion von „Kohle, Eisen, Kali und Verkehrsmitteln auf volle Touren zu bringen." Dazu müsse der Arbeitskräftebedarf „unter allen Umständen“ erfüllt werden ${ }^{315}$. Brack sprach sich dafür aus, nicht voll ausgelastete Handwerksund Handelsbetriebe auszukämmen und berufliche Umsetzungen bei Industrie und Handwerk vorzunehmen. Außerdem sollten ehemalige NSDAP-Mitglieder gezielt in diesen Wirtschaftszweigen eingesetzt werden. Nachdem einige Arbeitsämter dies als Aufforderung verstanden hatten, befristete Einsatzverpflichtungen auszusprechen, drängte das Landesamt darauf, Arbeitseinweisungen nicht zeitlich zu begrenzen, sondern grundsätzlich „bis auf weiteres“ auszusprechen ${ }^{316}$.

Die SMA Thüringen verfolgte mit wachsendem Interesse die Aktivitäten der Landesverwaltung und mahnte stets die Erfüllung der Befehle an. Beschwichtigenden Erklärungen von seiten der deutschen Arbeitsverwaltung entgegneten sowjetische Offiziere mit dem Hinweis, daß "der russische Arbeiter größere Schwierigkeiten gesehen hat als der deutsche Arbeiter"317. Da die Kali-Industrie während des Zweiten Weltkrieges kaum zerstört worden war, ging die Besatzungsbehörde davon aus, „daß der Plan, der auferlegt worden ist, bestimmt auch ausführbar ist."

Der Bedarf an Arbeitskräften ließ sich kurzfristig nicht befriedigen; hier ergaben sich im übrigen Parallelen zum Uranbergbau. Langfristig gesehen verlor der Kalibergbau für die Arbeitsämter an Bedeutung; spätestens Ende 1947 verfügten die Grubenleitungen über genügend Arbeiter ${ }^{318}$. Dagegen rückte die Frage der Überalterung und des beruflichen Nachwuchses immer mehr ins Zentrum der Aufmerksamkeit - auch dies ein Phänomen, das in anderen Bergbauzweigen ebenfalls zu beobachten war. Dabei schoben sich DVAS und Werksleitungen gegenseitig die Verantwortung zu. So kam ein Mitarbeiter der DVAS-Abteilung II (Ausbildung und Umschulung) nach einer Dienstreise in das Gebiet des Kalibergbaus von Aschersleben und Staßfurt Ende Mai 1947 zum Ergebnis: „Obwohl sich die Werksleitungen über die äußerst ungünstigen Nachwuchsverhältnisse im klaren sind, wird für deren Besserung kaum eine nennenswerte Initiative entwik-

313 Ebenda, Niederschrift über Tagung der Kali-Arbeiter am 12.6. 1946.

314 BAB, DQ 2/2060, Aktenvermerk der ZVAS vom 1. 3. 1946.

315 BAB, DQ 2/1568, Landesamt für Arbeit und Sozialfürsorge in Weimar am 4. 3. 1946 an die Direktoren der Âmter für Arbeit und Sozialfürsorge [Hervorhebung im Original].

316 Ebenda, Rundverfügung VIII 1043/R 69 des thüringischen Landesamtes für Arbeit und Sozialfürsorge vom 30. 3. 1946.

317 ThHStA, Land Thüringen, Büro des Ministerpräsidenten, Bd. 1678, Niederschrift über Tagung der Kali-Arbeiter vom 12.6. 1946 in Eisenach, S. 12 (Ausführungen des Leiters der Wirtschaftsabteilung der SMA Thüringen Schinkewitsch).

318 Vgl. BAB, DQ 2/1537, Niederschrift über den Verlauf der Arbeitstagung der DVAS (Abt. I b) in Leipzig am 6./7.1.1948, S. 25. 
kelt." 319 Der Vorsitzende des Gesamtbetriebsrates im Kaliwerk Staßfurt sah wenig später die Ursachen für die ausgebliebene Produktionssteigerung ganz woanders und hob die „sehr gedrückte und vor allem revolutionäre Stimmung" in der Belegschaft hervor ${ }^{320}$. Zur Begründung verwies er auf die nach wie vor bestehende mangelhafte Ausstattung mit Schuhwerk und Arbeitskleidung sowie die ungenügende Ernährungslage. Der Bericht gipfelte in dem Appell: „Gebt uns das, was wir brauchen, und nach einer Anlaufzeit von 5-6 Monaten sind wir in der Lage, die Anforderungen, welche gestellt werden, genau wie 1938 zu erfüllen." Die anschauliche Beschreibung der Arbeits- und Lebensbedingungen im Kalibergbau machte deutlich, daß in diesem Wirtschaftsbereich noch keine Anreize für einen freiwilligen Arbeitsplatzwechsel bestanden. Da der Bedarf allerdings nicht die quantitativen Ausmaße erreichte wie im Braun- und Steinkohlenbergbau oder dem Erzbergbau, bestand für die Arbeitsverwaltung und die SMA offensichtlich keine Veranlassung, materielle Verbesserungen herbeizuführen und damit öffentlich zu werben.

\section{Arbeitskräfte für den Mansfelder Kupferbergbau}

Der Kupferbergbau gehörte wie der Uranbergbau zum Wirtschaftszweig Erzbergbau, genoß jedoch nicht die gleiche Aufmerksamkeit wie die Wismut AG. Ausgangspunkt für die Bereitstellung von Arbeitskräften durch die deutsche Arbeitsverwaltung war auch hier ein sowjetischer Befehl. Mit dem SMAD-Befehl Nr. 124 vom 29. April 1946 wurde die Erhöhung der Kupfergewinnung angeordnet. In dem Zusammenhang erhielt der Präsident der Provinz Sachsen die Anweisung, den „Betrieben des Mansfelder Seekreises“ insgesamt 7400 Arbeiter zur Verfügung zu stellen, darunter 5350 für Schachtarbeiten und 2050 für Fabrikationsarbeiten. Die Kommunalverwaltung sollte den ankommenden Arbeitskräften Unterkünfte anbieten sowie deren Transport zu den Arbeitsstätten sicherstellen ${ }^{321}$. In der Anlage zum Befehl Nr. 124 war ein detaillierter Plan für die Zuteilung von Arbeitskräften für den Zeitraum Mai bis Oktober 1946 angegeben, der vom Chef der Industrieverwaltung Georgi G. Alexandrow und dem Chef der Abteilung Arbeitskräfte P. J. Morenow unterzeichnet worden war ${ }^{322}$.

Das zuständige Arbeitsamt in Eisleben bemühte sich zwar, den Arbeitskräftebedarf rasch zu befriedigen. Die Mansfelder Werksleitung bemängelte aber, daß durch die „auf die Erfassung ehemaliger Betriebsangehöriger gerichtete Auskämmaktion [...] nur sehr wenig voll leistungsfähige für die Strebarbeit unter Tage und für gleichschwere Arbeit auf der Hütte geeignete Arbeitskräfte" gefunden worden wären ${ }^{323}$. Die Aufnahmefähigkeit der Betriebe für „minderleistungsfähige" Arbeiter sei „bis auf weiteres voll erschöpft“. Es müsse vermieden werden, daß die im Zuge der Auskämmung erfaßten Betriebe „aus der Gesamtzahl der bei

$319 \mathrm{BAB}, \mathrm{DQ} 2 / 2166$.

$320 \mathrm{BAB}, \mathrm{DQ} 2 / 2166, \mathrm{Bl} .9$, Stimmungsbericht vom 15. 9. 1947.

$321 \mathrm{BAB}, \mathrm{DQ} 2 / 2137$.

322 Ebenda.

323 $\mathrm{BAB}, \mathrm{DQ} 2 / 2137$, Vermerk zur Besprechung mit dem Amt für Arbeit und Sozialfürsorge Eisleben am 5. 7. 1946, S. 1 . 
ihnen beschäftigten ehemaligen Belegschaftsmitglieder der Mansfeld-Betriebe nur die älteren und minderleistungsfähigen abgeben, die jüngeren, darunter insbesondere die Häuer, dagegen zurückbehalten, wie dies bisher häufig geschehen ist" ${ }^{\text {"324. }}$ Zwischen dem Arbeitsamt und dem Bezirksarbeitsamt in Merseburg herrschte Einigkeit darüber, daß diese „Rückführung abgewanderter Belegschaftsmitglieder grundsätzlich nur auf freiwilliger Grundlage" erfolgen könne ${ }^{325}$. Gleichzeitig erhielt das Arbeitsamt die Erlaubnis, einen nicht näher definierten "gewissen Druck“ ausüben zu können, „weil andernfalls unter den derzeitigen Umständen mit einem Erfolg [...] überhaupt nicht zu rechnen" sei. Die Werksleitung hatte die Initiative ergriffen und eine zentrale Arbeitseinsatz-Leitstelle geschaffen. Unter Umgehung der Arbeitsbehörden strebte sie offensichtlich die Gewinnung neuer Arbeitskräfte in eigener Regie an. Wegen Binnenwanderung und Fluktuation war jedoch eine langfristige Planung 1946 noch nicht möglich: Obwohl die Auflagen der sowjetischen Besatzungsmacht nahezu erfüllt werden konnten, sank doch letztlich der Beschäftigtenstand wegen der nicht vorhersehbaren Abwanderung zu anderen Betrieben. So konnten zwischen März und Juni 2207 Arbeiter gewonnen werden. Da in diesem Zeitraum 998 Arbeiter abwanderten, reduzierte sich somit der Nettozugang auf 1209326. Dieser Trend schwächte sich bis zum Jahresende etwas ab, da der Arbeitskräftezugang stärker anstieg als der -abgang 327 . Flüchtlinge und Vertriebene kamen als zusätzliches Arbeitskräftepotential, das für Mansfeld zu gewinnen gewesen wäre, nur sehr begrenzt in Frage, da der Anteil der arbeitsfähigen Männer stellenweise weit unter dem Durchschnitt lag. In dem Quarantänelager Volkstedt, das rund 650 „Umsiedler" aufgenommen hatte, entsprachen nur 50 Personen den Einstellungsvoraussetzungen für den Bergbau ${ }^{328}$.

Es hat den Anschein, als ob der Kupferbergbau sowohl bei der SMAD als auch bei der DVAS bald wieder an Bedeutung verlor. Nachdem der Startschuß für den Ausbau der Produktion gegeben worden war, blieb es den betroffenen Arbeitsämtern überlassen, ausgebildetes Fachpersonal zur Verfügung zu stellen. Da auf diese Weise der wachsende Bedarf nicht zu befriedigen war, wandte sich die Werksleitung im Sommer 1947 hilfesuchend an die DVAS, die es allerdings ablehnte, 2000 Bergarbeiter zuzuweisen ${ }^{329}$. Zu diesem Zeitpunkt genoß bereits die Erfüllung der Auflagen für den sächsischen Erzbergbau oberste Priorität. Die SMAD-Abteilung Arbeitskraft nahm dies nur zur Kenntnis und griff in die Auseinandersetzung vorerst nicht ein. Das änderte sich mit dem SMAD-Befehl Nr. 0313 vom 9. September 1947: Demnach hatte der Präsident der DVAS innerhalb von zwölf Tagen „2000 körperlich gesunde und für die Untertagearbeiten taugliche Arbeiter" für das Kupferkombinat Mansfeld zu stellen ${ }^{330}$. Bis zum Jahresende konnten

32+ Ebenda, S. 1 f.

325 Ebenda, S. 2.

326 Ebenda, S. 4.

$327 \mathrm{BAB}, \mathrm{DQ} 2 / 2137$, Bericht über die Arbeit der Berg- und Hüttenbetriebe der Mansfelder Kupferschieferbergbau AG im Monat November 1946, S. 2.

328 Ebenda, Vermerk zur Besprechung mit dem Amt für Arbeit und Sozialfürsorge Eisleben am 5. 7. 1946, S. $4 \mathrm{f}$.

32") $\mathrm{BAB}, \mathrm{DQ} 2 / 2040$, Bl. 66, Niederschrift der DVAS-Abt. I b über die Besprechung mit der SMAD in Karlshorst am 30.6. 1947.

$330 \mathrm{BAB}, \mathrm{DQ} 2 / 2017$. 
jedoch nur 1237 Personen eingestellt werden ${ }^{331}$. Ein Vertreter des Landesamtes für Arbeit und Sozialfürsorge in Halle/Saale wies anläßlich der Arbeitstagung am 6./7. Januar 1948 in Leipzig darauf hin, daß die Gewinnung von neuen Arbeitskräften erschwert werde durch die schlechten Unterbringungsmöglichkeiten sowie die festgesetzten Löhne und Verpflegungssätze, die den übrigen Bergbaubereichen nicht angeglichen worden seien ${ }^{332}$. Die DVAS wurde aufgefordert, Verhandlungen mit Karlshorst aufzunehmen, um auch für die Bergarbeiter in Mansfeld günstigere Arbeitsbedingungen zu schaffen. Nur so sei es möglich, die Freiwilligenwerbung erfolgreich abzuschließen. Da sich die SMAD mit der Anzahl der gewonnenen Arbeitskräfte, die unterhalb der Vorgabe lag, zufrieden gab, stieß der Vorschlag des Landesamtes ins Leere.

Gleichzeitig beauftragte die SMAD die DVAS mit der Überprüfung der wohnlichen Unterbringung der zugewanderten Arbeiter. Darüber hinaus sollte ein Bericht über die Ursachen der Fluktuation erstellt werden. Anfang 1948 veranlaßte die SMA von Sachsen-Anhalt die Zuteilung von insgesamt 1600 Arbeitskräften für den Mansfelder Kupferschieferbergbau und eine Angleichung der Löhne der Mansfelder Bergarbeiter an die der Braunkohlenarbeiter ${ }^{33}$. Als eigentliches Hindernis für eine zügige Arbeitskräftelenkung erwies sich aber auch hier die Wohnraumfrage ${ }^{334}$. Ein schlüssiges Konzept konnten weder die deutschen Verwaltungen noch die sowjetische Besatzungsmacht vorlegen - angesichts des Zerstörungsgrades infolge des Z weiten Weltkrieges war dies in der unmittelbaren Nachkriegszeit nicht weiter verwunderlich. Im übrigen herrschte die Mangelsituation auf dem Wohnungsmarkt keineswegs nur in der SBZ, sondern betraf ebenso die drei westlichen Besatzungszonen. Da zonale Lösungsvorschläge fehlten, waren auch in dieser Frage die Landesverwaltungen aufgefordert, provisorische Pläne auszuarbeiten. Dies geschah oftmals in enger Absprache mit der Kommunalverwaltung und vor allem mit der SMA. Gemeinsame Besprechungen zwischen allen Beteiligten dienten daher zunächst einmal dem Ideenaustausch: Nach den Vorstellungen von Major Wachnin (SMA der Provinz Sachsen) sollte die Zuweisung von Arbeitskräften sukzessive erfolgen: „[S]obald Wohnungen freigemacht sind, müssen auch die Arbeitskräfte gestellt werden." ${ }^{335}$ Dagegen sprachen sich Vertreter der DVAS dafür aus, die Wohnsitze derjenigen Arbeiter zu verlegen, die in Leuna und Buna beschäftigt waren, ihren Wohnsitz aber in Eisleben hatten. Dadurch könnten Unterbringungsmöglichkeiten für zuziehende Bergarbeiter geschaffen und das Transportnetz entlastet werden. Dabei wurde allerdings nicht berücksich-

${ }_{331} \mathrm{BAB}, \mathrm{DQ} 2 / 1711$, Niederschrift über die Besprechung mit der SMAD in Karlshorst am 23.12. 1947, S. 1 .

332 BAB, DQ 2/1537, Niederschrift von der DVAS-Abt. I b über die Tagung, S. 24.

${ }_{333} \mathrm{BAB}, \mathrm{DQ} 2 / 498, \mathrm{Bl} .219$, Bericht der DVAS-Abt. I b über die Besprechungen in Eisleben am 9. 1. 1948.

${ }^{334}$ Im Mansfelder Gebirgskreis wurden 10,2 qm Wohnraum pro Kopf der Bevölkerung registriert, im Mansfelder Seekreis 8,3 qm und in der Stadt Eisleben 7,3 qm (Stichtag: 31. 12. 1947). Diese Werte entsprachen nach Einschätzung der DVAS-Abt. IV (Abschnitt Wohnung und Siedlung) ungefähr den Durchschnittszahlen der SBZ und wurden "nicht als besonders besorgniserregend" eingestuft. Die Wohnungsnot in Eisleben ergab sich vielmehr dadurch, daß zahlreiche Wohnungen feucht und somit eigentlich unbewohnbar waren. Ein Ansteigen der Seuchenerkrankungen in der Stadt wurde darauf zurückgeführt. Vgl. BAB, DQ 2/1582, Aktenvermerk Bohlmanns vom 25. 3. 1948.

$335 \mathrm{BAB}, \mathrm{DQ} 2 / 498, \mathrm{Bl} .220$. 
tigt, daß die Mobilität von Arbeitern mit Familien stärker begrenzt war als die von Alleinstehenden. Zusätzlichen Wohnraum erhofften sich die deutschen Verwaltungen im Falle des Mansfelder Kupferbergbaus dadurch, daß Parteischulen der SED sowie die ehemalige Bergbauschule, die von Einheiten der Roten Armee belegt worden war, zur Verfügung gestellt würden. Weniger realistisch erschien die Zusage der sowjetischen Besatzungsbehörde, "mehr zusammenzurücken, um so verschiedene Häuser für die Unterbringung von Bergarbeitern freizumachen “ 336 . Des weiteren wurde in Eisleben eine Kommission aus Vertretern der Parteien, des FDGB und der Kommunalverwaltung gebildet, die „Wohnbegehungen“ durchführen sollte, um festzustellen, „inwieweit Familien bereit sind, ledige Bergarbeiter aufzunehmen “ ${ }^{337}$. Das sogenannte Kostgängersystem, das bereits vor 1945 weit verbreitet gewesen war, sollte auf diese Weise wieder aufgegriffen und mit propagandistischer Unterstützung ausgebaut werden.

$\mathrm{Da}$ an eine schnelle Besserung der Arbeits- und Lebensbedingungen nicht zu denken war, setzte sich die bereits zuvor registrierte Abwanderung von Arbeitern zum Kohlenbergbau noch weiter fort ${ }^{338}$. Im Dezember 1945 hatte die Gesamtbelegschaft im Mansfelder Kupferbergbau 5750 Personen umfaßt $t^{339}$. Nach Angaben des Arbeitsamtes in Eisleben waren zwischen März 1946 und März 194810345 Arbeitskräfte zugewiesen worden. Im Frühjahr 1948 lag die Zahl der Beschäftigten bei 12023 Personen, d.h. 4072 Arbeiter hatten in der Zwischenzeit ihren Arbeitsplatz gewechselt. Rund 25 Prozent der durch die Arbeitsämter vermittelten Personen waren somit abgewandert. Darüber hinaus ist auf die Heterogenität der beruflichen Qualifikationen der Arbeiter aufmerksam zu machen. Unter den 2549 Arbeitskräften, die aufgrund des Befehls Nr. 0313 neu eingestellt worden waren, befanden sich nur 123 Bergleute. Die größte Gruppe machten die Handwerker aus (1010), gefolgt von ungelernten Arbeitskräften (809), arbeitslosen Jugendlichen (385), Angestellten (127) sowie Landwirten (95) ${ }^{340}$.

Die Arbeitsverwaltung schätzte die Altersstruktur der Belegschaft beim Mansfelder Kupferbergbau als „äußerst ungünstig“ ein ${ }^{341}$. Nach Angaben des HVASMitarbeiters Krüger betrug das Durchschnittsalter 53 Jahre ${ }^{342}$. Damit bestätigte sich der Eindruck, der auch in den anderen Zweigen des Bergbaus gewonnen worden war. Der Betriebsleitung wurde vorgehalten, zu wenig unternommen zu haben, um „eine Ausbildung junger Kräfte durchzuführen." Im Frühjahr 1948 standen rund 500 Personen in einem Ausbildungsverhältnis. Krüger vermutete, daß „durchaus die doppelte Zahl beschäftigt werden könnte.“ Auffallend war jedoch insgesamt die Tatsache, daß die Gruben noch 1948 überhaupt nicht auf die massenhafte Neueinstellung vorbereitet waren. Es fehlte nicht nur ausreichende

336 Ebenda, Bl. 219.

337 Ebenda, Bl. 220.

338 $\mathrm{BAB}, \mathrm{DQ} 2 / 2137$, Bericht der DVAS-Abt. I b über Verhandlungen in Eisleben am 9. 1. 1948, S. 2.

339 BAB, DQ 2/1582, Zwischenbericht der Unterkommission über Fragen der Arbeitsorganisation, Leistungsfähigkeit und Arbeitskraft vom 5. 5. 1948, S. 1.

340 Ebenda.

341 BAB, DQ 2/1582, Bericht des Arbeitsamtes Eisleben über eine Besprechung mit Vertretern der HVAS und des Ministeriums für Arbeit und Sozialpolitik von Sachsen-Anhalt in Eisleben am 14. 4. 1948, S. 1.

342 BAB, DQ 2/2040, Bl. 128, Niederschrift der HVAS-Abt. I über die am 22. 5. 1948 stattgefundene Besprechung bei der SMAD. 
Arbeitsschutzkleidung; die Schachtanlagen waren technisch so schlecht ausgestattet, daß der in den Befehlen und Plänen anvisierte rasche Anstieg der Fördermenge überhaupt nicht verwirklicht werden konnte ${ }^{343}$. Während die Besatzungsmacht und die deutsche Arbeitsverwaltung die Unterbringung der zugeteilten Arbeitskräfte monierten, klagten die Gruben über die mangelhafte technische Ausstattung, die einer Produktionssteigerung im Wege stand.

Auf Veranlassung der SMAD-Abteilung Arbeitskraft erstellten Mitarbeiter der HVAS im Frühjahr 1948 einen ausführlichen Bericht über das Mansfelder Kombinat, in dem unter anderem die berufliche Ausbildung sowie die Zusammensetzung der Belegschaft thematisiert wurde ${ }^{344}$. Demnach setzte sich die Belegschaft ungefähr zu einem Drittel aus Stammarbeitern zusammen, die bereits vor $1945 \mathrm{im}$ Bergbau gearbeitet hatten, während zwei Drittel berufsfremd waren ${ }^{345}$. Die Tatsache, daß sich unter der Gesamtbelegschaft nur ein Drittel Stammarbeiter befanden, hing vermutlich mit dem Ende des Zweiten Weltkrieges und dem rapiden Produktionsabfall bzw. teilweise auch dem Produktionsstopp zusammen. Die Betriebsleitung hatte einen erheblichen Teil der Stammbelegschaft entlassen müssen, da finanzielle Mittel für die Weiterführung der Anlagen nicht zur Verfügung standen. Als dann kurze Zeit später die Kupfergewinnung wieder erhöht werden sollte, war es kaum noch möglich, die alten Belegschaftsmitglieder wieder zu gewinnen: Viele waren in der Zwischenzeit abgewandert oder hatten sich eine andere Beschäftigung gesucht. Daher waren die Arbeitsämter gezwungen, den $\mathrm{Be}-$ darf an Arbeitskräften aus anderen Berufsgruppen zu gewinnen. Darüber hinaus fanden wohl auch eine ganze Reihe von "Umsiedlern“ einen Arbeitsplatz im Mansfelder Kupferbergbau; dazu existieren jedoch für diesen Zeitpunkt keine genauen quantitativen Angaben. Da die Anzahl der qualifizierten Fachkräfte im Werk gering war und auf dem Arbeitsmarkt Facharbeiter für den Bergbau nur sehr begrenzt zur Verfügung standen, mußte die innerbetriebliche Arbeitsorganisation effizienter gestaltet werden. So mahnten die Berichterstatter an, daß qualifizierte Häuer nicht mit „Dienstleistungen“ belastet werden dürfen ${ }^{346}$, sondern nur als Streb- und Zimmerhäuer einzusetzen seien, die in dieser Funktion auch die Ausbildung des Nachwuchses zu übernehmen hätten ${ }^{347}$.

Sowohl die Frage der wohnlichen Unterbringung zugewiesener Arbeitskräfte als auch das Problem der betrieblichen Ausbildung von Facharbeitern ließ sich für die mittlerweile gebildete VVB Mansfeld bis zur DDR-Gründung nicht zufriedenstellend lösen. Langfristig war zwischen HVAS, dem zuständigen Landesamt sowie der Werksleitung geplant, in unmittelbarer Nähe zum Betriebsgelände Wohnungen für die Beschäftigten und deren Familien bereitzustellen. Bis zur vollständigen Realisierung dieses Wohnprogramms sprachen sich alle beteiligten

${ }^{3+3}$ Vgl. BAB, DQ 2/1582, Bericht des Arbeitsamtes Eisleben über eine Besprechung mit Vertretern der HVAS und des Ministeriums für Arbeit und Sozialpolitik von Sachsen-Anhalt in Eisleben am 14. 4. 1948, S. $1 \mathrm{f}$.

${ }^{344} \mathrm{BAB}, \mathrm{DQ} 2 / 137, \mathrm{Bl}$. 226-249, Untersuchungsbericht mit einem Anschreiben der HVAS an die SMAD-Abt. Arbeitskraft (Morenow) vom 26. 5. 1948.

${ }^{345}$ Zum folgenden: ebenda, Bl. 235.

346 Ebenda, Bl. 233.

${ }_{347}$ Ebenda, Bl. 231. 
Verwaltungen für eine behelfsmäßige Unterbringung aus ${ }^{348}$. In dem Zusammenhang wurde die Kommunalverwaltung angewiesen, ihre Propagandatätigkeit zur Bereitstellung von Wohnraum zu intensivieren. Die Unterbringung von Arbeitern, „die zur Erfüllung des Plansolls aus anderen Gebieten herangeführt werden müssen, [dürfe] nicht an der Zuweisung von geeigneten Wohnräumen scheitern“, so das Ministerium für Wirtschaft und Verkehr von Sachsen-Anhalt ${ }^{349}$. Daneben existierte auch im Frühjahr 1949 ein Bedarf an qualifiziertem Personal. Die Arbeitsämter konnten beispielsweise gelernte Häuer nicht mehr zuteilen, so daß sich die VVB Mansfeld bereit erklärte, „ungelernte Kräfte sowie Arbeitskräfte aus anderen Berufsgruppen aufzunehmen" 350 . Einzige Voraussetzung blieb aber nach wie vor die Feststellung der Bergbautauglichkeit durch einen der Betriebsärzte. Erst danach durften die neu gewonnenen Arbeiter in das Umschulungsprogramm aufgenommen werden.

Bis Ende 1948 hielt die Abwanderung vom Mansfelder Kupferbergbau unvermindert an, schwächte sich dagegen zu Beginn des Jahres 1949 deutlich ab ${ }^{351}$. So wurden dem Werk im Oktober 1948 insgesamt 192 Personen zugewiesen; gleichzeitig verließen 118 Personen den Betrieb. Der effektive Zugang betrug somit 74 Personen und sank im Dezember auf 64. In diesem Monat wurden 168 Arbeiter neu eingestellt, während 104 wieder abwanderten. Im Januar 1949 war die Wanderungsbewegung aus Sicht der Betriebsleitung relativ günstig: Das Arbeitsamt registrierte 302 zugewiesene Arbeiter, und die Betriebsleitung meldete 99 Abgänge. Die SMAD erhöhte nochmals die Zahl der Arbeitskräfte, die dem Kombinat Mansfeld durch die Arbeitsämter zuzuweisen waren: In einer Anlage zum Befehl Nr. 40 vom 11. April 1949 wurde festgelegt, daß im Laufe des Jahres 1949 weitere 1400 Arbeitskräfte neu eingestellt werden sollten ${ }^{352}$. Bis Ende April konnten bereits 1050 Arbeiter, das entsprach der angeforderten Summe für das erste Halbjahr, in Mansfeld überwiegend untertage eingesetzt werden ${ }^{353}$. Nach Einschätzung des Ministeriums für Arbeit und Sozialpolitik von Sachsen-Anhalt würde jedoch der Bedarf des Mansfelder Kupferbergbaus im dritten Quartal unter der von der SMAD geforderten Menge von 350 liegen. Damit wurde letztlich deutlich, daß nicht der Arbeitskräftemangel die Ursache für die Nichterfüllung der Produktionspläne war, sondern das Fehlen von Facharbeitern ${ }^{354}$. Aufschlußreich war außerdem, daß die beiden Arbeitsämter in Eisleben und Hettstedt, die für die Bereitstellung von Arbeitskräften für Mansfeld zuständig waren, von einer Auf-

${ }^{348}$ BAB, DQ 2/2132, Protokoll über die Sitzung am 14.3. 1949 im Verwaltungsgebäude der VVB Mansfeld, S. 3.

${ }^{349}$ Ebenda, Ministerium für Wirtschaft und Verkehr (HA Bauwesen) in Halle/Saale am 23. 3. 1949 an die HVAS.

350 Ebenda, S. 1.

351 BAB, DQ 2/156, Bl. 104, Aktennotiz der HVAS-Abt. I a vom 18. 3. 1949.

352 Die Anlage zum SMAD-Befehl Nr. 40 war vom Leiter der Verwaltung der Metallurgischen und Chemischen Industrie der SMAD, Alexander S. Boleuch, unterzeichnet worden. Demzufolge sollten im ersten Quartal 250, im zweiten Quartal 800 und im dritten Quartal 350 Arbeiter gewonnen werden. $\mathrm{BAB}, \mathrm{DQ} 2 / 2132$.

353 BAB, DQ 2/2132, Ministerium für Arbeit und Sozialpolitik der Landesregierung Sachsen-Anhalt am 6. 5. 1949 an die HVAS.

354 Ebenda, Notiz der HVAS (Donau) vom 4. 8. 1949. 
lage für den sächsischen Erzbergbau befreit wurden ${ }^{355}$. Aus Sicht der Mansfelder Betriebsleitung sah die Arbeitskräftelage jedoch nicht so rosig aus, da aufgrund der im Sommer wieder angestiegenen Abwanderung der effektive Zugang eher geringer geworden war ${ }^{356}$. Im Juli entsprach die Zahl der Zuwanderung sogar der der Abwanderung. Die Arbeitsverwaltung wurde deshalb aufgefordert, in $\mathrm{Zu}$ kunft Kündigungen nicht mehr ohne weiteres zu genehmigen.

\section{Arbeitskräfte für die Eisenbütten- und Stablwerke}

Zwischen 1945 und 1949 war dieser Wirtschaftszweig aus Sicht der Arbeitsverwaltung zunächst noch von sekundärer Bedeutung. Dies hing mit den Anforderungen für die sowjetische Besatzungsmacht, besonders für den Uranbergbau, aber auch mit den Demontagen und der daher verspätet anlaufenden Produktion in den Eisenhütten- und Stahlwerken zusammen. Darüber hinaus bestanden vor dem ersten Fünfjahrplan noch nicht so zahlreiche Werke; diese wurden vielmehr erst ab Anfang der fünfziger Jahre in einer großen Kraftanstrengung neu aufgebaut. Zu den wenigen Unternehmen, die bereits kurz nach Kriegsende ihre Tätigkeit wieder aufnahmen, gehörte das Eisenhüttenwerk Thale (Harz). Die Wiederaufnahme der Produktion ging zurück auf eine Anweisung von seiten der sowjetischen Besatzungsmacht. Innerhalb kürzester Zeit sollte das Provinzialamt für Arbeit der Provinz Sachsen 340 Arbeitskräfte zusammenstellen ${ }^{357}$. Nachdem sich das Provinzialamt vergeblich an die Landesarbeitsämter von Sachsen und Brandenburg gewandt hatte - eine telegraphische oder telefonische Verbindung war offensichtlich nicht herzustellen - schaltete Sachsen-Anhalt die ZVAS ein und bat um Unterstützung: Die beiden Landesarbeitsämter sollten angewiesen werden, "freiwerdende ausgleichsfähige Arbeitskräfte" zuzuweisen ${ }^{358}$.

Eine rasche Lösung der Wohnraum- und Transportfrage, die bisher bei sämtlichen Zweigen der Grundstoffindustrie relevant gewesen war und oftmals eine bedarfsgerechte Steuerung der Arbeitskräfte behindert hatte, schien sich für das Werk Thale überraschenderweise sehr frühzeitig anzudeuten. So hatte der Magistrat der Stadt Halberstadt das Gelände und die Anlagen der Firma Junkers Halberstadt mit dem Ziel angeboten, daß das Eisenhüttenwerk dort einen Zweigbetrieb errichten würde ${ }^{359}$. Die Betriebsleitung von Thale, die selbst an einer Expansion interessiert war, griff diesen Vorschlag zunächst auf, da sich dadurch die oben angesprochenen Hindernisse im Vorfeld bereits ausräumen lassen konnten. Sie sah darin allerdings nur eine längerfristige Perspektive und strebte kurzfristig die Einstellung neuer Arbeitskräfte aus Halberstadt an, für die ein Pendelverkehr eingerichtet werden sollte. Sobald die Blecherzeugung in Thale steige, werde man die Eröffnung eines weiteren Werkes in Halberstadt „ernstlich ins Auge fassen“, so

355 Ebenda.

356 BAB, DQ 2/2132, VVB Mansfeld am 9. 8. 1949 an die HVAS.

357 BAB, DQ 2/2161, Provinzialamt für Arbeit von Sachsen-Anhalt am 19. 10. 1945 an die ZVAS.

358 Ebenda.

359 SAPMO, DY 30/IV 2/6.02/22, Bl. 19, Vermerk des Chefdirektors der Eisen- und Hüttenwerke Thale, Rudolf Kögl, über eine Besprechung mit dem Geschäftsführer der Wirtschaftskammer Halberstadt Dr. Skop am 10. 11. 1945 in Halberstadt. 
Chefdirektor Kög1360. Der Vorstand der Eisen- und Hüttenwerke Thale richtete sein Anliegen auch direkt an das zuständige Arbeitsamt in Halberstadt und bat darum, „die Frage der Zuweisung von Arbeitskräften aus Halberstadt noch einmal zum Gegenstand einer eingehenden Untersuchung zu machen "361. Eine erste Absprache hatte offensichtlich nicht den erhofften Erfolg gezeigt, d. h. eine Zuteilung von Arbeitern war noch nicht erfolgt.

Versuche der ZVAS, aus dem stillgelegten Hüttenwerk Hennigsdorf Arbeitskräfte für Thale gewinnen zu können, scheiterten wiederum an der sowjetischen Besatzungsmacht. So berichtete das dortige Arbeitsamt: „Die im hiesigen Amtsbezirk vorhandenen Fachkräfte aus der Eisenhüttenbranche sind bis auf weiteres restlos von der russischen Abrüstungskommission für Demontagearbeiten eingesetzt. “"362 Ein Abzug dieser Facharbeiter könne nicht erfolgen, „da wegen Mangel an Arbeitskräften kein Ersatz gestellt werden kann." Daraufhin wollte die Zentralverwaltung der Industrie bei der SMAD in Karlshorst intervenieren, um die Freigabe der Hennigsdorfer Arbeiter zu erreichen ${ }^{363}$. Obwohl das Werk in Hennigsdorf auf der Demontageliste stand und die Produktion gestoppt worden war, mußten sich auf Anweisung der sowjetischen Besatzungsmacht die dort verbliebenen 454 Arbeiter ${ }^{364}$ für die bevorstehende Wiederaufnahme der Produktion bereithalten. Darüber hinaus war nach Informationen der Berliner Zentralverwaltung ein großer Teil „befähigter früherer Werksangehöriger“ beim Einmarsch der Roten Armee nach Westdeutschland abgewandert ${ }^{365}$. Die Demontage des Werkes Hennigsdorf zog sich bis 1947 hin: Der Wiederaufbau begann erst am 14. Oktober 1947, nachdem das Werk zwei Wochen zuvor in einen Volkseigenen Betrieb umgewandelt worden war ${ }^{366}$. Der Abstich des ersten von insgesamt vier vorgesehenen Siemens-Martin-Öfen erfolgte am 12. März 1948. Die SMAD verfolgte kritisch die Wiederaufnahme der Produktion ${ }^{367}$ und legte auch Zahlen bei der Arbeitskräftezuweisung fest ${ }^{368}$. Somit blieb ein Austausch von Facharbeitern zwischen den einzelnen Eisen- und Walzwerken weiterhin aussichtslos. Das Werk in Hennigsdorf wurde offensichtlich völlig überhastet aufgebaut; nur so läßt sich die Kritik an der Qualität der ausgelieferten Stahl- und Blecherzeugnisse erklären ${ }^{369}$. Die Produktions- und Arbeitsweise innerhalb des Betriebes mußten daher rasch verbessert werden, um den Ansprüchen der sowjetischen Besatzungsmacht gerecht werden zu können, deren vorgegebene Zeitplanung aber offenbar zu knapp

360 Ebenda.

361 Ebenda, Bl. 31, Vorstand der Eisen- und Hüttenwerke Thale am 23.11. 1945 an das Arbeitsamt in Halberstadt.

$362 \mathrm{BAB}, \mathrm{DQ} 2 / 2161$, Arbeitsamt Hennigsdorf am 7.11. 1945 an die ZVAS.

${ }_{363}$ Ebenda, Vermerk der ZVAS-Abt. II (Erfassung und Arbeitseinsatz) vom 4. 12. 1945.

${ }^{364}$ Ebenda, Vermerk der ZVAS-Abt. II vom 7. 12. 1945.

${ }_{365} \mathrm{BAB}, \mathrm{DQ} 2 / 1788, \mathrm{Bl}$. 72-74, hier Bl. 72, Aktennotiz der ZVAS-Abt. II b vom 5. 12.1945.

366 SAPMO, DY 34/21433, Notiz der HA II (Statistik) vom 24. 4. 1948.

367 SAPMO, NY 4182/1189, Bl. 44-47, Schreiben des Leiters der Metallurgieverwaltung der SMAD, Alexander S. Boleuch, an den stellvertretenden SED-Vorsitzenden Walter Ulbricht (vermutlich August 1949).

368 BAB, DQ 2/511, Protokoll der Besprechung beim Stellvertreter des Obersten Chefs der SMAD, Kowal, am 28. 10. 1948, S. 3 f.

${ }^{369}$ Einige Zuliefererbetriebe mußten ihre Arbeit einstellen, da sie das von Hennigsdorf produzierte Walzmaterial nicht weiter verwenden konnten. SAPMO, NY 4182/988, Bl. 2, Mitteilung der Instrukteurgruppe des Parteivorstandes vom 3. 8. 1949 an das Kleine Sekretariat. 
bemessen gewesen war. Bei dieser nachträglichen, primär organisatorischen und verwaltungstechnischen Ausbesserung, die immer stärker mit einer gezielten Kaderpolitik verbunden wurde, schaltete Walter Ulbricht die SED-Landesleitung sowie die SED-Betriebsleitung ein ${ }^{370}$.

Das Problem, ausreichenden Wohnraum für die zuziehenden Arbeiter und deren Familien zur Verfügung zu stellen, wurde schließlich dadurch verschärft, daß Ende 1945 Vertriebenentransporte nach Thale angekündigt wurden. Deren wohnliche Unterbringung mußte nunmehr mit berücksichtigt werden. Die Provinzialverwaltung versuchte zusammen mit Vertretern des Eisenhüttenwerkes, des Buna-Werkes in Schkopau und des Leuna-Werkes Lösungsvorschläge zu erarbeiten $^{371}$. Letztlich erhöhte sich der Handlungsdruck für die staatlichen Verwaltungen, der dazu führte, daß provisorische Regelungen verstärkt in den Mittelpunkt gelangten. Auf- und Ausbau von Barackenlagern hieß daher die folgerichtige Konsequenz. Dagegen zeigten sich die einzelnen Betriebsleitungen jedoch reserviert gegenüber der Idee, den Bedarf an Arbeitskräften auch aus den „Umsiedler“Transporten abzudecken. Aus Sicht des Provinzialamtes für Arbeit und Sozialfürsorge von Sachsen-Anhalt war dies jedoch zum gegenwärtigen Zeitpunkt die einzige Möglichkeit, zusätzliche Arbeitskräfte zu gewinnen, da der überbezirkliche Ausgleich noch nicht durchgeführt werden konnte ${ }^{372}$.

Der Arbeitskräftemangel hing zu einem geringeren Teil auch mit der Entnazifizierung in der SBZ ${ }^{373}$ zusammen, der sich in diesem Wirtschaftszweig besonders beim hochqualifizierten Fachpersonal bzw. den leitenden Angestellten bemerkbar machte, die aufgrund ihrer früheren Mitgliedschaft in der NSDAP entlassen worden waren und nunmehr bei der Wiederaufnahme der Produktion fehlten. Die ZVAS wurde von seiten der Betriebsleitungen frühzeitig auf diese Problematik hingewiesen und setzte sich dafür ein, eine pragmatische Lösung zu finden. Die Berliner Zentralverwaltung betonte zwar, daß man es sich „auf Dauer gesehen unmöglich leisten [könne], qualifizierte Fachkräfte nur deswegen von dem Wiederaufbau unseres Vaterlandes auszuschließen, weil sie der NSDAP als nominelle Mitglieder angehört haben" 374 . Eine allgemeine und sofortige Wiedereingliederung in das Berufsleben wurde damit allerdings nicht befürwortet ${ }^{375}$. Statt dessen wurde eine differenzierte Behandlung ehemaliger NSDAP-Mitglieder favorisiert.

Unterdessen stieg der Arbeitskräftebedarf in Thale weiter an: Die Betriebsleitung gab den Sofortbedarf Mitte Februar 1946 mit 967 Arbeitern an und bat das Arbeitsamt in Aschersleben (Nebenstelle Thale) um „schnellste Zuweisung“ der angeforderten Stahl- und Walzwerker ${ }^{376}$. Die ZVAS versuchte in Zusammenarbeit

370 SAPMO, NY 4182/1189, Bl. 44, SED-Hausmitteilung Ulbrichts an Stoph vom 19. 8. 1949.

371 LA Magdeburg LHA, Rep. K MW, Nr. 10576, Bl. 19-21, Protokoll der Sitzung am 5. 12. 1945.

$372 \mathrm{BAB}, \mathrm{DQ}$ 2/2161, Provinzialamt für Arbeit und Sozialfürsorge am 19. 2. 1946 an den Präsidenten der Zentralverwaltung der Industrie.

373 Vgl. allgemein dazu: Meinicke, Zur Entnazifizierung in der sowjetischen Besatzungszone; Melis, Entnazifizierung in Mecklenburg-Vorpommern; Welsh, Revolutionärer Wandel; dies., "Antifaschistisch-demokratische Umwälzung " und politische Säuberung; Wille, Entnazifizierung in der SBZ.

${ }^{374} \mathrm{BAB}, \mathrm{DQ}$ 2/1788, Bl. 80-85, hier Bl. 81, Bericht eines ZVAS-Mitarbeiters vom 8. 1. 1946.

375 Ebenda, B1. 83.

$376 \mathrm{BAB}, \mathrm{DQ} 2 / 2161$, Eisen- und Hüttenwerke Thale am 14. 2. 1946 an das Arbeitsamt Aschersleben (Nebenstelle Thale). 
mit anderen wirtschaftlichen Zentralverwaltungen, das Problem der bedarfsgerechten und rechtzeitigen Arbeitskräftelenkung zu lösen. Dies galt für nahezu sämtliche Großvorhaben, nicht nur für das Eisen- und Hüttenwerk Thale, dessen Bedeutung vor allem daraus resultierte, daß es das einzige Feinblechwalzwerk in der SBZ war ${ }^{377}$. Bei der Versorgung mit Arbeitskräften stand aber auch dieses Werk in Konkurrenz zu anderen Projekten. Pragmatische Lösungen, wie etwa der Austausch von Facharbeitern zwischen Hennigsdorf und Thale, verhinderte oftmals die sowjetische Besatzungsmacht, die eigene Interessen verfolgte. So konnten Ende Februar die Arbeiter, die von Hennigsdorf freigestellt worden waren, immer noch nicht vermittelt werden, weil die dortige Kommandantur diesem Arbeitsplatzwechsel ihre Zustimmung nicht geben wollte ${ }^{378}$. Die Überlegung, Arbeitskräfte für Thale aus anderen Betrieben zu gewinnen, beschränkte sich keineswegs nur auf Hennigsdorf, sondern erstreckte sich auch auf andere Werke, so etwa die beiden Stahlwerke in Gröditz und Riesa. Während die Leitung der sowjetischen Demontageabteilung in Riesa eine Bereitstellung von Arbeitskräften vor Abschluß der Demontagen kategorisch ablehnte, willigte der sowjetische Werkskommandant in Gröditz einem entsprechenden Antrag letztlich zu ${ }^{379}$. Die SMAD in Karlshorst hielt den Austausch von Arbeitskräften zwischen Riesa und Thale prinzipiell „für sehr schwierig“ und empfahl der DVAS, persönliche Verhandlungen mit beiden Betrieben aufzunehmen ${ }^{380}$.

Auch wenn der Zuzug von Arbeitern mit ihren Familien zunächst stark eingeschränkt werden konnte, so ließ sich diese Politik doch nicht lange durchhalten. Die DVAS befürchtete ansonsten ein Abfallen der Arbeitsleistung sowie ein Abwandern der Arbeitskräfte ${ }^{381}$. Die Betriebsleitung und die kommunale Verwaltung hatten sich frühzeitig dafür ausgesprochen, „die in Thale befindlichen evakuierten Personen, soweit sie nicht bereits auf dem Werk eingesetzt sind, nach auswärts" zu überführen, um dadurch neuen Wohnraum zu gewinnen ${ }^{382}$. Eine diesbezügliche Anordnung war vom sowjetischen Kreiskommandanten wieder zurückgezogen worden, nachdem zahlreiche Klagen von seiten der Betroffenen eingegangen waren. Daraufhin ordnete der Kreiskommandant an, die zuziehenden Arbeiter in Unterkünfte einzuweisen, ohne Aussiedlungen vorzunehmen. Er vertrat den Standpunkt, daß bei einer „energischen Durchkämmung noch genügend Wohnraum " für eine breite Familienunterbringung vorhanden sei, was von seiten der deutschen Verwaltung stark in Zweifel gezogen wurde. Die SMA von Sachsen-Anhalt sah keine Notwendigkeit, Arbeiter zusammen mit deren Familien nach Thale ziehen zu lassen, weigerte sich allerdings, in dieser Frage eine Entscheidung zu treffen. Ein sowjetischer Offizier formulierte die Position der Besat-

$377 \mathrm{BAB}, \mathrm{DO} 2 / 30, \mathrm{Bl} .74-82$, Protokoll über die von der Zentralverwaltung der Industrie einberufene Konferenz am 15. 3. 1946.

$378 \mathrm{BAB}, \mathrm{DQ} 2 / 546$, Aktenvermerk über Besprechung mit Vertretern der Zentralverwaltungen Industrie, Brennstoff, Land- und Forstwirtschaft, Handel und Versorgung am 22. 2. 1946.

379 SächsHStA, Landesregierung Sachsen, Ministerium für Arbeit und Sozialfürsorge, Bd. 208, Bericht des Landesarbeitsamtes Sachsen über Vorsprache bei den Mitteldeutschen Stahlwerken in Riesa und Gröditz am 27. 2. 1946.

$380 \mathrm{BAB}, \mathrm{DQ} 2 / 1, \mathrm{Bl}$. 29, Aktenvermerk über Verhandlungen mit der SMAD (Schaposchnikow) am 14. 1.1947 .

381 BAB, DQ 2/961, Vermerk der DVAS-Abt. II vom 9. 4. 1946 an Präsident Gundelach.

382 Ebenda. 
zungsmacht folgendermaßen: „Ihn interessiere vor allem, daß das Werk auf jeden Fall die benötigten Arbeiter bekommt und dafür müßten wir [DVAS] mit allen uns zu Gebote stehenden Mitteln sorgen.“383

Über die Zahl der vorgenommenen Arbeitsverpflichtungen für Thale liegen keine Angaben vor. Fest steht nur, daß auch bei diesem Werk Zwangseinweisungen durchgeführt wurden. So reagierte die Betriebsleitung auf Beschwerden einzelner eingewiesener Arbeiter aus Brandenburg, die sich hilfesuchend an das dortige Landesarbeitsamt gewandt hatten. Die Direktion des Eisen- und Hüttenwerkes Thale wies die vorgebrachte Kritik zurück, die sich in erster Linie auf die Aufnahmemodalitäten, die wohnliche Unterbringung sowie Fragen der Fahrtkostenerstattung und des Trennungsgeldes bezog. Dabei versuchte die Werksleitung nachzuweisen, „im Rahmen des Möglichen alles getan zu haben“, um die eingewiesenen Arbeitskräfte ausreichend zu betreuen, „daß für keinen der Dienstverpflichteten ein Anlaß besteht, sich zu beschweren oder sich seiner Dienstpflicht zu entziehen" 384 .

Ende Juni 1946 beschäftigte das Eisen- und Hüttenwerk Thale, das mittlerweile über drei Siemens-Martin-Öfen und zwei Lichtbogen-Öfen verfügte, die jeweils für einen 50- bzw. 10-Tonnen-Einsatz ausgerichtet waren, fast 4000 Arbeiter und Angestellte ${ }^{385}$. Da die maximale Auslastung des Werkes noch nicht erreicht worden war, stieg der Bedarf an Arbeitskräften vermutlich noch weiter an. Dieser ließ sich nach Ansicht der Provinzialverwaltung in Halle/Saale und der dortigen SMA nur durch eine verstärkte Anwerbung von „Umsiedlern“ abdecken ${ }^{386}$. Die SMAD hatte mit ihrem Befehl Nr. 32 vom 2. Februar 1946 „Maßnahmen zur Leistungssteigerung der Eisenhüttenwerke in den Städten Thale und Unterwellenborn“387 angeordnet. In dem Zusammenhang hatten die Landesverwaltungen unterschiedliche Auflagen erhalten, die jedoch nicht erfüllt werden konnten. So sollte das sächsische Landesarbeitsamt 600 qualifizierte Metallfacharbeiter für Thale zur Verfügung stellen; bis zum 20. August waren offensichtlich 460 Arbeiter zugeteilt worden, von denen aber nur 272 Arbeiter eingestellt werden konnten ${ }^{388}$. Da Sachsen aufgrund des Arbeitskräftebedarfs für den Uranbergbau sowie für die Textilindustrie nahezu ausgelastet war, und zudem Metallfacharbeiter für die landeseigenen Unternehmen dringend benötigt wurden, wurde die SMA Sachsen gebeten, eine Anweisung herauszugeben, welche die Auflagenerteilung für Sachsen aufheben sollte. Kurz darauf befaßte sich auch das SED-Zentralsekretariat mit der Lage in der Eisen- und Stahlindustrie und stimmte einem Maßnahmenkatalog zu, der allerdings auf die Abdeckung des Arbeitskräftebedarfs überhaupt nicht ein-

${ }_{383}$ BAB, DQ 2/961, Aktenvermerk vom 10.4. 1946 für Präsident Gundelach.

${ }^{384}$ BAB, DQ 2/2161, Eisen- und Hüttenwerk Thale am 3. 5. 1946 an das Landesarbeitsamt Potsdam, S. 3.

${ }^{385}$ Die Belegschaft setzte sich aus 3625 Arbeitern (2045 in der Stahlproduktion, 1550 in der Weiterverarbeitung sowie 30 in Verwaltung) sowie 370 Angestellten zusammen. SAPMO, DY 30/IV 2/ 6.02/22, Bl. 68f., Bericht von Dr. Ing. M. H. Kraemer vom 27.6. 1946 an das ZS der SED (Becker), S. 2.

386 BAB, DQ 2/2161, Provinzialamt für Arbeit und Sozialfürsorge der Provinz Sachsen am 5. 8. 1946 an die DVAS.

${ }^{387}$ Foitzik, Inventar, S. 90.

388 BAB, DQ 2/2161, Präsident des Landesarbeitsamtes Sachsen am 23. 8. 1946 an die SMA Sachsen (Abt. Arbeit, Löhne und Soziale Fürsorge). 
ging, sondern allgemein Vorschläge zur Produktionssteigerung in den einzelnen Werken sowie zur Güterverteilung enthielt ${ }^{389}$.

Auch im Verlauf des Jahres 1947 hielt der Bedarf an Arbeitskräften in Thale weiter an. Die Betriebsabteilung, Arbeitseinsatz' berichtete, daß dabei qualitative Aspekte eindeutig quantitativen untergeordnet werden mußten: „Die Bearbeitung innerbetrieblicher Fragen einer optimalen, individuellen Arbeitsplatzanpassung mußte hinter der Aufgabe der mengenmäßigen Bedarfsdeckung immer wieder zurückstehen. “390 Die Gesamtzahl der Neueinstellungen betrug 19472696 Männer und Frauen; darunter befanden sich 517 „Umsiedler“, 101 entlassene Kriegsgefangene sowie 43 ehemalige Kriegsgefangene, die sich während der Werbeaktion freiwillig gemeldet hatten. Der Vertriebenenanteil lag somit unterdurchschnittlich bei etwa 19 Prozent. Darüber hinaus verwies der Bericht auf die Gewinnung von Arbeitern aus der „Kraftreserve“ (430 Männer und Frauen), d.h. ausgelagerten und nicht direkt zur Produktion gehörenden Betriebsteilen. Das Eisen- und Hüttenwerk erhielt jedoch nicht nur Zugänge von außen, sondern versuchte offensichtlich, die Belegschaftsmitglieder effizienter einzusetzen. So konnten durch innerbetriebliche Umsetzungen insgesamt 1750 Arbeitskräfte an anderen Arbeitsplätzen eingesetzt werden. Welche Konsequenzen diese Maßnahme für die Produktion hatte, ließ der Bericht allerdings offen. Bemerkenswert war außerdem die relativ hohe Fluktuationsrate. Während 3126 Neuzugänge (Neueinstellungen und Zugänge aus den „Kraftreserven“) registriert wurden, meldete Thale im gleichen Zeitraum 2331 Abgänge (Entlassungen und Abgänge in die „Kraftreserve“). Somit betrug die effektive Zunahme der Belegschaft 1947 nur 795 Personen. Die Gründe für die Entlassungen waren vielfältiger Natur. Die mit Abstand meisten Entlassungen erfolgten aufgrund von "willkürlichen Arbeitsversäumnissen“ (813), gefolgt von Krankheit (234), beruflicher Weiterbildung (179), familiären Gründen (150) und Entpflichtungen von Zwangseingewiesenen (125)391. Der Anteil der durch Pression gewonnenen Arbeitskräfte an der Gesamtzahl der Neueinstellungen betrug im übrigen am 1. Januar 194814 Prozent. Aufschlußreich waren des weiteren Angaben zur Abwanderung von Belegschaftsmitgliedern: So wanderten 1947 insgesamt 107 Arbeiter in die westlichen Besatzungszonen ab sowie - erstaunlicherweise - 111 Personen in die ehemaligen deutschen Ostgebiete.

Im Frühjahr 1948 eskalierte der Konflikt zwischen den beiden Walzwerken Thale und Hennigsdorf, das mittlerweile die Produktion wieder aufgenommen hatte. Ursache für die neuerliche Auseinandersetzung war die Rückwanderung von Facharbeitern aus Thale, die anfangs in Hennigsdorf beschäftigt waren. Der Arbeitsplatzwechsel erfolgte ohne Zustimmung des zuständigen Arbeitsamtes bzw. der Betriebsleitung in Thale. Diese "unzulässige Handlungsweise" habe bereits - so die Einschätzung der HVAS-Abteilung I b - zu „Betriebsschwierigkeiten " geführt ${ }^{392}$. Das Potsdamer Landesarbeitsamt verteidigte dagegen die Vorgehensweise des Hennigsdorfer Betriebes sowie des dortigen Arbeitsamtes.

389 SAPMO, DY 30/IV 2/2.1/120, Bl. 18-23. 390 BAB, DQ 2/2161, Bericht der Abt. ,Arbeitseinsatz“ über die Entwicklung des Belegschaftsstandes
(Stand: 1. 1. 1948), S. 1 .

391 Ebenda, S. 3.

392 BAB, DQ 2/2161, Aktenvermerk der HVAS-Abt. I b vom 14. 5. 1948. 
Gleichzeitig wurde dem Werk in Thale vorgeworfen, keine Anstrengungen unternommen zu haben, um „Nachwuchs für die im Jahre 1946 nach Thale dienstverpflichteten Stahlwerker, die noch heute in Hennigsdorf, Velten und Leegebruch beheimatet sind, heranzubilden“393. Es sei nicht mehr länger vertretbar, „wenn Hennigsdorfer Walzwerker, deren Familien in Werkswohnungen untergebracht sind, weiterhin in Thale gegen ihren Willen verbleiben sollen."

Im Gegensatz zu Thale konnten die Mitteldeutschen Stahlwerke in Riesa die Produktion erst sehr viel später anfahren. Beim einzigen sächsischen Eisenwalzwerk zogen sich nämlich die frühzeitig aufgenommenen Demontagetätigkeiten in die Länge. Die Betriebsleitung verwies darauf, daß der Abbau der Produktionsanlagen ,jede Bautätigkeit im gesamten sächsischen und den angrenzenden Gebieten lahmlegen" würde ${ }^{394}$. Zu diesem Zeitpunkt schwankte die Gesamtbelegschaft zwischen 3800 und 4000 Arbeitern, von denen allein 2000 im Stadtgebiet Riesa ansässig waren. Das Durchschnittsalter lag bei rund 48 Jahren. Da die Gründung des Werkes bis in die zweite Hälfte des 19. Jahrhunderts zurückreichte, hatte sich eine zahlenmäßig nicht unbeträchtliche Stammbelegschaft herausgebildet, die trotz der vielfältigen politischen und wirtschaftlichen Umbrüche „schon seit Generationen" dort tätig war. Der Betriebsrat des Stahl- und Walzwerkes Riesa richtete daraufhin einen Appell an Karlshorst, die Demontage des Werkes zu unterbrechen sowie die weiteren geplanten Abbaumaßnahmen und die "teilweise Erhaltung vornehmlich der älteren Werksanlagen " zu überprüfen ${ }^{395}$. Ansonsten drohe die Stillegung des Betriebes und ein Ansteigen der Arbeitslosenzahlen, da andere Beschäftigungsmöglichkeiten in der Region nicht bestünden. Da die SMAD ein großes Interesse an der Aufnahme der Eisen- und Stahlproduktion in ihrer Besatzungszone hatte, erließ ihr stellvertretender Oberster Chef Konstantin I. Kowal am 9. September 1946 den Befehl Nr. 110, der die „teilweise Belassung der Produktions- und anderer Abteilungen im ehemaligen Werk ,Mitteldeutsche Stahlwerke' in Riesa" vorsah ${ }^{396}$. Damit konnte die betriebliche Produktion wieder aufgenommen werden.

Anfang Dezember besprachen Vertreter der DVAS, des sächsischen Landesarbeitsamtes und der Betriebsleitung den zukünftigen Arbeitskräftebedarf. Dabei machten die betrieblichen Vertreter darauf aufmerksam, daß in der Zwischenzeit Facharbeiter von Riesa nach Thale abgestellt und berufsfremd eingesetzt worden seien $^{397}$. Das Landesarbeitsamt überreichte der DVAS sogar eine namentliche Aufstellung von den nach Thale verpflichteten Arbeitskräften mit der Bitte, mit der SMAD Rücksprache zu nehmen, um die Rückführung dieser Arbeitskräfte nach Riesa erwirken zu können ${ }^{398}$. Die DVAS wollte diese Angelegenheit mit der Zentralverwaltung der Industrie und der SMAD klären, „da nur mit Zustimmung

${ }^{393}$ Ebenda, Landesarbeitsamt Brandenburg am 28. 6. 1948 an das Ministerium für Arbeit und Sozialpolitik der Landesregicrung Sachsen-Anhalt.

${ }^{394}$ SAPMO, NY 4182/957, Bl.6-9, hier Bl. 6, Bericht der Mitteldeutschen Stahlwerke vom 3. 7.1945 über das Werk in Riesa.

395 Ebenda, Bl. 10 f., hier Bl. 10, Schreiben des Betriebsrates vom 10. 7. 1945 an den Leiter der russischen Reparationskommission in Karlshorst.

396 BAB, DQ 2/1982.

397 BAB, DQ 2/1982, Niederschrift über die Besprechung am 7. 12. 1946, S. 1.

398 Ebenda, Landesarbeitsamt Sachsen am 13. 12. 1946 an die DVAS (Kreil). 
dieser Stellen der an sich erwünschte Abzug dieser Arbeitskräfte aus Thale zu bewirken sein wird“399. Bei Verhandlungen zeigte sich der Generaldirektor der Metallurgischen A. G. Eisen- und Hüttenwerke Thale, Smoljakow, grundsätzlich kompromißbereit. Er stimmte der Zurückführung der aus Riesa eingewiesenen Gießereifacharbeiter zu, knüpfte daran allerdings einige Bedingungen. So sollte die Zentrale der Sowjetischen Metallurgischen A. G. in Berlin-Weißensee ebenfalls ihre Zustimmung erteilen. Außerdem, und das stellte das entscheidende Hindernis dar, hatte Sachsen Ersatzkräfte in gleicher Anzahl und mit gleicher beruflicher Qualifikation zu stellen, die sich wiederum freiwillig zur Arbeitsaufnahme in Thale verpflichten sollten ${ }^{400}$. Die geforderte "Umsetzung Kopf gegen Kopf“ drohte die getroffene Abmachung wieder zum Platzen zu bringen. Das Vorhaben scheiterte letztlich daran, daß der Präsident der Sowjetischen Metallurgischen A. G., Wolkow, seine Zustimmung zu der geplanten Aktion nicht gab. Er zeigte zwar Verständnis für die Interessen des sächsischen Landesarbeitsamtes, wollte sich aber nicht mit der Rückführung der Arbeitskräfte nach Riesa einverstanden erklären, da er die Verantwortung für den damit verbundenen Produktionsrückgang in Thale nicht übernehmen könne $e^{401}$. Die DVAS-Abteilung I b sah keine Möglichkeit, den Arbeitskräfteaustausch auf anderem Wege herbeiführen zu können und bat Präsident Brack um Zustimmung, „die Angelegenheit als für uns erledigt betrachten zu dürfen, deren erneutes Aufgreifen erst dann wieder spruchreif würde, wenn sich neue Tatbestände ergeben" ${ }^{402}$.

Die beiden SMAD-Befehle Nr. 93 und 175 vom 19. Mai bzw. 10. November $1948^{403}$ enthielten nur Anweisungen zum Ausbau der Produktionsanlagen sowie zur Stahlerzeugung, jedoch keinerlei Angaben zur Deckung des Arbeitskräftebedarfs. Die Lösung dieser Frage blieb offenbar der deutschen Arbeitsverwaltung vorbehalten. Das SED-Zentralsekretariat versuchte unter dem Eindruck der anwachsenden Kritik an der Produktionsleistung der Stahl- und Walzwerke in der SBZ die Parteiarbeit in den drei wichtigsten metallurgischen Betrieben (Riesa, Hennigsdorf und Maxhütte) zu verstärken und setzte Kommissionen ein, die die Aufgabe erhielten, ,an Ort und Stelle in den Werken die politische, gewerkschaftliche und produktionstechnische Arbeit des Betriebes beratend zu reorganisieren [und] der Direktion, der Betriebsgruppen- und Betriebsgewerkschaftsleitung bei der Entwicklung neuer Methoden der Arbeit zu helfen"404. Die SED-Führung erneuerte rund einen Monat später diesen Beschluß und forderte die Landesvorstände in Thüringen, Sachsen und Brandenburg auf, „weiterhin ihr Schwergewicht auf die Verbesserung der Arbeit in den 3 genannten Stahlwerken zu legen und die Arbeit in diesen Werken weitgehendst zu unterstützen" ${ }^{405}$.

${ }^{399}$ BAB, DQ 2/2064, Aktenvermerk der DVAS-Abt. I vom 9. 12. 1946, S. 3.

${ }^{+0 C} \mathrm{BAB}, \mathrm{DQ} 2 / 1711$, Aktenvermerk der DVAS-Abt. I b über Verhandlungen am 23./24. 1. 1947 in Thale, S. 1.

401 Ebenda, Aktenvermerk der DVAS-Abt. I b über die Verhandlung mit Wolkow am 31.1. 1947.

402 BAB, DQ 2/2161, DVAS-Abt. I b am 7. 2. 1947 an Brack.

${ }^{403}$ SächsHStA, SED-Landesleitung Sachsen, Bd. 675, Bl. 1 f. und Bl.7-9. Vgl. Foitzik, Inventar, S. 155 und S. 161.

40+ SächsHStA, SED-Landesleitung Sachsen, Bd. 675, Bl. 46-48, hier Bl. 47f., Beschluß des ZS vom 25. 10. 1948 mit Anschreiben Stophs vom 27. 10. 1948.

tos Ebenda, Bl. 72f., hier Bl. 73, Beschluß des ZS vom 22.11. 1948 mit Anschreiben Stophs vom 30. 11.1948. 